\title{
VI. Die Finanz- und Währungseinheit: Vertagte Entscheidungen
}

Das umlaufende Stückgeld in Deutschland hatte sich von 1932 bis Kriegsende von 5,6 auf 73 Mrd. RM vermehrt, die Bankguthaben von 12,7 auf 100 Mrd. RM, die Spareinlagen von 15,3 auf 125 Mrd. und, infolge der Finanzierung der Kriegswirtschaft, die Reichsschuld von 11,4 auf 379,8 Mrd. RM. Liquidität und Reichsschuld zusammen waren damit im genannten Zeitraum um das 15 fache von 45,0 auf 677,8 Mrd. RM angewachsen ${ }^{1}$. Neuer Kredit, den sich die deutschen Verwaltungen gegen Kriegsende angesichts minimaler Steuereinläufe über einen „Operationsfonds“ verschafft hatten, steigerte den inflationären Druck. Mit Kriegsende entzogen Kontenblockierung, Gebietsabtrennungen und andere Einflüsse dem umlaufenden Geldvolumen etwa 173 Mrd. RM, doch die Lage verschlechterte sich bis zum Juni 1945 weiter, da der Kollaps der Finanzverwaltung ein geordnetes Wirtschaften unmöglich machte: Ohne effiziente Steuereintreibung, ohne öffentliche Anleihen, ohne Zugriff auf Bargeldreserven bei der Reichsbank oder Geschäftsbanken konnten die laufenden Kosten weder der deutschen noch der alliierten Dienststellen gedeckt werden. Die Alliierten, die über Beutebestände von mehr als $10 \mathrm{Mrd}$. RM verfügten ${ }^{2}$ und $2 \mathrm{Mrd}$. RM an Banknoten aus Druckreserven in Umlauf brachten, halfen sich durch die Ausgabe von Alliiertem Militärgeld im Umfang von 12 bis $15 \mathrm{Mrd}$. RM. Dem verfügbaren Geldvolumen von $500 \mathrm{Mrd}$. RM stand ein Sozialprodukt von $50 \mathrm{Mrd}$. RM gegenüber ${ }^{3}$.

Mit Proklamation Nr. 2 vom 20. September 1945 übernahm der Kontrollrat die Verantwortung für Geld, Währung und öffentliche Finanzen: Das Vermögen des Reiches, seiner Unterorgane und der Zentralbank wurde beschlagnahmt; deutsche Behör-

${ }^{1}$ Abelshauser, Wirtschaftsgeschichte, S. 46. BA, Z 45 F/OMGUS, 2/118-3/10-21 (CORC/P(47)40, 14. 2. 1947). Lebée, Réforme monétaire, S. 103.

Tab. 4: Die Lage der Finanzen in Deutschland, Frankreich, Großbritannien und den USA 1945. Steigerungsraten im Vergleich zu 1938 (in \%)

\begin{tabular}{lllll}
\hline & Deutschland & Frankreich & USA & England \\
Öffentliche Schuld & 233 & 337 & 545 & 180 \\
Papiergeld & 445 & 431 & 210 & 160 \\
Einlagen & 361 & 672 & 140 & 237 \\
Geldmenge & 380 & 497 & 123 & 144 \\
Preise & 15 & 280 & 32 & 56 \\
Industrieproduktion & -64 & -35 & 103 & \\
\hline
\end{tabular}

Infolge der Ausbeutung der besetzten Gebiete während des Krieges war die öffentliche Verschuldung des Reiches deutlich niedriger als die Frankreichs oder der USA.

2 Frankreich hatte in Elsaß-Lothringen 1,120 Mrd. RM erbeutet, die es zum Ankauf von Beteiligungen an der Saar-Industrie einzusetzen gedachte. AMAE, Y 653, Bl. 174 ff. (CGAAA, 15. 10. 1946). Die USA verfügten über 3 Mrd. Beute-Mark, die sie bis 1947 nicht antasteten. PRO, FO 371/65005/ CE1323 (Chambers, 28. 3. 1947). BA, Z 45 F/OMGUS, 11/411-9. Die sowjetischen Zahlungen mit Beute-Mark werden auf $6 \mathrm{Mrd}$. RM geschätzt. DDR-Handbuch, S. 726.

3 Rittmann, Geldgeschichte, S. 295 f. 
den und Privatpersonen mußten alle Devisen abliefern, die Behörden kostenlos alle von den Alliierten benötigten deutschen Zahlungsmittel bereitstellen und die Alliierte Militärmark zu den Bedingungen der Besatzungsmächte gegen Reichsmark einlösen. Durch das Verbot des grenzüberschreitenden Verkehrs sollte der Transfer deutscher Guthaben ins Ausland verhindert werden, sei es als Kapitalflucht, sei es als Finanzierung eines befürchteten Widerstandes aus dem Ausland. Damit sollte zugleich ausgeschlossen werden, daß das Reich durch gezielte Inflationierung abermals eine Revision der alliierten Reparationsforderungen erzwang. Doch trotz der prinzipiellen Übereinstimmung, daß im Interesse der vielfältigen besatzungspraktischen Bedürfnisse eine rasche Stabilisierung von Währung und Finanzen erforderlich sei, konnte angesichts unterschiedlicher währungstechnischer Lösungsansätze wie transformationspolitischer Nebenabsichten eine Einigung nicht erzielt werden. Ende 1945 standen sich drei Konzeptionen für eine Währungsreform mit „großen Differenzen bei den vorgeschlagenen Maßnahmen zur Überwindung der Schwierigkeiten" gegenüber" :

1. die sowjetische Radikallösung. Anders als in den Westzonen, wo in der Regel nur die Guthaben der Nationalsozialisten eingefroren und die Konten der NS-Organisationen alliierter Kontrolle unterstellt wurden, hatte die SMAD im Frühjahr und Sommer 1945 alle Banken geschlossen und die Guthaben gesperrt. Die Altguthaben bis 3000 RM wurden schrittweise wieder freigegeben, die darüber liegenden Beträge enteignet. Die finanziellen Verpflichtungen und Ansprüche der alten Banken wurden ebenso gestrichen wie die Reichsschuld, so daß nicht nur alle Inhaber von Staatspapieren als Finanziers des Krieges durch Enteignung bestraft wurden, sondern der Untergang eines entkapitalisierten Mittelstandes ebenso vorprogrammiert war wie eine Liquiditätskrise von Industrie und Großlandwirtschaft. Aber, das war neben der verdeckten Transformation das geldpolitische Ergebnis, ca. 80\% des liquiden Kapitals waren in der SBZ dem Umlauf entzogen, also etwa die Quote, die auch die USA für erforderlich hielten und die zufällig der Quote entsprach, in der die Banken private Einlagen zur Kriegsfinanzierung in Staatspapieren angelegt hatten ${ }^{5}$.

2. der französische und amerikanische Weg des Währungsschnitts, in unterschiedlicher Form verbunden mit einem Lastenausgleich durch eine Vermögensabgabe für Grund- und Sachbesitzer bzw. durch „eine Beteiligung des Staates oder der deutschen Staaten" am Kapital der Industrie-, Handels- und Agrarbetriebe. Der Plan des französischen Generalkontrolleurs Mitzakis sah eine Reduktion von Geldmenge, öffentlicher Schuld und Bankguthaben um $75 \%$ vor, ergänzt durch Preis- und Lohnkontrollen ${ }^{6}$. Dieser Plan, der aufgrund innerfranzösischer Differenzen dem Kontrollrat nie offiziell

${ }^{4}$ PRO, FO $371 / 55410$ (Chambers, ca. Dezember 1945).

s Rittmann, Geldgeschichte, S. 296 ff. Backer, Clay, S. 137 f. Angesichts des Ausbleibens der Währungsreform schien es dem Finanzberater Clays, Joseph Dodge, im Dezember 1945 wie auch den Briten im Juni 1946 bedenkenswert, ob man nicht nach dem sowjetischen Beispiel die privaten Konten blockieren solle. Das werde die umlaufende Geldmenge erheblich reduzieren, obne unmittelbare Enteignungswirkung, und Aufschub für die Entscheidung über die Konversionsrate dieser Guthaben verschaffen. PRO, FO $371 / 55410$ (5.1. 1946); FO 1046/94 (E.F. Schumacher, Extract from Progress Report, 12. 8. 1946, Appendix , $B^{\circ}$ ).

${ }^{6}$ Lebée, Réforme monétaire, S. 106, 115 ff. Möller, Vorgeschichte, S. 154 ff. TL, Tenenbaum Papers, box 3, folder: Background data (1). Das Finanzministerium neigte (mit Ausnahme des zentralistischen Bankensystems) den britischen Plänen zu, die GFCC dagegen nicht. AO, Berlin/3276/1/2007 (4. 1. 1946). Bedenken wurden gegen das Weiterbestehen der Reichsbank erhoben, auch wenn sie nach amerikanischem Vorschlag in Länder-Banken dezentralisiert werde. AMAE, Eu(1944-60)Allemagne/91, Bl. $111 \mathrm{ff}$. (Wenger-Valentin, 22. 9. 1945). 
vorgelegt wurde, entsprach in vielen Aspekten den im Colm-Dodge-Goldsmith-Plan (CDG-Plan) konkretisierten Vorstellungen der USA, nach Blockierung von $80 \%$ aller Bankeinlagen eine neue Währung auszugeben, „die, für den Augenblick Deutsche Mark genannt, 5 Reichsmark entsprechen würde"7.

3. das britische Modell einer „bewußten, kontrollierten und begrenzten Inflation über einen Zeitraum von zwei oder drei Jahren mit Hilfe von Preisanhebungen und Besteuerung“, das die Interessen der britischen Kapitaleigner wahrte, indem es keine Streichung der Reichsschuld vorsah, und daher auch von Teilen der französischen Behörden begrüßt wurde. Nachdem die Briten seit Anfang 1944 ohne greifbare Resultate das Problem diskutiert hatten, wie eine Wiederholung der Fehler der zwanziger Jahre zu vermeiden sei, bestanden noch 1946 intern „erhebliche Meinungsunterschiede“8.

Im Kontrollrat stießen die Briten auf geschlossenen Widerstand, als sie gemäß diesen Vorstellungen Anfang September 1945 ein Sofortprogramm zur Bekämpfung der Inflation einbrachten: Beschränkung der Ausgaben und deren Deckung durch Einkünfte oder Einsparungen, Einsatz von Bankkrediten nur für produktive Arbeiten, Einschränkung der Ausgabe von Barmitteln an die Besatzungstruppen, ein „Programm stark gesteigerter Besteuerung“ und strikte Kontrolle des Banknotendrucks? Dagegen nahmen die an Dezentralisierung des Finanzsystems und baldigem Währungsschnitt orientierten Gegenvorstellungen der Amerikaner und Franzosen eine gewisse Zeitverzögerung bei der Neugestaltung in Kauf, obwohl Dodge, der dramatischer als die Briten „alle Anzeichen nicht nur der Inflation, sondern des totalen und absoluten Zusammenbruchs“ in Deutschland zu erkennen glaubte, zur Eile drängte und die britischen Vorstellungen einer zeitlich gestreckten „kontrollierten Inflation“ zugunsten des sofortigen radikalen Währungsschnitts ungeduldig ablehnte; alles andere sei Verhandlungssache und könne anschließend mit größerer Ruhe und Gelassenheit erörtert werden ${ }^{10}$. Die Differenzen zwischen den Westmächten waren so prinzipiell, daß an eine rasche Einigung nicht zu denken war. Die Sowjetunion konnte sich daher konkreter Vorschläge enthalten. Wieder war ein System der Aushilfen erforderlich: durch steuerliche Abschöpfung des Geldüberhangs sowie durch rigide Lohn- und Preiskontrollen. Auf dieser pragmatischen Ebene der Sofortmaßnahmen war ein Minimalkonsens möglich, als die USA Mitte November 1945 ihren Maßnahmenkatalog vorlegten: „Reduktion“ der öffentlichen Schuld, zumindest im Inneren; Abwertung der Bankguthaben ohne Enteignungseffekt; Erhöhung der Steuern in Verbindung mit einer Begrenzung der öffentlichen Ausgaben; Preis- und Lohnstopp sowie kontrollierte Ausgabe der Alliierten Militärmark ${ }^{11}$. Aber die Steuerpolitik, der die Ersatzfunktion in dieser Übergangszeit zugedacht war, konnte weder ihre inflationsbekämpfende Funktion erfüllen, noch als gesamtwirtschaftliches Steuerungsinstrument dienen, da sie nur die Symptome bekämpfte, aber nicht das Grundübel beseitigte.

7 Zum CDG-Plan vgl. unten S. $281 \mathrm{f}$. Frankreich kritisierte an dem Plan, daß er in drei Stufen erfolgen, d. h. Dauer und Verwaltungsaufwand erheblich vergrößern werde; der Eingangssatz der Entwertung von $90 \%$ sei zu hoch; die Streichung der Reichsschuld werde ganze Sozialgruppen enteignen und Deutschland gegenüber den Siegern bevorzugen, die ihre Kriegsschulden bedienen mußten; der Lastenausgleich entschädige die Opfer, stelle aber internationale Verpflichtungen hintan.

8 PRO, FO 942/150 (Januar 1945); FO 1046/71 (Chambers, 9. und 17.6. 1945); FO 371/55410 (Chambers, Dezember 1945); FO 1046/528 (20. 2. 1946); FO 1046/94 (SCOPC/P(46)27).

$9 \mathrm{BA}, \mathrm{Z} 45$ F/OMGUS, 2/121-2/10-17 (DFIN/P(45)9, 7.9. 1945).

10 PRO, FO 371/55411/C1477/16/18 (5. 2. 1946).

11 BA, Z 45 F/OMGUS, 2/121-2/10-17 (DFIN/P(45)42, 15. 11. 1945). 
Doch die technischen Fragen ließen sich nur für eine begrenzte Zeit von den politischen Strukturentscheidungen trennen. An den divergierenden Konzeptionen für das zukünftige deutsche Bank-, Währungs- und Finanzsystem, die unlösbar mit der Grundsatzentscheidung über Eigentumsordnung und Wirtschaftsverfassung verknüpft waren, scheiterte letztlich die Wiedererrichtung der Finanz- und Währungseinheit. Die Westmächte sahen sich vor die Alternative gestellt, entweder in ihren Zonen einen Alleingang zu unternehmen oder aber zusammen mit der Sowjetunion gesamtdeutsch durch Übergangsregelungen und Hilfskonstruktionen zu improvisieren. Sie entschieden sich zunächst für die zweite Variante, weil es trotz gewisser Vorarbeiten und erster Vorschläge in den Gremien des Kontrollrats bis zum Jahresende 1945 keine durchdachten oder gar praktikablen Konzepte für die technische Durchführung einer Währungsreform gab und weil die Entscheidung für oder gegen eine gemeinsame Währungsreform nicht nur eine Entscheidung über die wirtschaftliche, sondern ebenso über die politische Einheit Deutschlands war.

\section{Die Steuerpolitik}

Angesichts der Methoden der deutschen Kriegsfinanzierung galt seit den ersten Planungen für die alliierte Besatzungspolitik die Verhinderung einer neuen Inflation als vordringlich, auch wenn Teile der USGCC unter dem Einfluß der „Morgenthau boys“ vorübergehend ein inflationäres Chaos als gerechte Strafe für die Deutschen betrachteten $^{12}$. Doch derartige Vorstellungen waren frühzeitig durch den Widerstand der Politischen und der Wirtschaftlichen Abteilung der USGCC sowie der Briten überwunden worden. Gleichwohl bestanden bei Kriegsende erhebliche Differenzen zwischen den britischen und amerikanischen Auffassungen über die ersten Maßnahmen. Während die USA Steuererhöhungen bis zu der Herstellung einer Vier-MächteEinigung vertagen wollten, verlangten die Briten zur Deckung der Besatzungskosten deren sofortige Anhebung und, im Interesse der Effizienz, eine zentralisierte Finanzverwaltung, die im Sinne eines Systems „indirekter Herrschaft“ auch ohne deutsche politische Instanzen auf zonaler wie auf Reichsebene unter der strikten Kontrolle der Alliierten tätig werden könnte. Die amerikanischen Vorschläge schienen ihnen die Gefahr zu bergen, daß die Finanzabteilung des Kontrollrats sich zu einer Art „zentralem Finanzamt“ entwickele, das „direkte Anweisungen an deutsche Verwaltungen aller Größen und Kategorien“"gebe. Das Argument, auf die sowjetischen Kollegen warten zu müssen, ließen sie nicht gelten; sie befürchteten vielmehr, durch Abwarten und durch Dezentralisierung des Finanzwesens nach amerikanischen Vorstellungen werde die „Aufsplitterung Deutschlands in vier separate wirtschaftliche Einheiten“ herbeigeführt ${ }^{13}$. Zentrale politische Koordination durch den Kontrollrat und zentrale technische Abwicklung durch die Deutschen, das war zu der Zeit ihr auf den Erhalt der wirtschaftlichen Einheit ausgerichtetes Konzept.

12 PRO, FO 942/150 (Januar 1945). CP, S. 3 (4. 4. 1945).

13 PRO, FO 942/41 (APW(44)105, 20. 10. 1944); FO 1046/71 (Chambers, 9. und 21. 6. 1945; CCG, Finance Division, 29.6. 1945). Van Scherpenberg, Rekonstruktion, S. 217. BA, Z 45 F/OMGUS, USGCC/44-45/4/3 (Milburn an Clay, 1. 5. 1945); POLAD/728/7 (Bogdan, 31. 5. 1945). Vgl. FRUS, 1945/III, S. 499 ff. (IPCOG 1, 26. 4. 1945, Part III: Financial). 
Als die USA Ende Juni 1945 einer Zusammenfassung deutscher Finanzexperten zustimmten, damit die drei westlichen (!) Kontrollratsgruppen in der Zeit bis zur Konstituierung des Kontrollrats mit diesen beraten konnten, ohne die Wiedererrichtung eines deutschen Finanzministeriums nur für ihre Zonen zu präjudizieren, begannen die Westmächte in Frankfurt-Höchst einen intensiven Abstimmungsprozeß im Gemeinsamen Finanzkomitee von SHAEF/CRAB ${ }^{14}$. Doch weder Briten noch Amerikaner waren bereit, ihre Vorstellungen aufzugeben, die sie dementsprechend einseitig in ihren jeweiligen Zonen zu realisieren begannen. Erstere zentralisierten das Steuerwesen auf Zonenebene, während letztere die Steuerhoheit den Ländern übertrugen. Obwohl die Briten auf der Potsdamer Konferenz durchsetzen konnten, daß als ein Element der Wirtschaftseinheit die „zentrale Besteuerung“ vorgesehen wurde, setzten sich die alten Debatten fort, als die Briten am 10. September im Kontrollrat die „Wiedererrichtung eines Zentral-Ministeriums für Finanzen“ beantragten. Dieses sollte den Kontrollrat „beraten“, unter der Leitung eines Staatssekretärs aus maximal 200 Personen bestehen und in seiner Tätigkeit auf die Bereiche beschränkt bleiben, die für die unmittelbaren Zwecke des Kontrollrats erforderlich schienen, vor allem Steuern und Anleihen. Jedoch fanden die USA mit ihrem dezentralen, zugleich die zonale Autonomie bewahrenden Gegenmodell Zustimmung bei Franzosen und Sowjets ${ }^{15}$.

Obwohl Grundsatzentscheidungen damit frühzeitig an den deutschland- und besatzungspolitischen Differenzen der Alliierten gescheitert waren, erzwangen die unmittelbaren besatzungspraktischen Bedürfnisse ad hoc-Lösungen, die nichts präjudizierten, indem einvernehmlich die Steuersätze heraufgesetzt wurden, die Organisation des Steuerwesens aber den Zonen überlassen blieb. Mit Gesetz Nr. 3 vom 20. Oktober 1945 kam der Kontrollrat der Empfehlung seines Finanzdirektorats nach, „daß die Besteuerung in Deutschland im größtmöglichen Maße gesteigert werden wird“, obwohl Clay die empfohlenen Maßnahmen für „nicht ausreichend zur Inflationsbekämpfung“ hielt. Die Lohnsteuer für die Zeit vom 1. Oktober bis 31. Dezember 1945 wurde um $25 \%$, die Einkommens- und Vermögenssteuer für das gesamte Jahr um 6,25\% erhöht ${ }^{16}$. Damit begann eine Serie von drastischen Steuererhöhungen, die sich in 19 Kontrollratsgesetzen niederschlug. Zwar wußten alle Beteiligten, daß auf diesem Wege die Folgen der verzerrten Relation von Gütermenge und Geldmenge nur vorübergehend eingedämmt werden konnten, aber man hoffte doch, den Geldüberhang soweit abschöpfen zu können, daß die politische Entscheidung über Art, Umfang und Wirkungen einer Währungsreform hinausgeschoben werden konnte. Nach einer weiteren Runde von Steuererhöhungen erreichten im Februar 1946 die Steuersätze in Deutschland eine bis dahin unbekannte Höhe.

Der Anteil des Volkseinkommens, der durch Steuern aufgesogen wurde, stieg durch die Maßnahmen des Kontrollrats auf 44\%, nachdem er 1929 bei 19\%, 1939 bei $30 \%$ und 1944 bei $35 \%$ gelegen hatte. Bis 1948 ging die Quote wieder auf $35 \%$ zurück. Während das Steueraufkommen in Deutschland 1946 36\% des Bruttosozialpro-

14 PRO, FO 1046/71. Von sieben Unterkomitees waren zwei mit Steuerfragen befaßt.

$15 \mathrm{BA}, \mathrm{Z} 45 \mathrm{~F} / \mathrm{OMGUS}, 2 / 121-2 / 10-17$ (DFIN/P(45)15, 19 und 31; meine Hervorhebung).

16 BA, Z 45 F/OMGUS, 2/121-2/1-4 (DFIN/M(45)6, 28. 9. 1945; DFIN/P(45)13). 
Tab. 5: Vergleich der Steuersätze 1945-1950 ${ }^{17}$

\begin{tabular}{lrrr}
\hline Steuerart & NS-Gesetze & KR-Gesetze & BRD-Gesetze \\
Einkommenssteuer & 1945 & 1946 & 1950 \\
$\quad$ bis 1000 RM & & & \\
bis 9000 RM & $12 \%$ & $17 \%$ & $10 \%$ \\
bis 70000 RM & $42 \%$ & $55 \%$ & $40 \%$ \\
Körperschaftssteuer & $67 \%$ & $95 \%$ & $70 \%$ \\
Vermögenssteuer & $30-55 \%$ & $36-65 \%$ & $50 \%$ \\
Erbschaftssteuer & $0,5 \%$ & $1-2,5 \%$ & $0,75 \%$ \\
Umsatzsteuer & $2-60 \%$ & $14-60 \%$ & $4-80 \%$ \\
Tabaksteuer & $2 \%$ & $3 \% \%$ & $3 \%$ \\
Alkoholsteuer & $35-75 \%$ & $80-90 \%$ & $30-60 \%$ \\
Zuckersteuer & $475 \mathrm{RM}$ & $11470 \mathrm{RM}$ & $1000 \mathrm{DM}$ \\
Kfz-Steuer & $21 \mathrm{RM}$ & $40 \mathrm{RM}$ & $30,5 \mathrm{DM}$ \\
\hline
\end{tabular}

dukts betrug ${ }^{18}$, waren es in den USA 28 und in England $32 \%$, allerdings bei wesentlich höherem Pro-Kopf-Einkommen. Das Steueraufkommen von 1945/46 verdoppelte sich 1946/47 durch die Maßnahmen des Kontrollrats auf 24 Mrd. RM, blieb aber deutlich unter dem Höhepunkt von 49,1 Mrd. RM im Finanzjahr 1942/43 ${ }^{19}$.

Nachdem Anfang 1946 bei der zweiten Runde von Steuererhöhungen erkennbar geworden war, daß die Steuerpolitik die Probleme nicht in den Griff bekam, wuchs die Kritik der deutschen politischen Stellen und Finanzbehörden: Die Kaufkraft werde nicht abgeschöpft, sondern die rigorose Besteuerung bewirke den Rückgriff auf stilliegendes Geldkapital, da die Sparguthaben von rund $125 \mathrm{Mrd}$. RM in den Westzonen nicht blockiert worden waren. Es überwögen die negativen Wirkungen, indem die Lebenshaltung der Arbeiterschichten unzumutbar belastet, die Privatinitiative der Wirtschaft gelähmt werde ${ }^{20}$. Darauf nahm aber zu dem Zeitpunkt die alliierte Steuerpolitik keine Rücksicht, da ihr ganz andere Prioritäten zugrunde lagen. Vielmehr wurden nach der Neuordnung der direkten Steuern im Februar 1946 durch Gesetz Nr. 12 im Mai und Juni auch die indirekten Steuern auf Tabak, Alkohol, Essig, Bier, Streichhölzer und Zucker angehoben. Als die inflationsdämpfende Wirkung ausblieb, mußten bereits im November 1946 und im Frühjahr 1947 neuerliche Steuererhöhungen erfolgen. Die Steuergesetze vom Oktober und Dezember 1947 gehörten zu den letzten Maßnahmen, die der Kontrollrat einvernehmlich verabschiedete.

Die Bekämpfung der Inflation durch Kaufkraftabschöpfung war von Beginn an zum Scheitern verurteilt. Das vorrangige Ziel der Steuerpolitik war indes, mit Hilfe der Steuereinnahmen den Ausgleich der öffentlichen Haushalte und die Deckung der Besatzungskosten zu sichern, die $40-50 \%$ der Haushaltsausgaben ausmachten, ebenso durch Gebührenerhöhung die Eigenfinanzierung von Post und Rundfunk ${ }^{21}$. Nachdem zunächst nur ein Bruchteil der Länderhaushalte durch das Steueraufkommen hatte gedeckt werden können, überstiegen in der amerikanischen und britischen Zone

17 Litchfield, Postwar Germany, S. 345.

18 In der SBZ waren es nach internen Schätzungen 1947/48 sogar 50\%, nämlich 8-9 Mrd. RM bei einem Sozialprodukt von 15-16 Mrd. RM. BAP, C-15/131, Bl. 17 (DWK, Hauptverwaltung Finanzen, 14. 1. 1949). BAC, N-1/2079-1, Bl. 10 (DZFV, 10.6. 1948).

19 Gottlieb, Economic Potential, S. 72. Newcomer, Developments, S. 1 f.

20 Hansmeyer/Caesar, Kriegswirtschaft, S. 419. AVBRD, Bd. 1, S. 434, 660, 863 ff.; dass., Bd. 2, S. 541 ff. Van Scherpenberg, Rekonstruktion, S. $225 \mathrm{ff}$.

21 BA, Z 45 F/OMGUS, 2/121-2/1-4 (DFIN/M(46)7). Newcomer, Developments, S. 1, 8 f. 
1946/47 die Steuereinnahmen offiziell die Ausgaben der Länder um fast 30\%. Ein Entlastungseffekt wurde jedoch nicht erzielt; denn tatsächlich bestand 1946 in der britischen Zone ein Nettodefizit von 1,3 Mrd. RM, das durch die Subventionen für Kohle und Lebensmittel in Höhe von 1,05 Mrd. bzw. 200 Mio. RM verursacht wurde und auch 1947 nicht aufgefangen werden konnte ${ }^{22}$. Insgesamt geschah der Ausgleich der öffentlichen Haushalte in einer künstlichen Welt der „Scheinbewirtschaftung“, da sich immer weitere Bereiche der Wirtschaft und des täglichen Lebens der umfassenden Kontrolle von Löhnen und Preisen, von Steuern und Staatsausgaben entzogen; der Maßstab des schwarzen und grauen Markts war die „Zigarettenwährung“. Nur eine geringe Rolle spielte in der alliierten Steuerpolitik das Argument, daß die Fortschreibung des riesigen Staatsdefizits nach dem Ersten Weltkrieg eine Hauptquelle der Inflation gewesen war; eine Wiederholung dieser Entwicklung war durch die alliierte Kontrolle der öffentlichen Finanzen vorerst ausgeschlossen.

Die Sowjetunion, die seit August 1945 auf drastische Steuererhöhungen gedrängt hatte, finanzierte über die öffentlichen Haushalte neben den Besatzungskosten einen großen Teil ihrer Reparationsentnahmen aus der laufenden Produktion ${ }^{23}$. Von Beginn an hatte sie daher den Zonenkommandeuren eine erhebliche Autonomie einräumen wollen, indem diesen gestattet werden sollte, innerhalb einer gewissen Spannbreite von den Steuertarifen des Kontrollrats abzuweichen. Im Dezember 1945 beantragte sie zur Unterstützung der Agrarreform das Recht, „gewissen Kategorien von Landwirten“ zusätzliche Befreiungen zu gewähren. Dann bat sie, unter Rücknahme ihres vorherigen Vorschlags, „die Steuern von einzelnen Gruppen von Einkommens- und Vermögenssteuerzahlern um bis zu $25 \%$ zu senken oder zu erhöhen“, im Januar 1946 gar um $50 \%$. In seinen Erläuterungen begründete Sokolowski diese Forderung damit, daß die Befreiungen für die Neu-Landwirte durch stärkere Belastung derer zu finanzieren seien, „die es tragen können“; eine einmalige außerordentliche Vermögenssteuer von 5-10\% hätte nach sowjetischen Schätzungen zwischen 11 und $13 \mathrm{Mrd}$. RM erbracht. Die Westmächte vermuteten transformationspolitische Nebenabsichten und weigerten sich im Namen der Wirtschaftseinheit, Sonderregelungen für einzelne Gruppen zonal einzuführen ${ }^{24}$. Insgesamt scheint der SMAD jedoch in erster Linie an der Ertragssteigerung zur Finanzierung der Reparationen gelegen zu haben, weniger an der Enteignungswirkung ${ }^{25}$. Nachdem der Kontrollrat die Forderungen der Sowjetunion abgelehnt hatte, gab die den Kostendruck auf anderem Wege an ihre Zone weiter.

22 Van Scherpenberg, Rekonstruktion, S. 235 f. PRO, FO 371/55411/C1477 (5. 2. 1946).

23 Die Reparationsentnahmen waren nach Auffassung der SBZ-Experten der Hauptgrund für die inflationäre Entwicklung. „Solange wir verpflichtet sind, einen großen Teil des Sozialprodukts als Reparationslieferungen abzuzweigen, fehle die entsprechende Gütermenge als Angebot auf dem Binnenmarkt.“ Gegen den Kaufkraftüberhang wirke nur eine „ehrliche“ Kostenrechnung, d. h. hohe Steuern und hohe Preise. „In unserer Situation müsse daher Deutschland die höchsten Steuersätze aufweisen." BAC, N-1/2079-1, Bl. 2, 10 (DZFV, 20. 5., 10.6. 1948).

24 BA, Z 45 F/OMGUS, 2/118-1/5-16 (CORC/P(45)214, 22. 12. 1945); 2/121-2/1-4 (DFIN/M(46)2, 11. 1. 1946); 2/121-2/10-17 (DFIN/P(46)5, 24. 1. 1946). Zur Praxis vgl. ThHStA, Amt zum Schutze des Volkseigentums/76-80.

25 Später wurde die DWK von der SMAD angewiesen, die Einkommenssteuertarife an die der Westzonen anzupassen. „Privilegierungen“ für einzelne Sozialgruppen (Neubauern, ledige Mütter, Alte, Akkordarbeiter) durch Freibeträge lehnte die SMAD ab. Infolge der radikalen Abschöpfung gingen im Oktober 1948 die Bankeinlagen zurück und traten Steuerrückstände ein; aufgrund sinkender Kassenbestände bei den Banken standen keine Kredite zur Finanzierung der öffentlichen Haushalte und der Investitionen zur Verfügung. BAP, C-15/731, Bl. 1 ff. (Gegenüberstellung der Grundzüge der Steuerreformpläne in der Ostzone und in den Westzonen, o.D.), 16, 65, $72 \mathrm{ff}$. 
Das gesamte bisherige Aufkommen aus Reichssteuern wurde zur Finanzierung von Reparationen und Besatzungskosten eingesetzt. Das Land Thüringen z. B. mußte Ende 1945 ca. 35\% des Etatvolumens für diese Zwecke aufwenden. Die bisher mit den Reichssteuern finanzierten Aufgaben verblieben jedoch bei den Ländern und mußten durch neue Steuern gedeckt werden. Da die Reichssteuern durch den Kontrollrat in ihrem Hebesatz gebunden waren, erhielten Länder und Gemeinden das Recht und die Verpflichtung, eigene, auch neue Steuern einzuführen ${ }^{26}$. Als damit das „Steuersoll“ nicht zu erfüllen war, suchte die SMAD durch „außerordentlich starken Druck“ und ohne Rücksicht auf die Konsumbedürfnisse der Bevölkerung, auf dem Umweg über Verbrauchssteuern zum Ziel zu kommen ${ }^{27}$.

Die Differenzen in der Steuerpraxis, die nach mancher Einschätzung bereits im Herbst 1946 trotz des vom Kontrollrat erlassenen Generalgesetzes Nr. 12 ,in unzähligen Einzelfragen in den Zonen und Ländern so verschiedenartig“ wie kaum ein anderer Bereich gehandhabt wurde, bestanden keineswegs nur zwischen Ost und West. Sie waren gerade zwischen der amerikanischen und der britischen Zone erheblich und konnten auch in der Bizone nicht vollständig ausgeräumt werden. Denn die Westmächte durchlöcherten ihrerseits die Steuereinheit durch einseitige Maßnahmen; so führten die USA als einzige in ihrer Zone eine Luxussteuer ein. Obwohl durch Gesetz Nr. 12 detaillierte Steuertabellen vorgegeben waren, wurden die direkten Steuern nicht in allen Zonen gleich berechnet ${ }^{28}$. Nach deutschen Berechnungen lagen die Steuern in der SBZ um 4-9\% über denen in der britischen und amerikanischen Zone, weil die Westzonen eine sanftere Progression in und zwischen den Einkommensklassen gewählt hatten. Immerhin gelang es dem Finanzdirektorat durch sein Steuerkomitee noch einmal, einheitliche Tabellen für alle Zonen zu erarbeiten, die zum 1. Januar 1947 in Kraft traten ${ }^{29}$. Solange es um ihre eigene Kostenrechnung ging, waren die Alliierten trotz aller politischen Differenzen bereit, sich auf Kosten selbst der umworbenen Sozialgruppen zu einigen. Durch Gesetz Nr. 61 vom 19. Dezember 1947, das letzte Kontrollratsgesetz, wurden die Tarife unterhalb des Progressionssprungs angehoben, so daß vor allem die unteren Lohngruppen betroffen waren, $d . h$. die Masse der Industriearbeiter. Die traditionelle Tendenz des deutschen Steuersystems, die niedrigeren Einkommen stärker zu belasten, wurde durch die kräftigere Anhebung der indirekten Steuern noch verstärkt. Ihr Anteil am gesamten Steueraufkommen stieg von 44\% 1945/46 auf 49\% 1946/47. Insgesamt tröstete man sich im Kontrollrat, daß der Anteil der indirekten Steuern bei einem ledigen Arbeiter mit einem Einkommen von 200 RM lediglich von 10 auf $14 \%$, bei einer vierköpfigen Familie von 3,5 auf $6 \%$ stieg; angesichts der geringen Verfügbarkeit der rationierten Waren falle das quantitativ kaum ins Gewicht ${ }^{30}$.

26 ThHStA, MFin/72 (25., 27. und 28. 8., 12. und 15.9. 1945).

27 Das Defizit der SBZ zwischen 1,305 Mrd. RM Einnahmen und 2,449 Mrd. RM Ausgaben im 4. Quartal 1946 sollte durch Erhöhung der Einkommensteuer um 25\% und der Spiritussteuer aufgebracht werden - weniger, indem die SMAD von den Tarifen des Kontrollrats abwich, sondern indem sie „wegen der Verbrauchsabgabe“ auf Kosten des Getreidekonsums Alkohol produzierte. ThHStA, MFin/72 (29. 11. und 6.12.1945, 21. 2. und 29. 10. 1946).

28 BA, Z 45 F/OMGUS, FIN/60/9-11

29 BA, Z 45 F/OMGUS, 2/96-3/17 (DFIN/P(46)109); 2/122-3/9 (DFIN/TC/Memo(46)21, 20.11. 1946). Gesetz Nr. 61 präzisierte die Steuerberechnung.

30 Newcomer, Developments, S. $8 \mathrm{f}$. 
Viel mehr Sorgen bereitete den (west)alliierten und deutschen Stellen, daß die wachsende Steuerbelastung bei den Konsumenten zum Druck auf die Löhne, bei den Produzenten zum Ausweichen auf den Schwarzmarkt führte. Da die dort verlangten Preise die Lebenshaltung tatsächlich bestimmten, konnte eine Fortsetzung der bisherigen Steuerpolitik weder auf der Nachfrage- noch der Angebotsseite positive Wirkung erzielen. Aufgrund der Forderungen ihrer deutschen Experten drängten die USA seit 1947 im Kontrollrat auf die Senkung der Einkommenssteuer, da die hohe Steuerlast die wirtschaftliche Initiative auch bei den Arbeitnehmern hemme, vor allem aber die Kapitalbildung behindere. Das Argument konnte die Sowjetunion nicht beeindrucken, die zu einer generellen Steuersenkung nicht bereit war, sondern den Ausgleich von Ungerechtigkeiten oder gezielte Entlastungen nur bei Kompensation an anderer Stelle akzeptieren wollte ${ }^{31}$. Insofern standen die Chancen schlecht, daß bei einer gemeinsamen Währungsreform durch eine entsprechende Steuerreform die hohen Belastungen wieder abgebaut wurden. Seit dem 2. Februar bzw. 15. März 1948 wurde die bizonale Revision der Steuergesetze des Kontrollrats von der Verwaltung für Finanzen in Zusammenarbeit mit Vertretern von OMGUS und CCG vorbereitet. Allerdings wurden die neuen Gesetze - anders als die preispolitischen Maßnahmen Anfang Juni 1948 auf alliierte Empfehlung noch zurückgehalten, um Spaltungsvorwürfen auszuweichen ${ }^{32}$.

\section{Die Preis- und Lohnpolitik}

Die Vertagung der Währungsreform und der Rückgriff auf die Steuerpolitik als Übergangs- und Notmaßnahme stellten die Alliierten vor die Notwendigkeit, flankierende Maßnahmen auf dem Gebiet der Preis- und Lohnpolitik zu ergreifen. Daß es trotz dieser auseinanderstrebenden Interessen zu einer einvernehmlichen Lohn- und Preispolitik im Kontrollrat kam, war wieder einmal in erster Linie besatzungspraktischen Zwängen zu verdanken. Da Preissubventionen ${ }^{33}$ aus der Kriegszeit für $20 \%$ des Defizits der öffentlichen Haushalte verantwortlich und $80 \%$ der Preissteigerungen auf Maßnahmen des Kontrollrats (Steuern und Gebühren) zurückzuführen waren, mußte ein Abwälzen dieser Belastungen auf die Preise und das Ingangsetzen einer inflationären Preis-Lohn-Spirale durch einen Lohn- und Preisstopp sowie durch Rationierungsmaßnahmen verhindert werden ${ }^{34}$. Damit eng verknüpft waren die deutschlandpolitischen Ziele: Ein einheitliches Lohn- und Lebenshaltungsniveau war ein zentrales Element der deutschen Wirtschaftseinheit. Preiserhöhungen in der einen Zone konnten zur Minderversorgung der anderen Zonen führen, wenn durch Schmuggel oder

31 BA, Z 45 F/OMGUS, 2/97-1/3 (US-Brief zu CORC/P(47)252, 15. 12. 1947; DFIN/Misc(47)58, 19. 6. 1947; DFIN/P(47)143, 30. 5. 1947). Newcomer, Developments, S. 9.

32 AVBRD, Bd. 4, S. 302, 392, 563.

$33 \mathrm{BA}, \mathrm{Z} 45$ F/OMGUS, 2/134-1/12-15 (SCPC/P(46)2 und 22). Die USA und (diesen notgedrungen folgend, um den Abfluß der Waren zu verhindern) Frankreich hoben zum 1.3. 1946 die landwirtschaftlichen Subventionen in ihren Zonen weitgehend auf, die in den vorangegangenen 12 Monaten 125 bzw. 240 Mio. RM in den jeweiligen Zonen verschlungen hatten. Die Briten hoben ihre Subventionen nur bei Getreide und Zucker auf, in der SBZ wurden alle Subventionen weiterbezahlt. AO, Berlin/3276/1/2007 (23.3. 1946).

34 BA, Z 45 F/OMGUS, 2/122-3/3 (DFIN/PPC/Memo(47)1, 6. 2. 1947). Hansmeyer/Caesar, Kriegswirtschaft, S. $407 \mathrm{ff}$. 
einen unkontrollierten Interzonenhandel die Waren in die Hochpreisgebiete abflos$\operatorname{sen}^{35}$. Die Sowjetunion, die - wie Frankreich - auf die Zustimmung in der Bevölkerung ihrer Zonen weniger Wert legte, war im Interesse hoher Reparationsleistungen an konstanten Preisen und niedrigen Löhnen interessiert. England und die USA waren dagegen an ökonomischer Effizienz und somit an „realistischen“ Preisen und Löhnen als Leistungsanreizen orientiert, zumal durch eine Erhöhung des Lebenshaltungsniveaus "Chaos und Unruhe“ als Nährboden kommunistischer Propaganda verhindert und im Kampf um die Deutschen eine „Magnet“-Wirkung erzeugt werden konnte.

Der Preis- und Lohnstopp war gemäß den Kriegsplanungen im Zuge der ersten Besatzungsmaßnahmen verhängt worden, indem die Oberkommandierenden in Ost und West übereinstimmend die Preise auf dem Stand vom 9. Mai 1945 bzw. der deutschen Stopp-Preise von 1944 eingefroren hatten. Daher hatte es der Kontrollrat trotz des Drängens des Wirtschaftsdirektorats nicht eilig, selbst tätig zu werden. Zum Zwecke der Behandlung Deutschlands als wirtschaftliche Einheit versprach er in Direktive Nr. 14 vom 12. Oktober 1945 „ein gemeinschaftliches Verfahren in Fragen, die sich auf Löhne, Preise und Zuteilung lebenswichtiger Verbrauchsmittel beziehen“. Doch zunächst waren die Kompetenzen zu klären. Am 16. November 1945 teilte das Koordinationskomitee auf britischen Vorschlag die Zuständigkeiten und übertrug dem Finanzdirektorat die allgemeine Preispolitik, dem Wirtschaftsdirektorat die individuelle Preisfestsetzung ${ }^{36}$. Die Errichtung eines zentralen, die Preispolitik der beteiligten Direktorate koordinierenden Ausschusses, den die USA und das (für die Löhne zuständige) Arbeitsdirektorat verlangten, konnte nicht erreicht werden. Mit Beschluß des Koordinationskomitees vom 7. Februar 1946 reservierte sich der Kontrollrat, gemäß einer Vorlage des Preispolitikkomitees im Finanzdirektorat, die Preisfestsetzung lediglich für die 17 Warengruppen, deren interzonale Zuteilung ihm selbst oblag. Alle anderen Preise unterlagen der Festsetzung durch die Zonenkommandeure „in Übereinstimmung mit den allgemeinen Grundsätzen“ des Kontrollrats ${ }^{37}$. Das entsprach zwar den ursprünglichen anglo-amerikanischen Vorstellungen, daß der Kontrollrat sich einige zentrale Bereiche selbst vorbehalten, im übrigen aber die Durchführung sekundärer Bereiche dezentralisieren und den Zonenbefehlshabern überlassen sollte; doch hatten sich die politischen Rahmenbedingungen längst geändert. So eröffnete dieser Kompromiß einerseits den Zonenkommandeuren die Möglichkeit, durch unilaterale Maßnahmen die Restkompetenzen des Kontrollrats immer weiter auszuhöhlen, andererseits ermunterte er sie zu dem Versuch, die finanzpolitischen Vorstellungen ihrer Regierungen auf Umwegen gegen die anderen Alliierten nachträglich durchzusetzen.

Es waren vor allem die Briten, die diesen Weg zu gehen versuchten. Sie zeigten von Beginn an das geringste Interesse, den Preisstopp in ihrer Zone rigoros zu handhaben. Und das aus zwei Gründen: Zum einen waren sie so sehr auf die Senkung der Besat-

35 BA, Z 45 F/OMGUS, 2/131-2/14 (DECO/CPC/Memo(47)1, 3. 1. 1947); 2/121-2/10-17 (DFIN/ $\mathrm{P}(46) 252$, 27. 12. 1946). PRO, FO 1046/752 (Chambers, 10.6. 1947). Tägliche Rundschau, 5. 1. 1947, S. $1 \mathrm{f}$.

36 BA, Z 45 F/OMGUS, 2/118-1/17-21 (CORC/P(46)56, 7. 2. 1946). Die Unterlagen des Preispolitikkomitees in: $2 / 122-3 / 2-3$, die des Preiskontrollkomitees in: $2 / 131-2 / 5-17$, die des Preiskontrollunterkomitees beim Handelskomitee in: 2/134-1/10-15.

37 BA, Z 45 F/OMGUS, POLAD/752/3; 2/134-1/12-15 (SCPC/P(46)25, 20. 8. 1946; P(46)25/1, 24. 8. 1946); Z 1/662, Bl. 38 ff. 
zungskosten bedacht, daß sie einen Alleingang ohne oder gegen den Kontrollrat ins Auge faßten, sollte der ihrem Wunsch nicht nachkommen, durch kostendeckende Preise für Kohle und Stahl eine weitgehende Selbstfinanzierung ihrer Zone zu gewährleisten. Bereits Anfang August 1945 hatte sich ein Kabinettsausschuß dafür ausgesprochen, daß das Preisgefüge von den vier Mächten festgesetzt werden sollte „oder, wenn das nicht möglich ist, von den drei Westmächten. Wenn es sich als ein schwieriger und langatmiger Prozeß erweisen sollte, solch eine Vereinbarung zustande zu bringen, dann sollten die Behörden der britischen Zone damit beginnen, den Alliierten Rechnungen auf der Grundlage ihres eigenen Preisgefüges auszustellen, die nach Weltmarktpreisen oder Durchschnittswerten festgelegt würden." Zwar hielten die Briten aus politischen Gründen an der Zuständigkeit des Kontrollrats fest, sie wollten ihm aber nicht mehr als die Festlegung allgemeiner „Prinzipien“ zugestehen; „danach wäre die Preisfestsetzung ein kontinuierlicher Prozeß“, von der CCG gesteuert, vom Kontrollrat lediglich überprüft und koordiniert ${ }^{38}$. Zum zweiten hofften sie, auf diesem Wege ihr Modell einer „kontrollierten Inflation“ doch noch durchzusetzen. Die drastische Anhebung des Preisniveaus würde Kaufkraft abschöpfen, eine ebenso drastische Besteuerung die durch Preissteigerungen erzielten Gewinne. Im Dezember 1945 forderten sie die pauschale Anhebung der Preise für Lebensmittel um 10\%, für Gebrauchsgüter um 50\%. Eine Reduktion der Reallöhne um 30\% schien ihnen akzeptabel, da der Geldmenge kein Warenangebot gegenüberstand und da der Industrieniveauplan eine Absenkung des Lebenshaltungsniveaus um diesen Prozentsatz vorsah. Sollte eine Einigung im Kontrollrat nicht möglich sein, müßten die Preise in der britischen Zone „durch einseitiges Vorgehen“ erhöht werden ${ }^{39}$. Nachdem eine Einigung im Kontrollrat ausblieb, da auch die USA - unter dem Einfluß der deutschen Länderregierungen ${ }^{40}$ - weder Kohlepreiserhöhungen noch allgemeine Preissteigerungen von mehr als $20 \%$ zugestehen wollten, handelten die Briten auf eigene Faust.

Für die USA waren in erster Linie politische Überlegungen maßgeblich, nämlich die Erhaltung der Wirtschaftseinheit und - zu diesem Zweck - die Liberalisierung des Interzonenhandels. Allerdings hatten wirtschaftliche Zwänge in der eigenen Zone die anfängliche Absenkung des Preisniveaus auf den Stand der Kriegszeit längst zunichte gemacht. Seit Januar 1946 genehmigte OMGUS in raschem Tempo Preissteigerungen von durchschnittlich $30 \%$ bei den Erzeugerpreisen, die mit der gesteigerten wirtschaftlichen Aktivität und der Notwendigkeit von Leistungsanreizen durch kostendeckende Preise begründet wurden ${ }^{41}$. Hinzu kamen, im Zeichen des konkurrierenden Werbens um die Deutschen, sozialpolitische Rücksichtnahmen. Aufgrund der Preissteigerungen und des gleichzeitig rigider durchgesetzten Lohnstopps waren die Nettoeinkommen von Kriegsende bis zum Frühjahr 1946 in der amerikanischen Zone um 20-25\% gesunken. Es war den nun einsetzenden Bemühungen zur Absenkung des

38 PRO, FO 1046/75 (ACAO, 7. 8. 1945). Unausgesprochen wollten die Briten durch die „Freiheit“ von Preisen und Löhnen die Wirtschaft rasch beleben, „um aus dieser in kürzester Zeit das Maximum an Reparationen herauszuziehen“. AO, Berlin/3282/5/2130C (GFCC, 21. 3. 1946). Zum "dollar-billing" vgl. oben S. 198.

39 PRO, FO 371/55410/C646 und 65004; FO 1046/94 (Juni 1946). AMAE, Y 453, Bl. 251.

io AVBRD, Bd. 1, S. 482, 578.

11 BA, Z 45 F/OMGUS, 2/134-1/10 (SCPC/I(46)16, 22.6. 1946); POLAD/752/3 (SCPC/P(46)25, 20. 8. 1946). 
Preisniveaus zu verdanken, daß sich die Schere nicht weiter öffnete und das Einkommensniveau im Frühjahr 1947 „nur“ um 20\% unter dem vom Mai 1945 lag $^{42}$.

Trotz des Lohn- und Preisstopps konnte auch die Sowjetunion zunächst in ihrer Zone die Entwicklung nicht vollständig unter Kontrolle halten. Obwohl „die in der Sowjetzone eingeleiteten Planungsarbeiten [...] eine grundsätzliche Preisstabilität“ erforderten, trugen im Zeichen der Reparationskonjunktur 1945/46 vor allem regionale Besatzungsbehörden maßgeblich zur Durchbrechung der Preisdisziplin bei. Mit Befehl Nr. 63 vom 26. Februar 1946, wenige Tage nach dem Grundsatzbeschluß des Kontrollrats vom 7. Februar, wurden alle Ausnahmegenehmigungen aufgehoben; die Bewilligung neuer Preiserhöhungen wurde deutlich erschwert, die Überwachung durch die "demokratische Kontrolle“ des FDGB forciert ${ }^{43}$. Von dieser Linie wich die SMAD trotz einiger Proteste von SBZ-Behörden bis zuletzt nicht wieder $a b^{44}$.

Die Franzosen waren nicht minder auf eine strikte Einhaltung des Preisstopps bedacht. Da sie sich durch die Preissteigerungen in den benachbarten Zonen unter Zugzwang gesetzt sahen, wollten sie das unkontrollierte Abfließen der Waren durch Schwarzmarkt und Schmuggel vermeiden. Es war aber weniger die Gefahr einer Inflation oder die Beeinträchtigung ihrer kommerziellen Interessen, die sie zur Intervention in Berlin bewogen, sondern die Befürchtung, daß eine allgemeine „wirtschaftliche Anarchie“ eintreten und zum „Argument der Befürworter der Wiederherstellung der Zentralverwaltungen" werden könnte ${ }^{45}$.

Noch waren es insgesamt mehr die besatzungspraktischen Zwänge und die ungeklärten Kompetenzen innerhalb der Kontrollratsbürokratie als die prinzipiellen ordnungs- und wirtschaftspolitischen Differenzen, die in kürzester Zeit die Finanzeinheit Deutschlands in Frage zu stellen drohten. Den Briten gelang es zwar nicht, mit dem Vorwand der Untätigkeit bzw. Handlungsunfähigkeit des Kontrollrats ihre globalen finanzpolitischen Ziele durchzusetzen, sie erzwangen aber doch gemeinsame Regelungen durch den Kontrollrat, wollten die anderen Mächte eine Sonderentwicklung der britischen Zone verhindern ${ }^{46}$. Am 1. April 1946 wurde ein Preiskontrollkomitee beim Wirtschaftsdirektorat ins Leben gerufen, das im Mai 1946 seine Arbeit aufnahm. Eine Bestandsaufnahme zeigte, daß die Preiseinheit nur noch eine Fiktion war. Die Proteste der anderen Mächte, die sich stärker (wenngleich mit Ausnahmen) an den Beschluß des Koordinationskomitees vom 7. Februar zu striktester Preisdisziplin gebunden fühlten, wurden von den Briten zurückgewiesen. Sie faßten diesen Beschluß nicht als

42 BA, Z 1/499, Bl. 247 ff. AVBRD, Bd. 1, S. 491 ff. Das PPC schätzte die Belastung der Lebenshaltungskosten auf $10 \%$. BA, Z 45 F/OMGUS, 2/122-3/2 (DFIN/PPC/P(47)2, 11. 1. 1947).

43 SAPMO, ZPA, Nl 182/1189, Bl. 11 (SMAD-Wirtschaftsabteilung, Dubrowski, 6. 3. 1946). Um ein antifaschistisch-demokratisches Deutschland, S. 72 ff. Zu Befehl Nr. 337 vom 6. 12. 1946 vgl. BAP, C-15/731, Bl. 50. BA, Z 1/500, Bl. 136 ff.; Z 45 F/OMGUS, 2/101-3/18 (DMAN/P(46)8, 6. 1. 1946).

44 ThHStA, MFin/62 (1. 10. 1947).

45 AO, Berlin/3282/5/2130C; 3274/3/106 (GMZFO, 2. 5. 1946).

46 PRO, FO 1046/94 (23. 7. 1946; Schumacher, Juni 1946). BA, Z 1/500, Bl. 53 ff. Eine Úbersicht des Kontrollrats über die Entwicklung von Oktober 1945 bis September 1946 zeigt keine erheblichen Abweichungen; danach lag die britische Zone auf einer Stufe mit der SBZ (die im Oktober 1945 das höchste Niveau erreicht hatte!) und noch hinter der französischen und amerikanischen Zone. $\mathrm{Z} 45$ F/OMGUS, 2/131-2/9-13 (CPC/P(47)35/1, 1. 5. 1947). Eine andere Erhebung des Kontrollrats kam im September 1946 zu dem Ergebnis, daß die Lebenshaltungskosten in den vier Zonen um 20-25\% gegenüber 1938 gestiegen waren. Lag demnach im Oktober 1945 die SBZ mit einer Steigerung um 18 Prozentpunkte noch günstiger als die Westzonen, so hatte sich nun das Verhältnis umgekehrt. 2/120-1/3 (CORC/P(48)37, Appendix ,B'). 
ein Verbot von Preiserhöhungen auf, zumal ihre Maßnahmen zu keiner dramatischen Erhöhung des Lebenshaltungsniveaus geführt hätten, sondern befürworteten eine „liberale Interpretation“ des Papiers: „Gewisse Preissteigerungen seien absolut notwendig für die wirtschaftliche Rettung der britischen Zone." Die sowjetische Delegation, ausdrücklich von Franzosen und Amerikanern unterstützt, kritisierte diese Politik scharf; sie stehe im Widerspruch zum Prinzip der Wirtschaftseinheit und behindere den Interzonenhandel ${ }^{47}$. Daraufhin einigten sich die vier Mächte im Juli 1946 auf ein formalisiertes Verfahren für Preisänderungen bei den 17 Warengruppen der Kontrollratsliste. Im September folgte ein Beschluß über die einheitliche Berechnung des Lebenshaltungsindex in allen Zonen, um die Wirkung der Preisbildungsmaßnahmen besser beurteilen zu können ${ }^{48}$. Jetzt vermochte sich der Kontrollrat auch auf Preisanhebungen bei einigen zentral bewirtschafteten Gütern zu verständigen, erstmals im August 1946 bei Stickstoffdünger, Saatkartoffeln, Getreide und Bahnfrachten. Bei Kohle wurde die Entscheidung zur Prüfung der Folgekosten für die industrielle Produktion verschoben ${ }^{49}$. Mehr noch, das Preiskontrollkomitee organisierte am 29. und 30. August 1946 in Berlin eine Konferenz von Vertretern deutscher Preiskontrollbehörden aus allen vier Zonen, „die erste vier-zonale offizielle Versammlung, die zur Diskussion wirtschaftlicher Probleme einberufen worden war ${ }^{\text {“50. }}$. Mit Hilfe der dort erarbeiteten Empfehlungen gelang es dem Preiskontrollkomitee im Herbst 1946, die Preise abzusenken, durch monatliche Berichte die Einhaltung der Preisdisziplin in den Zonen stärker zu kontrollieren und die zonale Preispolitik abzustimmen; bereits eingetretene Steigerungen mußten vom Preiskomitee genehmigt bzw. nach dessen Maßgabe zurückgenommen werden ${ }^{51}$.

Es war zweifellos ein bemerkenswerter Erfolg, daß es dem Kontrollrat gelang, den preispolitischen Wildwuchs auf ein relativ einheitliches Niveau zurückzuführen, nachdem mehr als 12 Monate die Zonenkommandeure die Preispolitik weitgehend autonom gestaltet hatten. Die Einigung stand in offenkundigem Zusammenhang mit den Bemühungen von Franzosen und Sowjets, nach dem Scheitern der Pariser Außenministerkonferenz die Wirtschaftseinheit durch Intensivierung des Interzonenhandels zu festigen und das amerikanische Bizonen-Angebot zu konterkarieren. Denn ohne Angleichung des Preisniveaus konnten die Restriktionen im Interzonenhandel nicht abgebaut werden ${ }^{52}$. In den Augen der Briten war dieser Erfolg jedoch ein Desaster, da die Sowjetunion weiterhin rigoros alle Preissteigerungen durch ihr Veto verhinderte. Das bestärkte ihre Entschlossenheit, sich der Fesseln durch einseitige Maßnahmen zu entledigen. Sie fühlten sich zum eigenen Nachteil gebunden und hofften, über den Kohlepreis eine Revision des gesamten Preisgefüges zu erzwingen. Auch die Franzo-

47 BA, Z 45 F/OMGUS, 2/134-1/10-15 (SCPC/P(46)13, 24. 6. 1946; SCPC/I(46)19, September 1946); 2/111-1/13-16 (DFIN/P(46)93, 5. 7. 1946). AO, Berlin/3274/3/106.

$48 \mathrm{BA}, \mathrm{Z} 45$ F/OMGUS, 2/131-1/10 (Zonenberichte); 2/131-2/14 (DECO/CPC/Memo(47)1, 31. 1. 1947). Die unterschiedlichen Indices und ihre Gewichtungen in: 2/95-2/22. Für eine fünfköpfige Arbeiterfamilie wurden in den vier Zonen im September 1946 als Lebenshaltungskosten zugrundegelegt: 266,17 RM in der amerikanischen, 175,39 RM in der britischen, 201,13 RM in der französischen und 205,95 RM in der sowjetischen Zone.

49 Der Kompromiß war prekär, da man sich nur auf Richtpreise einigte, die den Zonenkommandeuren erhebliche Gestaltungsspielräume ließen. BA, Z 45 F/OMGUS, 2/134-1/11 (SCPC/M(46)13, 14. 8.1946 (Kartoffeln); M(46)16, 26.9. 1946 (Dünger).

so $\mathrm{BA}, \mathrm{Z} 8 / 247$, Bl. $14 \mathrm{ff}$.; $\mathrm{Z} 1 / 499,500,662$.

31 AO, Berlin/3276/2/2009 (14.11. 1946).

s2 BA, Z 45 F/OMGUS, 2/134-1/12-15 (SCPC/P(46)25, 20. 8. 1946, und 25/1, 24. 8. 1946). 
sen zeigten sich, trotz ihrer offiziell zur Schau getragenen Prinzipientreue, inzwischen zu einer „flexiblen“ Preisgestaltung bereit ${ }^{53}$.

Der Kohlepreis ${ }^{54}$ war ein volkswirtschaftlicher Eckpreis, er war zugleich ein politischer Preis. England konnte hier kaum auf Entgegenkommen rechnen, nachdem im September 1946 die Kohlezuteilung durch den Kontrollrat eingestellt worden war. Seit dem Herbst 1945 hatten die Briten vergeblich auf die Erhöhung der auf dem Niveau von 1932 festgeschriebenen Preise gedrängt. Nachdem dieser Antrag erfolglos durch verschiedene Gremien von Wirtschafts- und Finanzdirektorat gelaufen war, wurde er von der Pariser Außenministerkonferenz an das Komitee der Kohleexperten überwiesen ${ }^{55}$. Doch mündete all das nur in eine Erhöhung der Bergarbeiterlöhne von 20\% (um eine Produktionssteigerung zu erzielen), nicht aber in eine Anhebung der Preise. Zusätzlich sahen sich die Briten bald den neuen Zwängen der Bizone ausgesetzt. Diese erwies sich, sofern sie von der Hoffnung auf Abwälzung der Besatzungskosten auf die USA begleitet war, als Enttäuschung. Daraufhin verlangten die Briten von Frankreich die Bezahlung der Exportkohle in Dollar und beantragten abermals im Kontrollrat, den Inlandspreis heraufzusetzen. Doch trotz des allgemeinen Interesses an einer Steigerung der Kohleförderung hatte die CCG kein politisches Druckmittel in der Hand, denn angesichts der voraussehbaren Folgen einer Preiserhöhung für alle industriellen, öffentlichen und privaten Haushalte leisteten die anderen Alliierten erbitterten Widerstand. Das Koordinationskomitee wollte sich bestenfalls auf eine vorsichtige, langfristige Strategie einlassen, die auf „Zwischenlösungen“ abzielte, obwohl man den Briten zugestand, daß infolge des Krieges und der „Umstände der Besatzung“ an sich „exzessive“ Steigerungen des inländischen Preisniveaus erforderlich seien, da die Subventionen (die im sächsischen Kohlebergbau mit 25 RM deutlich höher lagen) „ruinöse“ fiskalische Belastungen heraufbeschworen ${ }^{56}$. Angesichts der Produktionsbedingungen waren bei einer Tagesproduktion von 185.000 t die Gestehungskosten von über $30 \mathrm{RM}$ pro t „abnorm“, nämlich doppelt so hoch wie der Preis. Indem das als „vorübergehende“ Ausnahmesituation definiert wurde, galt ein an den Kosten orientierter Preis als nicht gerechtfertigt. Das Wirtschaftsdirektorat empfahl mit Mehrheitsbeschluß [!], den Preis nach den „dauerhaften“ Kosten zu bemessen, wie er sich bei einer vom Industrieniveauplan angestrebten Produktion von $400.000 \mathrm{t}$ pro Tag ergebe. Obwohl die daraus abzuleitende Preisanhebung minimal gewesen wäre, lehnte das Preispolitikkomitee des Finanzdirektorats eine solche als politisch und volkswirtschaftlich schädlich ab. Wohl würden die privaten Haushalte von einer derartigen Preiserhöhung nur im Rahmen von 1-4\% direkt belastet; der Hauptteil, der von den öffentlichen Haushalten und der Industrie aufgefangen werden müsse, könne durch steuernde Maßnahmen der Preiskontrolle über einen längeren Zeitraum allmählich an die Verbraucher weitergegeben werden, ohne sofort zu einer Erhöhung

53 BA, Z 45 F/OMGUS, 1/190-2/10 (OMGUS, September 1946). Auf Empfehlung deutscher Stellen führten sie eine gleitende Preisskala ein, die den Produzenten bei einem Auslastungsgrad von mehr als $80 \%$ den Richtpreis, bei sinkender Auslastung einen "Ausgleich“ in Gestalt von Preiszuschlägen von bis zu $18 \%$ (bei $40 \%$ Auslastungsgrad) zubilligte.

54 Zum folgenden BA, Z 45 F/OMGUS, 2/132-3/2-3; 2/134-1/11-15.

55 Vgl. oben S. 163.

561946 waren 500 Mio. RM an Subventionen für den Ruhrbergbau erforderlich; das entsprach einem Zehntel der gesamten öffentlichen Ausgaben, inkl. Besatzungskosten. PRO, FO 1046/94 (Chambers, 1. 11. 1946, S. 15). 1947 mußten 1 Mrd. RM aufgewendet werden. Berichte und Drucksachen des Wirtschaftsrats, Bd. 2, S. 429. 
des Lohnniveaus zu führen. Dem Komitee erschien es jedoch fraglich, ob das den Einsatz massiver Subventionen rechtfertige.

Während die Westmächte eine Abwälzung höherer Kosten auf die Deutschen als eine Konsequenz des Industrieniveauplans für vertretbar hielten, spezifische Härten durch steuerliche Maßnahmen oder durch exakt begrenzte Subventionen abmildern wollten, exzessive Subventionen aber - so der amerikanische Vertreter - als „ungesunde Methode der Geschäftspraxis“ und als inflationsfördernd ablehnten, wiesen die Sowjets jede Erhöhung des Kohlepreises zurück; eine Steigerung des Kohlepreises um 7-8 RM pro t bedeute eine Erhöhung der Produktionskosten von 14\% bei Stahl, $13 \%$ bei Gas und Strom oder $9 \%$ bei Zement, mit anderen Worten: eine Erhöhung der Produktionskosten von Reparationsgütern. Zugleich verwarfen sie den Vorschlag, die Subventionskosten auf alle Zonen zu verteilen. Die Minderproduktion sei durch die Unfähigkeit der britischen Behörden verursacht worden und könne nicht zu Lasten der kohleempfangenden Zonen, d. h. der SBZ, gehen. Unannehmbar war für sie die Möglichkeit, den günstigen Inlandspreis durch Verdoppelung des Exportpreises zu finanzieren: Damit sollten, so beschuldigte Sokolowski die Briten, entweder „unmäßige Gewinne“ erzielt oder die Empfängerländer politisch unter Druck gesetzt werden. Die Franzosen waren sich uneins über den einzuschlagenden Kurs. Eine Erhöhung des Exportpreises, der sie direkt betraf, kam für sie nicht in Frage. Doch im Hinblick auf Gestehungskosten und Förderleistung waren das Pariser Finanzministerium und einige Vertreter der GFCC nicht abgeneigt, im Sinne der britischen Konzeption der kontrollierten Inflation eine „allgemeine Hausse“ des Preisniveaus, inkl. des Kohlepreises, zu akzeptieren. Angesichts der zu erwartenden Nachteile für die eigene Zone plädierten sie für ein System allmählich abnehmender Subventionierung, um die Anpassungsprobleme auffangen zu können. Je stärker aber der inflationäre Druck wurde, um so ablehnender wurde ihre Haltung ${ }^{57}$.

Die Briten setzten sich zwar im Finanzdirektorat mit ihrem Vorschlag einer Kombination von bescheidenen Preiserhöhungen einerseits und zeitlich (bis 31 . Dezember 1948) und in der Summe begrenzten Subventionen andererseits durch; doch nutzte ihnen der Erfolg wenig, da er auf höherer Ebene nicht bestätigt wurde. Denn im Dikkicht der Kontrollratsinstanzen wurden neue Hürden aufgebaut. Dem sowjetischen Vorschlag, die Anhebung des Kohlepreises mit der Währungsreform und der Frage des Banknotendrucks zu koppeln, schloß sich das Finanzdirektorat, aber nicht dessen Preispolitikkomitee an: Die Erhöhung des Kohlepreises sei eine Art Experiment, dessen Wirkungen man sorgfältig abschätzen und beobachten müsse. Damit unterstrich es seine Hilflosigkeit gegenüber der Komplexität eines ungewohnten wirtschaftlichen Steuerungsversuchs. Es blieb alles beim alten, obwohl sich bis zum November 1947 selbst in den Augen der Sowjets die „dauerhaften“, erst bei höherer Produktivität zu deckenden Gestehungskosten pro Tonne von 17,50 RM im Juni 1946 auf 21,20 RM erhöhten. Über den Ausgleich der Differenz zwischen „vorübergehenden“ und „dauerhaften" Kosten durch eine Subvention in Höhe von 7 RM pro Tonne bestand gemäß einem Vorschlag des Finanzdirektorats prinzipielle Einigung, jedoch nicht darüber, ob die Subvention von der britischen Zone allein oder von allen Zonen anteilig aufzubringen sei. Die Hoffnung der Briten vom Sommer 1947, sich mit ihrer Linie 
durchsetzen zu können, da die USA und Frankreich immer stärker ihrem Konzept der „stetigen Preisanpassung“ zuzuneigen schienen und auch die Sowjets in der Subventionsfrage sich kompromißbereiter zeigten ${ }^{58}$, erwies sich als Trugschluß. Ein britisch-amerikanischer Kompromißvorschlag im Preiskontrollkomitee, dem sich die Franzosen unter Vorbehalten (und mit dem Versuch neuer Verzögerungen) anschlossen und der eine Kombination von Preiserhöhung und Subvention vorsah, wurde von der Sowjetunion im Interesse niedriger Reparationskosten abermals mit dem Argument abgelehnt, das werde zu einem allgemeinen inflationären Preisschub führen ${ }^{59}$. Damit war für die Briten der Punkt zum Bruch erreicht. Sie (und die Amerikaner) waren jetzt entschlossen, bilateral vorzugehen (bzw. trilateral, sollte Frankreich sich anschließen), wenn die Sowjets weiterhin ihre Zustimmung versagten. Das Ende des Kontrollrats bot die ersehnte Gelegenheit dazu: Die unilaterale Preisrevision in der Bizone bei Kohle und Stahl erfolgte noch im März/April $1948^{60}$.

Wieder erwies sich die Sowjetunion als unfähig, im Interesse ihrer Reparationsforderungen einen Kompromiß mit den Westmächten zu finden, obwohl die Deutschen die Rechnung hätten bezahlen müssen und obwohl auch die Experten der DWK Anfang 1948 sich für die Bereinigung der Preisstruktur aussprachen. „Die alten, aus der Rüstungs- und Kriegswirtschaft übernommenen Löhne und Preise hemmen auf die Dauer die Entwicklung der Produktivkräfte der neuen demokratischen Wirtschaft und berücksichtigen nicht die erheblichen Veränderungen der Produktivkräfte, die sich aus der verminderten Leistungsfähigkeit der Arbeitskräfte und Arbeitsmittel ergeben als Folge der übermäßigen Ausbeutung und Abnutzung durch den Krieg und seine Auswirkungen." Heftige Kritik wurde an der zonalen Zentralverwaltung für Finanzen geübt, die mit sowjetischer Rückendeckung Preiserhöhungen verhindere, so daß ,größte Schäden für die Wirtschaft auftreten, die besonders darin zum Ausdruck kommen, daß die Reparationsaufträge zu Preisen ausgeführt werden müssen, die in keiner Weise mehr den heutigen Verhältnissen entsprechen“. Die durch Befehl festgelegten Preise deckten nur 50-80\% der Kosten, die Preissubventionen seien reine „Reparationsleistungen"61. Die SMAD mußte schließlich doch einer Preisreform zustimmen. Nachdem die Westmächte in ihren Zonen vorangegangen waren, hatte die DWK am 21. April 1948 vergeblich versucht, die Preiserhöhungen im Westen durch neue Subventionen aufzufangen. Doch mit den um ein Drittel niedrigeren Preisen in der SBZ geriet sie sowohl im offiziellen Interzonenhandel als auch durch den illegalen

58 PRO, FO 1046/752 (Chambers, 10.6. 1947).

59 BA, Z 45 F/OMGUS, 2/95-3/2 (US-Brief zu CORC/P(48)12, 27. 1. 1948). Als Beleg galt den Sowjets, daß Briten und Amerikaner eine gleichzeitige Anhebung der Preise bei Koks, Briketts, Stahl, Walzprodukten, chemischen Grundstoffen, Strom und Gas vorschlugen, die der Zustimmung des Kontrollrats bedurften. Nach ihren Berechnungen lagen die Auswirkungen der britischen Kohlepreis-Vorstellungen auf das allgemeine Preisniveau doppelt so hoch wie nach denen der Briten. 2/122-3/2 (DFIN/PPC/Memo(47)2, 12. 11. 1947).

60 AVBRD, Bd. 4, S. 467. Zum 1. 4.1948 erhöhte das Bipartite Board die Kohlepreise pro $t$ um $10 \mathrm{RM}$, so daß die Preise auch in anderen Industriesparten zwischen 1 und $10 \%$ stiegen. Bis Ende 1948 war eine Subvention von 3 RM für Kohle vorgesehen. Berichte und Drucksachen des Wirtschaftsrats, Bd. 2, S. 429, 473. Die Anhebung der Preise galt den Anglo-Amerikanern wie den Deutschen zur Bereinigung der Preisrelationen im Vorfeld der Währungsreform als unabdingbar, um deren Erfolg nicht durch nachträgliche Preisanhebungen zu beeinträchtigen. AVBRD, Bd. 3, S. 848.

61 ThHStA, MFin/62 (1. 10. 1947). Die Forderung, „Mißstände“ durch Subventionen abzubauen, wurde von der SMAD abgelehnt. BAP, G-2/1044, Bl. 71 ff. (8.-11. 1. 1947); C-15/259, BI. 48 (28. 1. 1948); C-15/659, Bl. $60 \mathrm{ff}$ (DWK, Hauptverwaltung Wirtschaftsplanung, 19.4. 1948), 63 (dies. an SMAD, 19. 4. 1948). BAC, N-1/2079-1, Bl. 2, 10 (20. 5. und 10.6. 1948). 
Abfluß von Waren unter Druck. Daraufhin genehmigte die SMAD am 7. Juni die gewünschten Preiserhöhungen. Jetzt wurden auch die Länderhaushalte von den Subventionen für Verbrauchsgüter entlastet, um angesichts des erhöhten Preisniveaus neuen Spielraum für die Finanzierung der Reparationen $\mathrm{zu}$ gewinnen ${ }^{62}$. Nachdem die SMAD durch ihre - von den Ostdeutschen immer wieder beklagte - zeitraubende Schwerfälligkeit ökonomisch rationale Lösungen ver- oder doch behindert hatte, war sie nun, als ihre Interessen bedroht waren, zu raschen Maßnahmen fähig. Aber die Frage, ob eine frühere Entscheidung der gemeinsamen Währungsreform zum Erfolg verholfen hätte, erscheint müßig, da es der Sowjetunion nicht um ökonomische Rationalität, sondern um reparationspolitische Autonomie ging.

Mit den Ansätzen zu einer Revision der Preispolitik im Frühjahr 1946 geriet zeitgleich der Lohnstopp ins Wanken, den der Kontrollrat am 12. Oktober 1945 durch Direktive Nr. 14 bestätigt hatte. Die Ausführung der alliierten Richtlinien wurde von Beginn an den deutschen Behörden auf der Grundlage der deutschen Bestimmungen und Tarifordnungen aus der Zeit vor der Kapitulation übertragen. Zugleich wurde das Recht der Gewerkschaften und Arbeitgeberverbände zu autonomen Lohnverhandlungen vorgesehen, die Errichtung öffentlich-rechtlicher, paritätischer Beiräte dieser Verbände avisiert und für die Übergangszeit den deutschen Behörden das Recht eingeräumt, den Alliierten - nach Rücksprache mit den Gewerkschaften und Arbeitgeberverbänden - Empfehlungen für die Lohngestaltung zu unterbreiten. So bedeutsam die politischen Implikationen der Direktive waren, so eng wurden den deutschen Behörden und Interessenverbänden bei der Lohnfindung die Spielräume gezogen ${ }^{63}$. Da die lohnregulierenden Maßnahmen des Kontrollrats „fakultativ“ waren, d. h. die Zonenbefehlshaber sie nicht ausführen mußten, war ihre Umsetzung weitgehend an die Initiative der Gewerkschaften gebunden. Insgesamt wurde ein relativ einheitliches Lohnniveau erhalten, da die Grundlohnsätze bestehen blieben. Kriegsprämien, die der Arbeitsmarktsteuerung zugunsten der Rüstungsindustrie gedient hatten, wurden abgeschafft; Änderungen der Lohnsätze waren nur zulässig, soweit sie das durchschnittliche Lohnniveau nicht erhöhten. Die Annahme, die Preisentwicklung werde mit wenigen Ausnahmen zu keinem Druck auf die Löhne führen, weil die Bevölkerung ausreichend mit Bargeld versorgt sei, wurde durch das Komitee für Arbeitsnormen und Löhne beim Arbeitsdirektorat rasch korrigiert. Durch die seit Kriegsende eingetretenen Preiserhöhungen hatte sich die Lebenshaltung stärker verteuert als während des gesamten Krieges. Zusätzlich war allein durch den Fortfall von Überstunden, Prämien und Zuschlägen, durch die Erhöhung von Preisen, Steuern und Gebühren, durch den vermehrten Einsatz von Frauen und Jugendlichen in Männerberufen das Einkommensniveau weiter abgesenkt worden. Nach dem Bericht des Arbeitsdirektorats vom April 1946 kamen unregelmäßig beschäftigte Ungelernte auf ein Jahresein-

62 BAP, C-15/731, Bl. 39 (SMAD, Finanzverwaltung, Abteilung Preise, 7.6. 1948); C-15/137, Bl. 5 ff. (DWK, Hauptverwaltung Finanzen, 22. 6. 1948). Am 14. 4. 1948 hatte die SMAD sich bereit erklärt, höhere Preise bei Einfuhren aus den Westzonen zu genehmigen, wenn der Preissprung nicht zu drastisch ausfalle; eine Erhöhung der Preise in der SBZ wurde abgelehnt. ThHStA, MFin/62.

63 Nach Empfehlung des Arbeitsdirektorats durften bei Lohnverhandlungen nur Regelungen für Miet-, Familien- und Alterszulagen, Treueprämien, Lohndifferentiale zwischen Männern und Frauen bei gleicher Arbeit verhandelt werden, solange sich die Durchschnittslöhne nicht änderten. Regionale Lohndifferentiale und Ortsklassen waren dieser Zuständigkeit entzogen, doch durften Vorschläge an die Militärbehörden unterbreitet werden. BA, Z 45 F/OMGUS, 2/114-1/7 (DMAN/ $\mathrm{P}(45) 63$ (Final), 31. 12. 1945); Z 8/224, Bl. 9 ff.; Z 1/920, Bl. 385 ff. 
kommen von 1200-1500 RM, während der Mindestbedarf einer vierköpfigen Familie mit 1400 RM angesetzt wurde. Viele Arbeiter konnten ihre Familie nicht mehr ernähren. „Es erscheint unmöglich“, so das Resümee, „den Lohnstopp aufrechtzuerhalten, wenn die Preise weiter steigen sollen" ${ }^{\text {"64. }}$.

Es waren abermals die Briten, die im Mai 1946 ihren Vorsitz in den Gremien des Kontrollrats nutzten, um im Arbeitsdirektorat ${ }^{65}$ (im Hinblick auf ihre Preispolitik) eine Grundsatzentscheidung über die Lohnpolitik herbeizuführen. Den Zonen sollte eine größere Autonomie bei der Lohnfestsetzung eingeräumt werden, indem diese lediglich der Rahmenkompetenz des Kontrollrats unterstellt oder ganz den Zonenkommandeuren überlassen werde. Der Vorstoß der Briten führte zu „erheblichen“ Debatten auf Direktoratsebene. Erst im Koordinationskomitee zogen Sowjets und Franzosen am 3. September 1946 ihre diversen Vorbehalte zurück. Das Ergebnis war eine „Ergänzung“ zur Direktive Nr. 14: Gemäß sowjetischem Wunsch wurde die Gleichstellung von Frauen und Jugendlichen als Kann-Bestimmung verankert ${ }^{66}$; die Zonenkommandeure erhielten die Möglichkeit zu einer Flexibilisierung in den „Problem-Industrien“, um die Abwanderung von Arbeitskräften zu verhindern; ein Mindestlohn von $50 \mathrm{Pfg}$. wurde gleichfalls als Kann-Bestimmung genehmigt; auf britischen Wunsch wurde den Zonenkommandeuren das Recht übertragen, die Ortsklasseneinteilung zu verändern. Damit sollte „ein bescheidener Grad von Flexibilität eingeführt werden, der in den ersten Monaten der Besatzung nicht angebracht schien, der aber zum gegenwärtigen Zeitpunkt als wesentlich erachtet wird“. Wieder waren die Zonenkommandeure zu Lasten des Kontrollrats aufgewertet worden. Als nicht minder folgenreich sollte sich die Ermächtigung für das Arbeitsdirektorat erweisen, in Abstimmung mit den Finanz- und Wirtschaftsdirektoraten sowie in Zusammenarbeit mit den deutschen Behörden Lohnanhebungen zu genehmigen, wenn diese die Gesamtlohnsumme zusammen um nicht mehr als $5 \%$ erhöhten. Lediglich die darüber hinausgehenden Anhebungen behielt sich das Koordinationskomitee zur Entscheidung vor. Alle zonalen Tarifvereinbarungen waren dem Arbeitsdirektorat zur Begutachtung innerhalb von zwei Wochen vorzulegen, so daß im Sinne anglo-amerikanischer Vorstellungen die Deutschen eigenverantwortlich, aber nicht - wie die Franzosen durchgesetzt hatten ${ }^{67}$ - unbeaufsichtigt handeln durften. Insgesamt war derart der Kontrollrat von einem riesigen Verwaltungsaufwand entlastet und auf seine Funktion der Kontrolle zurückgeführt worden.

Diese Beschlüsse führten noch im September 1946 zu dem Vorstoß der Briten, gemäß den Empfehlungen der Kohleexperten die Bergarbeiterlöhne um 20\% anzuhe-

${ }^{64}$ BA, Z 45 F/OMGUS, 2/101-3/8. Nach Erhebungen in der amerikanischen Zone vom Dezember 1946 verdienten bei normalen Arbeitsbedingungen männliche Arbeiter kaum genug, um das Minimum an Lebensmitteln (45 RM pro Woche) für eine vierköpfige Familie zu garantieren: bei einer Arbeitszeit von 48 Stunden betrugen die Wochenverdienste zwischen 24,60 RM in der Textil- und $45 \mathrm{RM}$ in der eisen- und stahlverarbeitenden Industrie. BA, Z 1/969 (16.12. 1946).

65 BA, Z 45 F/OMGUS, 2/113-3/14.

66 Die SMAD ordnete am 17.8. 1946 durch Befehl Nr. 253 die Gleichstellung an. Um ein antifaschistisch-demokratisches Deutschland, S. 328. Die USA sahen, unter Berufung auf die Deutschen, dafür keinen Bedarf. BA, Z 45 F/OMGUS, 2/102-1/2 (US-Brief zu CORC/P(46)285, 7.9. 1946). Die westlichen Zonenkommandeure überließen es den Tarifparteien, ob sie den gleichen Lohn einführen wollten; das kam der Ablehnung gleich. Im September 1945 hatten die USA und England keine Einwände gegen die geringere Bezahlung von Frauen und Jugendlichen im Arbeitsdirektorat erhoben, da das keine NS-Maßnahme und auch in ihren Ländern üblich sei.

67 AO, Berlin/219/3/1ère Conférence GM-GFCC (5./6. 8. 1946); 3275/3/602 (2. 7. 1946). 
ben. Obwohl Lohnerhöhungen im Kohlebergbau als Anreiz zur Leistungssteigerung prinzipiell als unumgänglich angesehen wurden, kam es zu Differenzen und neuen Verzögerungen: Die Westmächte wollten Lohnerhöhungen bis zu 20\% nur empfehlen, die Sowjets forderten jedoch eine verbindliche Anhebung um 20\%. Durch eine Steigerung der Produktion erhofften sie die Spielräume gewinnen zu können, die eine Rückkehr zur Vier-Mächte-Kohlezuteilung ermöglichten. Möglicherweise provozierten sie den Dissens auch nur, um sich in Verfahrensfragen durchsetzen zu können, daß nämlich das Arbeitsdirektorat keine Anweisungen an die Zonenkommandeure geben dürfe. Sie setzten sich in Direktive Nr. 41 vom 12. Oktober 1946 (unterstützt von Frankreich) mit beidem durch, auch wenn nach westlicher Vorstellung die Tarifverträge von den Verbänden der Arbeitnehmer und Arbeitgeber im Rahmen der Kontrollratsbestimmungen, aber in freien Verhandlungen abzuschließen waren. Ausdrückliches Ziel der Direktive war es, die Bergleute lohnpolitisch zu „einer meistbegünstigten Klasse“ zu machen. Indem die Lohnspannen zwischen Übertage- und Untertagearbeit auf $20 \%$ festgesetzt und die Löhne für Lehrlinge besonders stark angehoben wurden, sollte dem Arbeitskräftemangel begegnet, aber keinesfalls ein Signal zur allgemeinen Erhöhung des Lohnniveaus oder gar des Kohlepreises gegeben werden, obwohl in der Folge die Briten (und Franzosen) sich zu unilateralen Lohn-Folgeerhöhungen animiert und berechtigt sahen ${ }^{68}$.

Unterstützung für ihre unermüdliche Forderung nach einer allgemeinen Anhebung der Löhne fanden die Briten seit dem Sommer 1946 beim Arbeitsdirektorat, das angesichts des ständig sinkenden Lebenshaltungsniveaus die rigide Linie des Finanzdirektorats bekämpfte. Nach seiner Auffassung ließen sich Lohnerhöhungen nicht länger vermeiden, zumindest nicht in den unteren Einkommensgruppen, auch wenn das eine Nivellierung der Löhne und Einkommen bewirken werde. Im Juni 1947 wurden, um ständig neue Einzelbeschlüsse zu vermeiden, in der Bauindustrie die Stundenlöhne so definiert, daß sie mindestens $7 \%$ unter denen eines gelernten Hauers im Ruhrbergbau lagen. Die Löhne in der Textilindustrie wurden stärker angehoben, um die ehemalige Niedriglohnindustrie im Sinne des Industrieniveauplans attraktiver zu machen. Als die Sowjetunion - nach kurzem, durch Uneinigkeit ihrer Vertreter in unterschiedlichen Gremien bedingtem Zögern - Ende Juni der Erhöhung zustimmte, beantragten die Westmächte (nach Rücksprache mit den deutschen Ländern, aber nicht immer mit deren Zustimmung oder gar auf deren Veranlassung ${ }^{69}$ ), andere „Problemindustrien“ folgen zu lassen. Damit war für die Sowjetunion wieder der Punkt erreicht, rasche Beschlüsse zu verhindern; sie sah ein solches Vorgehen durch die Entschließungen des Koordinationskomitees formal nicht gedeckt. Im November 1947 weigerte sie sich, einer Anhebung der Mindestlöhne auf 75 Pfg. zuzustimmen, da zwei Drittel der Arbeiter betroffen gewesen wären und somit eine Überschreitung des gesamtwirtschaftlichen Fünf-Prozent-Limits für Lohnsteigerungen drohte, obwohl die Anhebungen nach westlichen Berechnungen nicht mehr als eine Steigerung von $2,84 \%$ bewirkt hätten; die zur Diskussion stehenden Anhebungen in der Forstwirtschaft (vor allem wegen des Grubenholzes), in der Bekleidungsindustrie, im Bergbau

${ }^{68} \mathrm{BA}, \mathrm{Z} 45$ F/OMGUS, 2/102-1/4 (DMAN/P(46)180, 4. 12. 1946). Zur Praxis in den einzelnen Zonen und Branchen, die offenbar mit alliierter Genehmigung die Direktive nach zonalen Bedürfnissen unterlief, vgl. Quellen Gewerkschaftsgeschichte, Bd. 7, S. $563 \mathrm{ff}$.

69 AVBRD, Bd. 2, S. 243; dass., Bd. 3, S. $316 \mathrm{f}$. 
und bei der Bahn in Höhe von 10-12\% fügten nach britischen Angaben lediglich ca. $0,65 \%$ hinzu.

Die Geduld der Bizonen-Mächte war jetzt erschöpft. Die Briten hatten ihre Forderung nach einem Mindestlohn von $75 \mathrm{Pfg}$. ohnehin in erster Linie erhoben, um damit einen Ansatzpunkt für die allgemeine drastische Anhebung des Lohnniveaus zu gewinnen. Wie sie waren auch die USA gewillt, im Hinblick auf die so oder so bevorstehende Währungsreform zu einer Generalrevision der Lohnpolitik, d. h. der Direktive Nr. 14, zu kommen ${ }^{70}$. Rücksicht auf die Franzosen nahmen die Bizonen-Mächte dabei nicht. Diese verfolgten zu offenkundig eine opportunistische Strategie; sie lehnten alle Lohnerhöhungen ab bzw. forderten deren strenge Begrenzung, soweit sie für ihre Zone unerheblich waren, z. B. in der Textilindustrie, drängten aber auf drastische Steigerungen in den Branchen, an deren Leistungsfähigkeit sie im Hinblick auf die Bedürfnisse ihrer nationalen Industrie ein Interesse hatten ${ }^{71}$. Mit dem Scheitern dieser Verhandlungen war für die Anglo-Amerikaner der Zeitpunkt zum Bruch mit der gemeinsamen Lohn- und Preispolitik im Kontrollrat gekommen, wie sie durch die Direktive Nr. 14 und den Beschluß des Koordinationskomitees vom 7. Februar 1946 festgelegt worden war. Für sie erwies sich die Festschreibung des niedrigen Preisniveaus als nachteilig, weil sie - anders als die Sowjetunion - nicht durch eine radikale Abschöpfung der privaten Kaufkraft den Druck auf den Schwarzmarkt beseitigt bzw. reduziert hatten. Wollten sie eine kostengerechte, marktgesteuerte Produktionspolitik betreiben, mußten sie höhere Preise befürworten. Die Preiseinheit erwies sich zunehmend als Hindernis für ihre Wiederaufbaupolitik. Eine Anhebung des Preisniveaus war aber ohne grundlegende Korrektur der Lohnpolitik nicht möglich, da „die Löhne infolge der Vier-Mächte-Blockade beinahe vollständig eingefroren sind, während die Preise von Fall zu Fall durch bizonale und Länderbeamte angepaßt worden sind"72.

Im Herbst 1947 begannen die Bizonen-Mächte im Hinblick auf die Währungsreform eine gezielte Preistreiberei, um die Preisstruktur zu bereinigen und die Währungsumstellung zu erleichtern: $25 \%$ bei landwirtschaftlichen Produkten, $35 \%$ bei Konsumgütern und $100 \%$ bei Industriegütern. Zur Jahreswende 1947/48 erhielt der britische Zonenkommandeur die Ermächtigung, im Kontrollrat ultimativ eine Gesamtlösung zu fordern, andernfalls auf seiner Handlungsfreiheit als Zonenkommandeur zu bestehen. Eben das war die Linie, die Clay gemäß der traditionellen amerikanischen Interpretation des Kontrollabkommens einschlug. Dieser war ebenfalls zu der Auffassung gelangt, „daß wir, wenn diese Diskussionen nicht sofort befriedigende Er-

70 BA, Z 45 F/OMGUS, 2/125-3/13 (DMAN/M(47)27, 17. 11. 1947; M(48)5, 27. 2. 1948). Zusätzlich machte sich in den Westzonen der Druck der Tarifparteien bemerkbar, die angesichts der offenen oder verdeckten Preissteigerungen, des „bekannten Anwachsens der grauen und schwarzen Löhne“ und der wachsenden Unruhe in der Arbeiterschaft, wie sie in dem „Generalstreik“ der Bergarbeiter am 3. 4. 1947 einen ersten Höhepunkt erfahren hatte, stets höhere Löhne forderten, als die Alliierten schließlich gewährten. Der lohnpolitische Ausschuß der britischen Zone, in dem Arbeitgeber, Arbeitnehmer und Arbeitsbehörden gemäß Direktive Nr. 14 vertreten waren, hatte in Anwesenheit von Vertretern des bizonalen Verwaltungsamts für Wirtschaft eine Lockerung des Lohnstopps gefordert. In Abstimmung mit den Arbeitsministern der amerikanischen Zone wurde eine „Ermächtigung“ für die Arbeitsverwaltungen verlangt, Lohnerhöhungen von bis zu $30 \%$ als „zweckmäßig“ anzusehen. Z 1/920, Bl. 255 f. OMGUS bewilligte im April 1948 Lohnerhöhungen durch Tarifvereinbarungen von maximal 15\%; ebenda, Bl. 68 f. Der Druck der Verbände wurde von der CCG im April 1948 zur Legitimation des einseitigen Vorgehens herangezogen; ebenda, Bl. 103.

71 AO, Berlin/3275/3/602 (GFCC, Division Travail, 1. 12. 1947).

72 TL, Tenenbaum Papers, box 4, folder: Currency reform 3 (Ozer an Werts, 27. 8. 1947). 
gebnisse bringen, in der Bizone unseren eigenen Weg werden gehen müssen“. Zwar zuckte das Foreign Office noch einmal zurück und wies Robertson an, nicht gezielt auf einen Bruch hinzuarbeiten; er wurde aber ermächtigt, „vollständige Freiheit“ für alle Zonen zu verlangen, „Löhne und Preise selbst festzusetzen“, bei einer bloßen wechselseitigen Informationspflicht „im Hinblick auf die Abminderung der Wirkungen, die sich aus der Trennung der wirtschaftlichen und finanziellen Reformen ergeben“. Das bedeutete letztlich nichts anderes als den kaum verhüllten Bruch $^{73}$.

Aber auch die Sowjetunion richtete sich offenkundig zunehmend auf einen Alleingang in ihrer Zone ein. Ohne Konsultation der Deutschen (und der westlichen Alliierten) ordnete die SMAD mit Befehl Nr. 234 vom 7. Oktober 1947 den Übergang zum „progressiven Akkordlohn“ an. Die „produktiven Leistungslöhne“ wurden zum einen an die Produktivität der Betriebe gebunden, zum anderen bildete der allgemeine Lohnstopp die „obere Grenze“, so daß die Differenzierung nur einer Umverteilung innerhalb einer konstanten Gesamt-Lohnsumme gleichkam. Der Verteilungsspielraum war so gering, daß sich ,in der überwiegenden Mehrzahl der Betriebe eine starke Ablehnung“ gegen den „,Mord'-Lohn“ bemerkbar machte. Gegen alle Einwände, auch seitens der SED, setzte die SMAD seit Februar 1948 ihre Forderungen durch ${ }^{74}$. Während sie in ihrer Zone eine Leistungssteigerung ohne materielle Gegenleistung erzwang, startete die SMAD Anfang Januar 1948 im Kontrollrat eine Propagandaoffensive, indem sie überraschend alle bisher geltend gemachten inhaltlichen Bedenken und verfahrensrechtlichen Vorbehalte zurückstellte. Offenbar versuchte sie, im Vorfeld der entscheidenden Auseinandersetzungen um die Währungsreform, ihre eigene verschärfte Ausbeutung durch einen Generalangriff auf die Lohnpolitik in den Westzonen zu entlasten: Weder hätten die Westmächte die gleiche Bezahlung von Mann und Frau, noch einen Minimallohn von 50 Pfg. realisiert, noch die Lohnerhöhungen in den „Problemindustrien“ umgesetzt. Die Empfehlung, die Kontrollratsbeschlüsse durch die deutschen Tarifparteien umsetzen zu lassen, sei eine bloße Willensäußerung, solange die Unternehmer nicht zur angemessenen Erhöhung der Löhne gezwungen würden. Die Sowjetunion forderte daher verbindliche Zwangsmaßnahmen, u. a. ein Kontrollratsgesetz über den gleichen Lohn, dazu eine allgemeine Lohnerhöhung von 15\% über dem Niveau vom Mai 1945, die Einführung einer Arbeitswoche von 42 bzw. 45 Stunden für Jugendliche, bezahlten Urlaub von 18-24 Arbeitstagen, einen Hausarbeitstag pro Monat für Frauen, die Abschaffung von Geldstrafen in allen Betriebsordnungen, erweiterte Kompetenzen des Arbeitsdirektorats (Lohnerhöhungen von bis zu 10\% statt bisher 5\% der Gesamtlohnsumme) und eine Veränderung der Lohnstruktur mit dem Ziel einer Förderung der Friedensindustrien ${ }^{75}$.

Dieser allgemeinpolitische, wohl mehr an Propagandaerfolgen als an Kompromiß interessierte Schwenk der Sowjets kam den Angelsachsen nicht ungelegen. Sie antworteten mit der Forderung nach umfassenden, aber differenzierten Lohnerhöhungen um ca. $30 \%$. Aber an einer Einigung waren auch sie nicht mehr interessiert. Vielmehr unternahmen sie am 6. März 1948 im Koordinationskomitee einen Vorstoß, dessen

73 PRO, FO 1046/643 (Currency Reform, 7. 9. 1949, S. 1, Annexes 7 [FO, 16. 1. 1948], 10 [CCG, 19. 1. 1948], 17 [FO, 8. 2. 1948]).

74 BAP, C-15/657, Bl. 20 ff., 33 f.; C-15/510, Bl. 101; G-2/1164 (12. und 13. 2. 1948). BAC, N-1/ 2080-1, Bl. $120 \mathrm{ff}$. (28. 5. 1948).

75 BA, Z 45 F/OMGUS, 2/118-3/10-21 (CORC/P(48)37, 18. 3. 1948); 2/102-1/3. 
Ziel es war, wie die Briten ihren französischen Kollegen am Vortag eröffnet hatten, „dem Kontrollrat jegliche Kompetenz in den Preisfragen zu entziehen“; die Löhne würden zwangsläufig folgen. Während die Franzosen noch durch ein gewisses Entgegenkommen eine pragmatische Lösung herbeiführen zu können hofften, „der die Befugnisse des Kontrollrats stärkt und eventuell unsere Position vis à vis der Bizone“, waren die Angelsachsen daran nicht mehr interessiert, zumal sie wußten, daß Frankreich in seiner Zone sich dem Vorgehen der Bizone auf Dauer nicht entziehen konnte $^{76}$. Wenn die Sowjetunion, so am 10. Februar 1948 der Chef der OMGUSPreiskontrollabteilung Ostrander, einer Preisbereinigung bei Kohle, Stahl und Eisenerz nicht zustimme, müsse es „einen entschiedenen Bruch mit dem Prinzip der VierMächte-Vereinbarungen in diesem Bereich“ geben; notfalls müßten Kartoffeln und Schlachtvieh „in einen einseitigen Bruch mit dem Kontrollrat in Preisfragen“ einbezogen werden. Seine britischen Kollegen schlossen sich an, indem sie Vier-Mächte-Diskussionen nur noch zu führen empfahlen, „um den Schein zu wahren“, z. B. durch neue Anträge auf Lohnanhebungen, im übrigen „aber mit der entschiedenen gegenwärtigen Absicht, uns von Vier-Mächte-Bindungen in diesem Bereich zu befreien". Ende Februar hatten die Experten von BICO das Schema der angestrebten Preiserhöhungen bzw. -senkungen beschlossen und empfahlen ihren Militärregierungen ,einen sofortigen Rückzug von den Vier-Mächte-Verpflichtungen, ein vereinbartes Preisniveau beizubehalten, und innerhalb kurzer Zeit ein ähnliches Vorgehen hinsichtlich der Löhne“. Die Ankündigung der einseitigen Anhebung der Preise für Kohle und Stahl war das Signal zum endgültigen Bruch, der im Kontrollrat über die anhängige Anhebung der Löhne gesucht wurde: „Dem Koordinationskomitee ein Statement vortragen, das mit Vier-Mächte-Verbandlungen über Lobnerböbungen bricht", so entwarf Ostrander am 12. März 1948 gegenüber seinem Kollegen Wilkinson die Strategie. „Das ist eine lebenswichtige Folge des Bruchs bei den Preisverhandlungen. Die Militärregierung hat bereits der Presse mitgeteilt, daß der Bruch beim Lohn gemacht wird. Werden sich die Berater für Arbeitsfragen dem gleich anschließen? Es sollte keine Verzögerung beim Ergreifen dieser Folgemaßnahmen geben. “77

Als der neuerliche Vorstoß im Koordinationskomitee programmgemäß scheiterte, entzogen die USA und Großbritannien noch vor dem sowjetischen Auszug aus dem Kontrollrat die Preisfestsetzung auch für die 17 reservierten Produktgruppen einseitig dem Kontrollrat und übertrugen sie mit dem (seit Ende August 1947 vorbereiteten) Preisübergangsgesetz vom 17. März 1948 der Bizone, nachdem Clay am 14. Februar den Bruch noch einmal im Hinblick auf die Verhandlungen im Kontrollrat vertagt hatte. Das am 10. April von den Militärregierungen gebilligte Preisgesetz und die Lohndirektive Nr. 40 vom 26. April vollzogen die lohn- und preispolitische Spaltung zwischen Ost- und Westdeutschland ${ }^{78}$.

${ }^{76} \mathrm{AO}, \mathrm{Berlin} / 3282 / 5 / 2130 \mathrm{C}$. Nach den früheren Auseinandersetzungen über das „dollar-billing“ erkannten die Franzosen die Gefahr und boten für die Zeit nach der Klärung der Währungsreformfrage Gespräche über eine Erhöhung des Kohlepreises an. AMAE, Eu(1944-60)Allemagne/91, Bl. 33 (CGAAA, 5. 3. 1948).

77 PRO, FO 1046/103 (Hervorhebung im Original).

78 AVBRD, Bd. 4, S. 308 f. (Anm. 13), 394 (Anm. 29), 467. Berichte und Drucksachen des Wirtschaftsrates, Bd. 2, S. 378 ff.; dass., Bd. 4, S. 199 ff., 315 ff., 327 ff. Zur bizonalen Lohnpolitik und der Direktive Nr. 40 vom 26. 4. 1948 vgl. Quellen Gewerkschaftsgeschichte, Bd. 7, S. 565-81. - In Berlin machten die Westmächte, nachdem die Verhandlungen in der Kommandantur keinen Erfolg in ih- 


\section{Die Währungsreform}

Um die Jahreswende 1945/46 hatte noch keine der vier Mächte klare Vorstellungen in den währungstechnischen Fragen entwickelt, und eine scharfe Frontenbildung zwischen Ost und West war noch nicht gegeben. Mangels politischer Vorgaben und mangels detaillierter technischer Konzepte waren die unteren Ebenen des Kontrollrats zunächst nicht in der Lage, eigenständige Vorschläge zu entwickeln, sondern man verschaffte sich eine Atempause hinsichtlich der finanzpolitischen Grundsatzentscheidungen mit Hilfe der Steuer-, Lohn- und Preispolitik. Diese Verzögerung aber bewirkte, daß die vier Alliierten ihre jeweiligen Lösungsvarianten zunächst auf nationaler Ebene ausarbeiteten und so weit verfeinerten, daß ein Kompromiß immer schwieriger wurde. Hinzu kam die steigende Überfrachtung mit deutschland- und transformationspolitischen Absichten. Eine Währungsreform war ohne Grundsatzentscheidungen über Zentralbank, Bankenstruktur und Wirtschaftsverfassung ebensowenig denkbar wie über Einkommensverteilung, Eigentumsordnung und Sozialstruktur.

Die Briten, intern gespalten, standen mit ihren Vorstellungen von „kontrollierter Inflation" und zentralistischer Finanzverwaltung allein. Wieder wurden zuerst bei ihnen Stimmen laut, die aufgrund prinzipieller Differenzen den Bruch mit der Sowjetunion forderten. Bereits im Juni 1945 hatte Chambers, Leiter der CCG-Finanzabteilung, seine Regierung gedrängt, einer Regelung nur für die drei Westzonen den Weg freizugeben, um unverzüglich deutsche Experten an die Arbeit setzen zu können; mit den Sowjets seien detaillierte Diskussionen zur Zeit nicht möglich. Gleichwohl seien seine Vorschläge so gestaltet, „daß sie auf ganz Deutschland ausgedehnt werden können. Sehr ernste finanzielle Probleme würden in wenigen Monaten entstehen, wenn keine Einigung mit unseren russischen Alliierten über die Grundfragen erzielt wird." ${ }^{\text {"79 }}$ Trotz des zur Schau getragenen Optimismus, eine Einigung sei möglich, da die Sowjets „ebenso an einer Währungsreform interessiert sind wie wir“, verfolgte er angesichts der Stagnation im Kontrollrat zur Jahreswende 1945/46 konsequent die Alternative einer separaten Reform in der britischen und amerikanischen Zone als „allerletzten Schritt“. Die Weigerung der Sowjets, der Reorganisation des Bankensystems zuzustimmen, diente ihm als Beleg, daß diese mehr an "Chaos“ in den Westzonen als an konstruktiven Lösungen interessiert seien; er war überzeugt, daß der wahre Grund für die sowjetische Ablehnung „nicht in irgendwelchen Meinungsverschiedenheiten über technische Details zu finden ist oder in abstrusen Finanztheorien, weil nämlich in diesen Fragen zwischen den Experten Übereinstimmung erzielt wurde. Dieser Grund kann nur in den fundamentalen Unterschieden in der grundsätzlichen Politik gegenüber Deutschland gefunden werden. Daß das so ist, wird durch den Verlauf der Diskussionen klar und durch die Art, in der, nach der Einigung in technischen Fragen, die endgültige sowjetische Zustimmung [...] auf die Billigung aus Moskau warten mußte, die nicht kam.“ Dahinter vermutete Chambers die sowjetischen Reparations-

rem Sinne erbracht hatten, noch am 17.6. 1948, also am Vorabend der Währungsreform in den Westzonen, in ihren Sektoren den Weg frei für autonom zwischen Arbeitgebern und Gewerkschaften auszuhandelnde Lohnerhöhungen um bis zu 20\%. Berlin, Behauptung, S. 507.

79 PRO, FO $1046 / 71$ (9.6. 1945). 
interessen. Im Falle der (umstrittenen) Besatzungskosten „zeige die sowjetische Haltung dieselben separatistischen Tendenzen wie in der Frage des Banknotendrucks oder der Bankenorganisation“. Sollten die Sowjets über die vollständige Streichung der Reichsschuld ihr Ziel erreichen, das traditionelle Bankensystem zu zerstören und die privaten Besitzer von Kriegsanleihen zu enteignen, würde für sie der Zwang entfallen, einer radikalen Reduktion der Guthaben im Verhältnis von 10:1 zuzustimmen, weil das die beschlagnahmten Guthaben für den eigenen Gebrauch (Truppensold, Reparationen) entwerten und die Kaufkraft in den umworbenen Arbeiterkreisen vernichten würde. Im Kern ging es also um „tiefgreifende ideologische Differenzen" ${ }^{\text {"80. }}$. Im Juli 1946 wies Chambers in internen Diskussionen erneut darauf hin, die Lösung dieser Fragen würde „durch die Abspaltung der sowjetischen Zone erleichtert“. Im Bereich des Banken- und Versicherungssystems seien Vereinbarungen mit den Sowjets durchaus möglich, dieses Argument galt in anderen Bereichen auch, „aber die konsequente Durchführung der Vereinbarung wäre unwahrscheinlich“. Bei einer separaten Westlösung - bei der „die drei Westmächte sich aus Berlin zurückziehen“ - könnten alle verbleibenden Probleme zwischen den Westmächten einvernehmlich geregelt werden, selbst wenn angesichts der französischen Widerstände eine deutsche Zentralverwaltung für Finanzen nicht zustandekam ${ }^{81}$. Chambers hatte mit seinen Mahnungen so viel Erfolg, daß seine Regierung seit Ende 1946 auf eine separate Reform in der Bizone drängte, in dem Bewußtsein, daß „zwei Währungen oder zwei separate Finanzsysteme in Deutschland zu haben in der Tat Deutschland in zwei Länder teilen würde “82. Scharf wurde den Sowjets vorgeworfen, sie hätten „keine Absicht, Deutschland für lange Zeit als eine wirtschaftliche oder politische Einheit zu behandeln“83.

In der Tat scheinen die Sowjets ihre Finanzpolitik auf das doppelte Ziel der „Demokratisierung" des Finanzwesens und der Durchsetzung ihres Anspruchs auf $\$ 10$ Mrd. Reparationen ausgerichtet zu haben. Beide Ziele ließen sich leicht mit den transformationspolitischen Nebenabsichten verbinden. Altguthaben aus der Zeit vor dem 9. Mai 1945 wurden gesperrt, staatliche Altschulden nicht mehr bedient, die alten Versicherungen beschlagnahmt und neue als Kapitalsammelstellen eingerichtet. Im März 1946 mußten die Banken Kredite aus der Zeit vor dem 9. Mai 1945 einziehen; die Beträge wurden den Landesregierungen gutgeschrieben. Den Volks- und Genossenschaftsbanken wurde das 1933 beschlagnahmte Eigentum zurückgegeben, die privaten Ansprüche aus der Zeit vor dem 9. Mai 1945 wurden jedoch nicht ausgezahlt ${ }^{84}$. Mit den beschlagnahmten Geldern konnten die neuen Länderbanken und das Berliner Stadtkontor versorgt, die hitzige „Reparationskonjunktur“ finanziert werden. Der Gedanke eines Lastenausgleichs spielte auf kommunistischer Seite im Interesse

${ }^{80}$ PRO, FO 1046/94 (1. 11. 1946); FO 1034/17 (5. 12. 1946). „It remains now for us on the British side to make up our minds [...] how far we are prepared to go in the interests of preserving the whole framework of quadripartite government in Germany. If we fail to reach agreement, or a sufficient measure of agreement, on the main financial problems [...], it is clear that we shall have to abandon the hope of effectively governing Germany on a quadripartite basis.“ FO 371/55410 (Chambers, Anti-Inflationary Measures in Germany, ca. Dezember 1945).

81 PRO, FO 1046/94 (Financial Plans for Germany in the Light of the Paris Conference, 16. 7. 1946). Vgl. oben S. 242 und unten S. $303 \mathrm{f}$.

82 TL, Tenenbaum Papers, box 2 (The German Mark, Ch. 13, S. 13). PRO, FO 371/65030/CE65 (Waley/Treasury an Hall-Patch, 28. 2. 1947).

83 BA, Z 45 F/OMGUS, 2/118-2/1-7. FRUS, 1946/V, S. $626 \mathrm{ff}$.

84 Sitnin, Finansy, S. $12 \mathrm{ff}$. 
ihrer Bündnispolitik anfangs durchaus eine gewisse Rolle ${ }^{85}$. Letztlich beeinflußte aber auch in der SBZ zunehmend, die schlechte Geldverfassung die Produktion und ihre Verteilung“, da die Blockierung der Konten zwar deflatorisch gewirkt, aber den Notenumlauf als solchen nicht begrenzt hatte und dadurch „größtenteils unwirksam geworden" war $^{86}$. Die SMAD konnte insofern nur bedingt auf Zeit spielen.

Wenngleich die Franzosen (wie die Briten) die Hauptzeichner der Kriegsanleihen und Finanziers des Krieges nicht schonen wollten, so lehnten sie eine radikale Vernichtung ganzer Sozialgruppen durch faktische Enteignung ab, wie die Sowjetunion sie betrieb. Sie forderten die Beibehaltung der Reichsschuld, und das nicht nur, um die Interessen ihrer eigenen (privaten) Gläubiger zu schützen oder um über die hohen Belastungen des Staatshaushalts Deutschland zu schwächen und zu kontrollieren ${ }^{87}$. Das Finanzministerium befürchtete vielmehr, eine solch radikale Maßnahme werde keineswegs nur die Rentner und die Reichen, sondern ebenso die privaten Versicherungen wie die sozialen Sicherungssysteme, die Banken und die Industrie enteignen. Das konnte nicht in den (Reparations-)Interessen der Franzosen liegen. Aus den gleichen Gründen lehnten sie daher eine „kontrollierte Inflation“ gemäß den britischen Forderungen ab. Ebenso wiesen sie die „radikale“ Abwertungslösung der USA zurück, sondern wollten erst eine Stabilisierung der wirtschaftlichen Situation in Deutschland abwarten, die die USA jedoch im Falle weiterer Verzögerungen gerade nicht für möglich hielten ${ }^{88}$. Darüber hinaus wollte Frankreich jede zentralistische Organisation der Finanzverwaltung verhindern, im übrigen seine Besatzungskosten abdecken ${ }^{89}$. Der Einigungszwang erhöhte sich indes, da seine Zone durch forcierte Ausbeutung und partielle Isolierung beständig an (wirtschaftlichem wie politischem) Wert verlor.

Der amerikanische CDG-Plan ${ }^{90}$, der am 20. Mai 1946 ausgearbeitet vorlag, sah die 80\%ige Sperrung aller Bankguthaben (erforderlichenfalls die zusätzliche Einschränkung der Verfügbarkeit) vor, die vollständige Streichung der Reichsschuld, eine „drastisch progressive“ Kapitalsteuer sowie ein nominal unverändertes, aber durch die Deflation verfünffachtes Lohn-Preis-Niveau. Erst im Verlauf der Beratungen war die Vorstellung des Lastenausgleichs hinzugetreten'1. Aus diesen Maßnahmen ergaben sich die Vorschläge zur zeitlich-technischen Abwicklung des Plans. In der ersten

85 Dokumente zur Geschichte der kommunistischen Bewegung, Bd. 2, S. 395 (Leuschner, 22. 12. 1945: „sozialer Ausgleichsfond“).

86 SAPMO, ZPA, N1 90/332, Bl. 1 (Kommentar zur vorgesehenen Erklärung zur Währungsreform, 10. 1. 1947). Hinterziehung, Schwarzmarkt und fehlende Kontrolle seien das Ergebnis. „Die Masse der Bevölkerung verlangt eine Geldreform, unabhängig von gewisser Pressebeeinflussung." Vgl. unten S. 292 Anm. 136.

87 TL, Tenenbaum Papers, box 4, folder: currency reform (2), (Financial Reform for the Bizonal or Trizonal Area; ca. Anfang 1947).

88 PRO, FO 1046/528 (Finanzministerium an GFCC, 10. 1. und 20. 2. 1946).

${ }_{99}$ Quellen zur Geschichte von Rheinland-Pfalz, S. 115 ff. (Auboyneau, 7. 11. 1945).

90 Autoren waren die emigrierten deutschen Wissenschaftler Gerhard Colm und Raymond W. Goldsmith sowie Clays Finanzberater, der Bankier Joseph Dodge. Anfang 1946 begannen die Vorbereitungen für die Mission, die im März ihre Arbeit in Deutschland aufnahm. Materialien zur Entstehung in TL, Fox Papers, box 8. Die Deutschen sprachen im Februar/April 1946 von einem Dodge-Plan. TL, Tenenbaum Papers, box 3, folder: currency reform (1). Möller, Deutsche Mark, S. $214 \mathrm{ff}$. (Teilabdruck des CDG-Plans), $282 \mathrm{ff}$.

91 NA, RG 59/ASSOA, box 1 (Colm/Goldsmith, Outline of a tentative plan, 8. 4. 1946). Da die Reduktion des Kaufkraftüberhangs nur den Geldbesitz betraf, sollten die Besitzer von Sachwerten durch eine „Zwangshypothek“ von bis zu 50\% zur Finanzierung eines „Ausgleichsfonds für Kriegsverluste“ sowie durch eine progressive Kapitalsteuer von $25-80 \%$ herangezogen werden. Möller, Vorgeschichte, S. $10 \mathrm{ff}$. 
Phase war der Währungsschnitt vorgesehen, inkl. der Abwertung der monetären Ansprüche und Verpflichtungen. Im zweiten Schritt sollte die Einrichtung des Lastenausgleichsfonds folgen, im dritten die Erhebung der Kapitalsteuer, zahlbar über zehn $\mathrm{Jahre}^{92}$. OMGUS war die Bedeutung der Währungsreform für Wirtschaftsverfassung und Sozialordnung nicht entgangen und hatte eben deshalb den Lastenausgleich aufgegriffen. „Die ökonomische Klasse in Deutschland, von der wir am meisten bei der Verwirklichung unserer Ziele abhängig sind, ein friedliches und demokratisches Deutschland zu schaffen, ist die Klasse der kleinen Bezieher von festen Einkommen und Kleinsparer, die zumeist gesetzestreu sind und die vergleichsweise am meisten unter einem ungeordneten Anstieg der gesetzlichen Preise zu leiden haben werden.“933 Der Furcht vor einer Vernichtung der Mittelschichten durch die enteignende Wirkung einer Inflation oder einer Streichung der Guthaben stand das wirtschaftliche Argument gegenüber, daß die Verfügbarkeit dieser Guthaben den ökonomischen Arbeitszwang (anders als in der SBZ) aufhob und den Schwarzmarkt begünstigte. Damit schienen alle Voraussetzungen für eine Steigerung der Produktivität und für eine Wiederbelebung marktwirtschaftlicher Austauschbeziehungen so stark beeinträchtigt, daß der Einfuhrbedarf zu Lasten der Besatzungsmächte steigen würde und der wirtschaftliche Kollaps drohte. Hinzu kamen ordnungspolitische Überlegungen: „Zudem können die Westmächte aus politischen Gründen keine substantielle Abweichung von den privatwirtschaftlichen Praktiken unternehmen, durch die die sowjetischen Behörden mit teilweisem Erfolg den Einfluß von Geld und Produktion ausgeschaltet haben.“ Während die Sowjetunion einen „Nervenkrieg“ führe, „sicher in dem Wissen, $\mathrm{da} ß$ ihre Zone wahrscheinlich länger als die Westzonen gegen die offene Zurückweisung der Währung bestehen könne“, stieg der wirtschaftliche wie der politische Handlungsdruck auf seiten der Westmächte. Da die „amerikanische Politik das freie Unternehmertum favorisiert", wurden Struktur und Ergebnis der Währungsreform diesem politischen Ziel untergeordnet. Mit den Briten und Franzosen bestand darüber, bei allen Differenzen im Detail, prinzipielle Übereinstimmung ${ }^{94}$.

Clay hatte das Projekt ursprünglich mit Mißtrauen betrachtet, weniger weil er auf einen kontrollratsinternen Lösungsvorschlag hoffte, sondern weil er eine Beeinträchtigung seiner Handlungsfreiheit fürchtete. Nachdem er sich den Plan zu eigen gemacht hatte, ließ er ihn den Finanzexperten der drei anderen Mächte zukommen, brachte ihn allerdings noch nicht im Kontrollrat ein, da er aus Washington kein grünes Licht

92 CP, S. 151 (27. 1. 1946), 208 ff. (23. 5. 1946). FRUS, 1946/V, S. 556 ff.

93 FRUS, 1946/V, S. 634 (Clay, 2. 11. 1946). Eine Erhebung in der amerikanischen Zone ergab 1946, daß im Durchschnitt die Sparguthaben in der Zone von 2350 im Januar auf 2300 RM gesunken, in Berlin von 1425 auf 1625 RM gestiegen waren, die Girokonten 2575 bzw. 2325 RM aufwiesen. TL, Tenenbaum Papers, box 4, folder: currency reform (4). 25-30\% aller Haushalte verfügten über Barvermögen unter 500 RM. BA, Z 45 F/OMGUS, FINAD/2/102-4 (Anlage zum US-Entwurf vom 26. 6. 1947). Die schmale Deckung bzw. Unterdeckung der privaten Haushalte machte in den Augen der USA wie der Vertreter der britischen Minderheitenposition eine „kontrollierte Inflation“ unmöglich; nach dem Ersten Weltkrieg seien Arbeiterschaft und Mittelstand durch die Inflation den Nazis in die Arme getrieben worden; der Industrie habe sie zu „excessive concentrations of economic power“ verholfen, „which later provided the Nazis with the resources necessary to gain power and the ideal organization for the supply of aggressive war“. TL, Tenenbaum Papers, box 4, folder: currency reform (2), (Financial Reform, Februar 1947, S. 10).

94 TL, Tenenbaum Papers, box 4, folder: currency reform (2), (Financial Reform, Februar 1947; Financial Reform for the Bizonal or Trizonal Area, Anfang 1947). 
erhielt. Dort bestanden Bedenken, der Plan sei „zu ehrgeizig und weitreichend in seinem Ansatz“; er belaste die Alliierten mit der Verantwortung für das Gelingen und enthalte durch die „Wirkung auf die Vermögensverteilung in Deutschland [...] weitreichende soziale Implikationen"95. Ende Juni 1946 mahnte Clay in Washington eine Entscheidung an. Zwar könne er die Annahme im Kontrollrat ebensowenig garantieren wie einen währungstechnischen Erfolg; doch die Zeit dränge, da die Inflation immer schwieriger zurückzustauen sei. Das SWNCC wollte nur den ersten Teil des CDG-Plans, also den Währungsschnitt, billigen, nicht aber den Lastenausgleich, der „sowohl komplex als auch, in gewissem Sinne, radikal“ sei. Doch Clay beharrte darauf, nur den vollständigen Plan dem Kontrollrat vorzulegen. Die Kritik, der Plan fördere die „wirtschaftliche Konzentration“, wies er zurück und äußerte stattdessen die Überzeugung, durch eine mutige Währungsreform „stabile fiskalische Bedingungen zu schaffen, die der Demokratie und dem freien Unternehmertum förderlich sind“. Stur wies er die von Washington vorgetragene Einzelkritik zurück, ebenso das Verlangen, Alternativen entwickeln oder den CDG-Plan durch eine neue Expertengruppe überprüfen zu lassen. Nachdem seine zuständigen Beamten mit ihren alliierten Kollegen Kontakt aufgenommen hätten, so suchte er Washington auf seine Linie festzulegen, „sind wir aufgrund dieser informellen Diskussionen zu der Auffassung gekommen, daß unser Vorschlag im allgemeinen akzeptabel ist“. Wiederholt verlangte er Instruktionen aus Washington, weigerte sich aber, solche zu akzeptieren, wenn sie seinen Vorstellungen widersprachen. Schließlich ließ er über Hilldring Rücktrittsgedanken durchblicken, wenn er weder freie Hand noch klare Anweisungen erhalte ${ }^{96}$. Nach langen Debatten entschied das SWNCC am 21. August, den CDG-Plan in seiner Gänze im Kontrollrat einzubringen, nachdem es zögernd Clays Argumente akzeptiert hatte, daß eine schematische Abwertung aller Guthaben soziale Härten mit sich bringen werde und daß sich die USA nicht gegen die deutsche Zustimmung zum Lastenausgleich stellen dürften. Infolge dieser Verzögerungen wurde der Plan erst am 28. August 1946 im Koordinationskomitee eingebracht, fand dort aber nur bei Robertson in Abweichung von den Empfehlungen seines Finanzexperten Chambers Unterstützung97. Robertsons Antrag, die Beratung dieser „immens wichtigen“ und „extrem dringenden" Frage im Finanzdirektorat durch eine Grundsatzerklärung des Koordinationskomitees zu beschleunigen, wurde am 3. September von der Sowjetunion abge-

95 NA, RG 59/ASSOA, box 1 (Cramer an Hilldring, 31. 5. 1946); RG 59, 740.00119 Control(Germany)/11-246 (Echols an Hilldring, 30. 7. 1946). Die ersten Planungen waren offenbar nur den Briten vertraulich zugegangen. PRO, FO $371 / 55410$ (FO, 5. 1. 1946) und 55411 (Halifax, 4. 2. 1946); FO 1046/94 (16. 7. 1946).

96 CP, S. 231 f. (28. 6. 1946), 245 f. (3. 8. 1946), 251 (13. 8. 1946), 258 f. (20. 8. 1946). Hughes, Lastenausgleich. BA, Z 45 F/OMGUS, 2/121-2/5-9 (DFIN/P(46)141).

97 Im Finanzdirektorat stellte sich Chambers gegen die amerikanischen Vorstellungen, um seine Konzeption der "controlled inflation" durchzusetzen: Der Währungsschnitt von 10:1 werde eine enteignende Wirkung haben; auch die Finanzminister der amerikanischen Zone zweifelten an der „advisability of implementing the Dodge Plan“; die technischen Aspekte des Lastenausgleichs seien für eine rasche Durchführung zu kompliziert. PRO, FO 1046/94 (1. 11. 1946); FO 1046/221 (CCG/Finance Division, Banking Branch, 21. 10. 1946); FO 1046/642 (Quadripartite Discussions on Financial Reform, 20.9. 1948). Chambers repräsentierte die „Mehrheitsmeinung“ in COGA und CCG; Schumacher neigte mehr der amerikanischen Position zu und befürwortete keine „Enteignung“, sondern die „Blockade“ der privaten Altguthaben. FO 1046/94 (SCOPC/P(46)27; E.F. Schumacher, Extract from Progress Report, Appendix ,B‘, 12. 8. 1946); FO 371/55410 (5. 1. 1946). Möller, Vorgeschichte, S. $158 \mathrm{ff}$. 
lehnt; dem Direktorat müsse jede Freiheit der Beratung belassen werden. In diesen verfahrenstechnischen Debatten kündigten sich prinzipielle Differenzen an. Jetzt waren die Frontlinien weniger durch die Probleme der technischen Bewältigung der Deflation gezogen als durch die damit verknüpften Weiterungen für Gesellschaftsordnung und Wirtschaftsverfassung.

Vor diesem Hintergrund rückten seit Oktober 1946 die Kontrolle des künftigen Drucks der neuen deutschen Banknoten bzw. der Druckort in den Mittelpunkt der Währungsreformdiskussion im Kontrollrat. Wieder diente eine scheinbar technische Frage dazu, politische Grundsatzentscheidungen zu vertagen oder zu verhindern. Nur vordergründig ging es darum, ob die Sowjetunion sich durch den ungehemmten Druck Alliierter Militärmark einseitige Vorteile verschafft hatte. Dieser Punkt war Ende 1945 zum politischen Ärgernis geworden. Gemäß alliierter Vereinbarung hatte SHAEF für den Bedarf der westlichen Besatzungstruppen 12-15 Mrd. Militärmark gedruckt und einen zweiten Satz von Druckplatten den Sowjets ausgehändigt. Seit November 1945 strömten sowjetische Militärmark in die Westzonen ein: über Bankeinzahlungen, Krankenkassen- oder Versicherungsbeiträge von Bewohnern der SBZ, die diese über Offiziersmessen, durch den Verkauf von (privatem wie industriellem) Besitz an Armeeangehörige u.ä.m. erhalten hatten ${ }^{98}$. Als die Westmächte im Kontrollrat zur Überwachung der Ausgabe Quartalsberichte jeder Zone forderten ${ }^{99}$, verweigerte die SMAD jegliche Angaben. Sie teilte lediglich am 11. Januar 1946 im Finanzdirektorat mit, daß seit dem 1. Dezember 1945 die öffentlichen Ausgaben ihrer Zone nur noch durch Reichsmark (d. h. über Steuern und Gebühren), aber nicht mehr durch Militärmark bestritten würden. Die Emission von Militärmark wurde jedoch, wie sie am 26. November 1946 ergänzte, erst zum 1. Juli 1946 vollständig eingestellt. „Es gibt keinen Grund, ihr Statement anzuzweifeln“, so urteilten die Briten, „da ihre sonstigen Maßnahmen im monetären Bereich ihnen genug Geld für alle ihre Zwecke zur Verfügung gestellt haben dürften durch den Überschuß der staatlichen Einnahmen." Wenn diese Einschätzung zutraf, so war es unverständlich, daß die Sowjets dem Kontrollrat einen Bericht hartnäckig verweigerten. Möglicherweise hatten sie selbst den Überblick verloren ${ }^{100}$. Sie ließen sich auch nicht dadurch unter Druck setzten, daß die Westmächte dem Finanzdirektorat im Juni und (letztmalig) im November 1946 ihre Stati-

98 PRO, FO 1046/528. Nach amerikanischen Angaben waren allein in Berlin durch Tausch oder Verkauf von PX-Waren sowjetische Militärmark im Wert von $\$ 300$ Mio. angefallen, die die amerikanische Treasury der Army nicht honorierte, obwohl sie den Sowjets die Druckplatten überlassen hatte. Clay, Entscheidung, S. 79 f. Die Soldaten der Westmächte konnten die (westliche) Militärmark in ihre Landeswährung zurücktauschen, so daß diese an die Besatzungsverwaltungen und in den Geldkreislauf zurückflossen. Da die SMAD ihre Militärmark nicht zurücktauschte, mußte angesichts des fehlenden Rücklaufs beständig nachgedruckt werden.

99 BA, Z 45 F/OMGUS, 2/118-1/5-16 (CORC/P(45)209=DFIN/Memo(45)31). Für Kindleberger war die Aufregung über das sowjetische Drucken von Militärmark ein „red herring“. In Deutschland betrugen die Verluste nach seinen Angaben $\$ 400$ Mio., ,,and it had nothing to do with the plates". "The problem is that the people who are interested in the issue were later smeared with the McCarthy brush and never could get their story out"; namentlich Harold Glasser und Harry White. „The Army [...] stole the money back over the next five years in the occupation currency. [...] And so they really took it from the civil GARIOA plan". In Japan hatte MacArthur - ohne sowjetische Einflußnahme - \$300 Mio. Verlust gemacht. TL, Oral History, Kindleberger (1973), S. 32 ff. Nur in Italien, wo die Praxis ähnlich war wie die sowjetische in der SBZ, seien keine Verluste entstanden.

100 PRO, FO 1046/94 (Chambers, 1. 11. 1946); FO 1046/752 (Coates, 14. 7. 1947). Im Koordinationskomitee erklärte die Sowjetunion am 14.6. 1946, die Erfassung der Militärmark bereite Probleme, da deren Ausgabe vor Errichtung der SMAD begonnen habe. 
stiken vorlegten ${ }^{101}$. Aber es wurde immer deutlicher, daß sie allein aus prinzipiellen Gründen nicht gewillt waren, Angaben zu machen, um keinen Einblick in ihre Zone zu gewähren. Die Drohung Clays, wenn nicht bald Klarheit hergestellt werde, würden die USA „die Ausgabe einer neuen Währung empfehlen“, erzielte keine Wirkung.

Die Vorbehalte der Sowjetunion waren von zwei „außerwirtschaftlichen, politischen Erwägungen“ bestimmt: der Absicherung der transformationspolitischen Maßnahmen in ihrer Zone und mehr noch der Gewährleistung ihrer Reparationsinteressen. Dabei zeigte sich erneut ihr Dilemma, zentrale Regelungen nur unter dem Vorbehalt zonal autonomer Umsetzung akzeptieren zu können ${ }^{102}$. Gegen die Empfehlung des Finanzdirektorats, den Druck ausschließlich in der Berliner Staatsdruckerei unter der Aufsicht alliierter Druckexperten durchzuführen, hatte ihr Vertreter im Koordinationskomitee den politischen Vorbehalt geltend gemacht: „Bis zu der Vier-Mächte-Einigung über den Reparationsplan, der Schaffung einer deutschen Zentralverwaltung und der Inkraftsetzung anderer notwendiger Maßnahmen, die eine einheitliche Finanzpolitik in Deutschland garantieren“, sei es „unmöglich, den Währungsdruck an einem Ort zu zentralisieren, und jede Besatzungsmacht muß das Recht besitzen, das Geld nach einem einheitlichen Muster in Druckstätten in ihrer Besatzungszone zu drucken. “103 Die SMAD befürwortete einerseits die „gleichmäßige Regelung in ganz Deutschland“, in deren Rahmen „auf die Dauer“ eine Zentralnotenbank unentbehrlich sei, andererseits wollte sie letztere Maßnahme auf „später“ vertagt sehen ${ }^{104}$. Als die Westmächte in der Kontrollratssitzung vom 18. Oktober 1946 eine Alliierte Bankenbehörde und eine deutsche zentrale Kommission von Länderbanken vorschlugen, damit zentrale und föderale Aspekte verknüpfend, verlangte die Sowjetunion im Gegenzug die vorherige Vernichtung der alten Monopolbanken in den Westzonen; deren bloße Entflechtung sei ungenügend. Die Währungsreform dürfe nicht wieder in den Händen der alten Banken liegen, die Hitlers Krieg finanziert hätten ${ }^{105}$.

Zugleich warfen die Sowjets den Westmächten vor, eine eigene alliierte Sonderwährung eingeführt zu haben. Diese hatten an die Angehörigen ihrer Truppen, aber auch an das von ihnen beschäftigte deutsche Personal „Gutscheine“ (vouchers, pay-

101 BA, Z 45 F/OMGUS, 2/118-1/17-21 (CORC/P(46)210, 11.6. 1946); 2/118-2/8-20 (CORC/ $\mathrm{P}(46) 379,23.11$. 1946); FINAD/11/420-2. Demnach hatten, von den jeweils zur Verfügung stehenden 3 Mrd. Militärmark, bis zum 30. 9. 1946 die Briten relativ konstant ca. 1,8 Mrd. im Umlauf. Die Franzosen hatten ihre umlaufende Militärmark von 1,2 auf 0,5 Mrd. reduziert, die USA (die anfangs Frankreich, die kleineren Westmächte sowie Polen und die Tschechoslowakei mit ausgestattet hatten!) von 3,8 auf $0,6 \mathrm{Mrd}$. Ende 1946 verfügte OMGUS über einen Kassenbestand von ca. 7,3 Mrd., der aber nicht (mehr) in Umlauf gebracht wurde. Die sowjetischen Zahlungen mit Militärmark werden auf 9 Mrd. RM geschätzt. DDR-Handbuch, S. 726. Im November 1947 tauchten neue sowjetische Noten auf, von denen die SMAD angeblich nichts wußte, die aber von den Banken eingelöst werden mußten. BAC, N-1/2519, Bl. 34. Das mochte mit der bevorstehenden Währungsumstellung zu tun haben, denn bei den sowjetzonalen Landeskredit- sowie den Emissions- und Girobanken der Länder stiegen die Militärmarkbestände vom 31.12. 1947 bis 31.3. 1948 von 5,3 auf 7,1 Mrd. RM, die im Verhältnis von 1:1 umgestellt werden mußten und möglicherweise speziell für den Zweck gedruckt worden waren. N-1/804, Bl. 141, 240. Vgl. unten S. 300 Anm. 166.

$102 \mathrm{Im}$ September 1945 hatte die SMAD im Finanzdirektorat „central loans“ abgelehnt und statt dessen vorgeschlagen, „that it will be preferable for Zones to issue their own loans after a general sanction had been given by the Control Council". Frankreich war nicht abgeneigt, wollte aber nur genau begrenzte Anleihen akzeptieren. BA, Z 45 F/OMGUS, 2/121-2/1-4 (DFIN/M(45)6, 28. 9. 1945). Das Koordinationskomitee stimmte zu; 2/118-1/5-16 (CORC/P(45)194).

103 BA, Z 45 F/OMGUS, 2/118-2/8-20 (CORC/P(46)324, 14. 10. 1946).

104 Tägliche Rundschau, 14. 8. 1946, S. 5.

$105 \mathrm{Vgl}$. SAPMO, ZPA, Nl 90/332, Bl. 17 (16. 1. 1948). 
ment certificates) ausgegeben, die nur von den Berechtigten verwendet werden durften, aber bald über diesen Personenkreis hinaus illegal Verbreitung fanden. In sowjetischen Augen waren die Gutscheine eine „besondere Art von Geld, das dazu benutzt wird, einen Teil der Handelstransaktionen zu bestreiten und derart entsprechend den Bedarf an Mark zu verringern“. Da das einen Verstoß gegen die Vereinbarung darstelle, daß die alliierten Truppen nur Reichsmark und Militärmark verwenden dürften, hätte der Kontrollrat konsultiert werden müssen. Die Angelsachsen bestritten vehement, daß die Gutscheine eine „Währung im üblichen Sinne“ darstellten; sie seien interne „Tauschmittel in amerikanischen und britischen Einrichtungen“, die vorher in Fremdwährung gekauft werden müßten und nicht „zur Bezahlung der Besatzungskosten" verwendet werden dürften. Aber ihr Argument konnte nicht recht überzeugen, die Gutscheine seien per se als „nicht im Umlauf“ anzusehen, da deutschen Staatsbürgern der Besitz offiziell nicht gestattet sei $^{106}$. Die zusätzlichen Vorteile, die die Angelsachsen ihren Soldaten in Form der „Zigaretten-Währung“ einräumten, kamen in dem Zusammenhang erst gar nicht zur Sprache ${ }^{107}$. Eine Einigung konnte erwartungsgemäß nicht erzielt werden, so daß die Franzosen noch einen Schritt weitergingen; sie führten zum 1. Februar 1947 einen Besatzungs-Franc in ihrer Zone ein, der für Zivilisten bis zu 4000 Francs bereitgestellt wurde und nicht in Reichsmark eintauschbar war. Damit sollte vermieden werden, daß französische Francs gegen Reichsmark aus obskurer Herkunft und gegen Militärmark eingetauscht wurden ${ }^{108}$.

Trotz der weitgehend festgefahrenen Positionen kam zur Jahreswende 1946/47 noch einmal Bewegung in die Fronten. Das mochte einerseits die Bereitschaft der Kontrollratsdelegationen reflektieren, über einen Kompromiß in der Reparationsfrage zu einer einvernehmlichen Globallösung zu gelangen. Dahinter stand andererseits das Bestreben, im Vorfeld der Moskauer Ratstagung der Außenminister noch einmal Flexibilität und Kompromißbereitschaft zu demonstrieren, um sich nicht die Schuld für die mögliche Teilung Deutschlands anlasten lassen zu müssen. Bis dahin war die Druckfrage weder den Briten ${ }^{109}$ noch den Franzosen ${ }^{110}$ noch einem Teil der amerika-

106 BA, Z 45 F/OMGUS, 2/118-2/8-20 (CORC/P(46)347, 24. 10. 1946, und 347(Revise), 14. 12. 1946); 2/118-2/1-7 (CORC/M(46)57, 62 und 66). Die USA hatten die Coupons im November 1945 in Berlin eingeführt; das System war so umständlich, daß es am 16.12. 1946 durch „dollar military scrips“ abgelöst wurde. Clay, Entscheidung, S. 79 f. Die Briten vermuteten, die Sowjetunion lehne die Gutscheine ab, weil es den Westmächten ,an independence of the restraints in Reichsmark expenditure which they do not possess" gebe. PRO, FO 371/65004 (3.3. 1947). Das bestätigte die Vorwürfe.

1071947 verfügten die USA über 1,5-2,5 Mrd. „Zigarettengeld“, die Briten über 1-1,5 Mrd. RM, die sie gegen Pfund Sterling ihren Truppen für schwarz getauschte bzw. durch den Verkauf von Zigaretten erworbene Reichsmark abgekauft hatten. Das „Zigarettengeld“ wurde wie eine reguläre Währung behandelt, als es 1947 um die Umstellung dieser Markbestände bei einer Währungsreform ging. Das Foreign Office wollte die Guthaben streichen, doch verhinderten die Militärs das. Die Briten hatten 1 Mrd. RM über die Zonenhauptkasse „abgeschrieben“; die USA hofften ihr Geld „by various means, more or less legitimate" loszuwerden, z. B. beim Einkauf für die sog. Post Exchange shops und die Bezahlung von deutschen Angestellten oder Kriegsgefangenen. PRO, FO 371/ 65005/CE1323 (28. 4. 1947); FO 1064/752 (Chambers, 10.6. 1947; Coates, 14. 7. 1947). Vgl. Kindleberger, Letters, S. 7 f., 45. CP, S. 335 f. Jerchow, Deutschland, S. $401 \mathrm{ff}$.

108 PRO, FO 371/64452/C1676/591/18 (Instruction No. 11, 6. 1. 1947; 3. 2. 1947).

109 PRO, FO 1046/94 (Chambers, 11. 10. 1946; Conference with Regional Commissioners, 17. 12. 1946); FO 371/65004 (3. 3. 1947). Dazu mochte beitragen, daß die Briten die amerikanische Befürchtung nicht teilten, die Sowjets könnten bei getrennten Druckorten unkontrolliert Geld ausgeben, zur Finanzierung ihrer Reparationen und Besatzungskosten oder gar zur Destabilisierung der deutschen Wirtschaft im Sinne revolutionärer Aspirationen, zumal der Druck auch in Leipzig unter 
nischen Experten ${ }^{111}$ als ein zentrales Problem erschienen. Erstere äußerten intern Unverständnis für die „Verzögerungstaktik“ der USA, die sie auf deren Entscheidungsunfähigkeit zurückführten. Die Westmächte - davon überzeugt, daß die sowjetische Bejahung der Wirtschafts- und Währungseinheit nur ein Lippenbekenntnis war suchten andere Gründe für das Beharren der SMAD auf dem getrennten Druck in Berlin und Leipzig. Nach britischen Vermutungen befürchteten diese, bei einer VierMächte-Kontrolle von Druck und Ausgabe eine zu geringe Ausstattung ihrer Zone mit Barmitteln - vor allem für die Finanzierung ihrer Truppen und der Reparationen aus laufender Produktion - zu erhalten bzw. die entsprechenden Daten offenlegen zu müssen ${ }^{112}$. Dahinter mochten, wie auch die USA spekulierten, die sowjetischen Erfahrungen mit der Währungsreform in Österreich stehen. Dort hatte es aufgrund der „schrittweisen Beschränkung des Geldbetrages, der den sowjetischen Truppen zur Verfügung gestellt wurde“, „ständige Reibereien“ über die Interpretation des alliierten Abkommens gegeben, das der österreichischen Nationalbank das alleinige Recht zum Notendruck zugestand. Jetzt befürchte Moskau möglicherweise „eine ähnliche Tendenz, um sie zur Reduktion ihrer Ausgaben in Deutschland zu zwingen“. Der teilweise Druck der Währung in ihrer Zone „würde ihre Stellung in Vier-Mächte-Verhandlungen, direkt oder indirekt, hinsichtlich des bereitgestellten Währungsbetrags stärken, um ihre Bedürfnisse zu befriedigen" ${ }^{113}$.

Doch solche Spekulationen waren überflüssig geworden, nachdem am 29. Dezember 1946 die Briten den USA offiziell Verhandlungen über eine bilaterale Währungsreform für die Bizone angeboten hatten ${ }^{114}$. Im Januar 1947 wurde die Finance Division der CCG beauftragt, eine separate Währungsreform vorzubereiten ${ }^{115}$. Jetzt erst machte auch Robertson den Notendruck zur politischen Prinzipienfrage: „Ich betrachte das als einen Testfall“, nämlich ob und inwieweit die Sowjets die deutsche Wirtschaftseinheit tatsächlich wollten ${ }^{116}$. Tenenbaum (OMGUS) sprach seit Anfang

Vier-Mächte-Kontrolle stehen würde und die Sowjets aufgrund eines französischen Kompromißvorschlags angeboten hatten, den Druck nicht anteilig pro Banknoten, sondern nach Notenwerten aufzuteilen.

110 AMAE, Eu(1944-60)Allemagne/91, Bl. 128 ff. (DFIN, 24. 9. 1946). PRO, FO 1046/643 (Currency Reform, Annex 8 [18.1. 1948]). Auch die Franzosen betrachteten die Druckfrage eher als ,technisches“ Problem, obwohl Koenig und der Vertreter im Finanzdirektorat, Masson, den einheitlichen Druckort aus Gründen der Sicherheit und der Praktikabilität befürworteten. Zur Überwindung eigener Bedenken überlegten die Franzosen Anfang 1946, das Geld zentral zu drucken, aber ,sur le plan régional par les Länder“ auszugeben. FO 1046/528 (20. 2. 1946).

11 Die Treasury war der eigentliche Bremsklotz. Das State Department bemühte sich vergeblich, mit britischer Rückendeckung deren Vorbehalte auszuräumen. NA, RG 59/Bohlen, box 4, folder: Financial Provisions (17.6. 1947); RG 59, 740.00119 Control(Germany)/9-547. Tenenbaum (OMGUS), Kindleberger und weitere Mitglieder des State Department glaubten nicht, die Sowjetunion wolle unter den Augen der westlichen Kontrolleure in Leipzig heimlich Geld drucken.

112 PRO, FO 1094/94 (Chambers, 1. 11. 1946); FO 371/65004 (3. 3. 1947).

113 TL, Tenenbaum Papers, box 4, folder: currency reform (2), (Financial Reform: The Present Status of Discussion, Februar 1947); ebenda, box 2 (The German Mark, Ch. 13, S. 10 ff.). PRO, FO 1046/585 (Strang, 30. 10. 1947).

114 PRO, FO 1046/94 (Chambers, 1. 11. 1946); FO 1046/752 (BIB/P(47)11 = BIFIN/P(47)22 (Revise), 28. 1. 1947; Debenham, Currency Reform on a Bipartite Basis, 17. 7. 1947). TL, Tenenbaum Papers, box 4, folder: currency reform (5), (OMGUS/Finanzabteilung, 28. 12. 1946).

115 PRO, FO 1046/585 (21.10. 1947).

116 PRO, FO 371/64452/C3352 (Playfair an Burrows, 26. 2. 1947; Debenham an Playfair, 27. 2. 1947); FO 1046/642 (Quadripartite Discussions on Financial Reform; DT/KPW, 20. 9. 1948). 
1947 ebenfalls nur noch von einer bi- bzw. trizonalen Reform ${ }^{117}$. Als McNarney derartige Überlegungen am 22. Januar 1947 vor der Presse bestätigte, gaben nach sowjetischen Protesten im Finanzdirektorat alle Delegationen offiziell zu Protokoll, niemand bereite in seiner Zone eine separate Währungsreform vor; doch das Nachdenken über einen solchen Schritt war damit keineswegs aufgegeben ${ }^{118}$. Denjenigen, die seit Anfang 1947 in den USA eine zonale bzw. bizonale Reform befürworteten, um eine Verschlechterung der wirtschaftlichen Situation in der eigenen Zone zu vermeiden, war bewußt, daß dies „als ein Abgehen von den Bestimmungen des Potsdamer Abkommens angesehen werden könnte“, auch wenn sich die USA (wie in Korea) auf den Standpunkt stellen könnten, „daß unter den gegebenen Umständen durch eine solche vorläufige Währungsumstellung Deutschland wirtschaftlich nicht endgültig geteilt wird“. Hilldring ließ sich im Januar 1947 dazu bewegen, Riddleberger mit der Überprüfung von Maßnahmen für eine (bi)zonale Währungsreform für den Fall zu beauftragen, daß auf der Moskauer Außenministerkonferenz keine positiven Ergebnisse erzielt wurden $^{119}$. Draper sprach sich im April 1947 dezidiert für eine separate bizonale Reform aus, akzeptierte aber „zögernd“, zuvor müsse sichergestellt sein, daß eine VierMächte-Reform nicht möglich sei; er hielt zwar die Wirtschaftseinheit weiterhin für „wünschenswert“, räumte ihr aber nur noch eine Chance „von 40:60“ ein ${ }^{120}$. Im Kern ging es ausschließlich um die taktische Frage, „ob die USA und Großbritannien das gegenwärtige Übereinkommen, die neue Währung unter Vier-Mächte-Kontrolle zu drucken, aufheben und sofort die etwaige bizonale Ausgabe vorbereiten oder die Pläne für eine vierseitige Ausgabe weiterverfolgen sollten, in der Annahme, daß es politisch und möglicherweise physisch unmöglich sein würde, die neue Währung in Berlin unter Vier-Mächte-Kontrolle drucken zu lassen und später für den bizonalen Gebrauch in Besitz zu nehmen" ${ }^{121}$. Mit anderen Worten: Jede Beteiligung der Sowjetunion am Druck der Banknoten würde den Alleingang erschweren; die Bizonenmächte würden ihre Handlungsfreiheit einbüßen. Angesichts dieses Zögerns monierten die Briten, die USA - „,in Übereinstimmung mit ihrer generellen Politik der Unentschlossenheit“ nähmen zuviel Rücksicht auf die Sowjetunion und wollten „die bestehende Unklarheit fortbestehen lassen“. Doch mochte deren Nachgeben in nebensächlichen Punkten in erster Linie dem Ziel dienen, um an den grundsätzlichen Punkt zu kommen, an dem die Sowjetunion sich nicht länger hinter technischen Fragen verstecken konnte $^{122}$. Daß die Sowjetunion im Vorfeld der Moskauer Konferenz mit der Forderung den Spieß umzudrehen versuchte, vor der Klärung der technischen Fragen müßten die Grundsatzentscheidung über Ziele, Methoden und Modalitäten der Währungsreform getroffen werden, wurde als ein eher propagandistisches Angebot an die Deutschen angesehen. Denn auf der Konferenz selbst wurde deutlich, daß es Moskau in erster Linie um ganz andere Ziele ging: Die Währungsreform „müsse die Gelder

117 TL, Tenenbaum Papers, box 4, folder: currency reform (2), (Financial Reform, Februar 1947; Financial Reform for the Bizonal or Trizonal Area, Anfang 1947).

118 BA, Z 45 F/OMGUS, 2/121-3/1-2 (DFIN/M(47)4, 24. 1. 1947; M(47)5, 4. 2. 1947).

119 NA, RG 59/ASSOA, box 1 (10.1. 1947).

120 AMAE, Y 185, Bl. 133. PRO, FO 371/65005/CE1419 (19. 4. 1947). Das mochte eine taktische Äußerung sein, um die Franzosen mit dem Argument zum Anschluß an die Bizone zu bewegen, dieser Beitritt werde die Sowjetunion zur Kooperation zwingen.

121 NA, RG 59, 740.00119 Council/4-1947.

122 PRO, FO 371/65004/CE259 (Chambers, 3. 3. 1947); FO 1046/542 (30. 10. 1947). 
bereitstellen, die für Reparationen und Besatzungskosten erforderlich sind“123. Sie war, wie ihre Kompromißangebote auch im Kontrollrat nahelegen, vor allem darauf bedacht, ihre Besatzungsinteressen nicht beeinträchtigen zu lassen bzw. aus der Währungsreform zusätzliche Vorteile zu ziehen.

Vor diesem Hintergrund trat das Finanzdirektorat am 6. Januar 1947 erneut in die Diskussion der Druckfrage ein und legte dem Koordinationskomitee auf der Grundlage britisch-französischer Vermittlungsvorschläge ein Kompromißpapier vor. Beide wollten angesichts sowjetischer Zugeständnisse den parallelen Druck in Berlin und Leipzig akzeptieren, solange die Vier-Mächte-Kontrolle an beiden Orten gewährleistet war. Sowjets und Amerikaner hielten aus Prestigegründen an ihren Grundsatzpositionen fest, aber die USA, in deren Sektor die Reichsdruckerei lag, offerierten deren Ausgliederung aus dem amerikanischen Hoheitsbereich, und die Sowjets boten für Leipzig die gleichen Sicherheitskontrollen an wie für Berlin. Angesichts der sowjetischen Zugeständnisse waren plötzlich die Fronten vertauscht: Hatten zunächst die drei Westmächte einmütig gegen die Sowjetunion gestanden, so drohten nun die USA isoliert zu werden. Dadurch unter Druck gesetzt, empfahl Clay, mehr im Interesse der westlichen Einheit als der Einigung mit den Sowjets, trotz anhaltender Skepsis seiner Regierung am 17. Januar 1947 die Annahme des Kompromisses ${ }^{124}$. OMGUS und State Department schoben sich nun gegenseitig die Verantwortung für die bisherige Stagnation zu, und die amerikanische Seite bot ein Bild interner Konfusion und Uneinigkeit über die Deutschlandpolitik ${ }^{125}$, die sich in der kontroversen Debatte über den von Clay und Sokolowski ausgehandelten Kompromiß in der Reparationsfrage reproduzierte. Ersterer sah sich schließlich gezwungen nachzugeben, und er akzeptierte am 10. Mai 1947 im Kontrollrat Leipzig als Druckort, allerdings unter dem Vorbehalt (von dem er wissen mußte, daß er einem Veto gleichkam), daß dies erst nach Errichtung einer deutschen Zentralverwaltung für Finanzen geschehen könne. Sokolowski begründete sein Festhalten an Leipzig mit ausschließlich technischen Gründen und schloß, als versöhnliche Geste, einen dritten Druckort nicht aus. Allerdings wies er (anders als sein französischer Kollege!) die Bedingung Clays zurück, den Banknotendruck in Leipzig an die vorherige Errichtung einer Zentralverwaltung zu binden, obwohl die Sowjetunion derartiges im Oktober 1946 selbst vorgetragen hatte. Briten und Franzosen erklärten sich mit beiden Vorschlägen einverstanden, so daß Sowjets und Amerikaner unter Zugzwang standen. Beide signalisierten Kompromißbereitschaft, indem sie darauf verzichteten, das Thema von der Tagesordnung abzusetzen, schoben aber die Entscheidung ihren Regierungen $\mathrm{zu}^{126}$. In den westlichen Hauptstädten hatten sich indes die Maßstäbe wie die Interessen verschoben. Denn mit der Gründung der Bizone war eine Alternative vorhanden, die den Zwang zum Kompromiß reduzierte, sondern vielmehr die Möglichkeit eines anglo-amerikanischen Alleingangs attraktiv und machbar erscheinen ließ.

123 FRUS, 1947/II, S. 418 (CFM (47) (M) 74, 28. 3. 1947).

124 PRO, FO 371/64452/C3352 (Playfair an Burrows, 26. 2. 1947; Debenham an Playfair, 27. 2. 1947); FO 371/65004/CE1132 (Makins, 28. 3. 1947), CE520 (Burrows, 24. 3. 1947). CP, S. 302 f. (17. 1. 1947).

125 PRO, FO 371/65005/CE1303 (16. 4. 1947), CE1419 (19. 4. 1947).

126 PRO, FO 1046/642 (Quadripartite Discussions on Financial Reform; DT/KPW, 20. 9. 1948). 
In Washington berieten am 17. Juni State Department, War Department und Treasury die neue Lage. Clay empfahl, wie schon im Januar 1947, abermals ein Einlenken: „Trotz vieler Zweifel bin ich jedoch bereit, im Interesse der Einstimmigkeit das Risiko einzugehen, daß wir das Drucken der neuen Währung kontrollieren können, auch wenn die Sowjets Druckplatten in Händen haben." Für das State Department signalisierte Hilldring Zustimmung, doch dürften die Vorbereitungen für eine bizonale Währungsreform nicht aufgegeben werden ${ }^{127}$. Dahinter stand die Empfehlung von Donald Heath, der nach Rücksprache mit Wilkinson (OMGUS), Carl J. Friedrich (Harvard) und Fritz Oppenheimer (State Department) seine Warnung vor einem Einlenken mit dem Rat verbunden hatte, die Westmächte sollten in Berlin einseitig mit dem Druck des neuen Geldes „als einer Vorsichtsmaßnahme“ beginnen und den Sowjets unmißverständlich eröffnen, daß in den sechs bis acht Monaten der Druckzeit eine Regelung im Kontrollrat erreicht sein müsse; andernfalls würden sie die neue Währung in der Bizone (aber nicht in ihren Berliner Sektoren ${ }^{128}$ ) einführen, ohne damit die Tür für eine nachträgliche gesamtdeutsche Währungsreform zuzuschlagen. „Ich glaube, daß die bloße Bekundung unserer Entschlossenheit zum Handeln die Sowjets veranlassen könnte, ihre Obstruktion beim finanziellen Großreinemachen aufzugeben, ehe die Währung zur Ausgabe fertig ist. Wenn sie nicht sofort nachgeben, werden sie binnen kurzem durch die verbesserten wirtschaftlichen und sozialen Zustände im Bizonengebiet dazu gezwungen werden." Die Sowjets würden sich in dieser Frage nicht isolieren wollen, allein um in der Gunst der Deutschen keine Punkte zu verlieren. Das Argument von Bennett (OMGUS), ein solches Vorgehen werde die endgültige Teilung Deutschlands bedeuten, wies Heath zurück: „Die Teilung besteht doch de facto [...]; die Sowjets fürchten die formelle Teilung Deutschlands - noch mehr, als wir das tun“129. Clay sprach sich am 9. Juli für einen Kompromiß aus, nämlich die Druckplatten insgeheim, das Spezialpapier aber unter Information der Sowjets „vorsorglich“ zu produzieren, um keine weitere Zeit zu verlieren, entweder für eine bibzw. trizonale oder eine gesamtdeutsche Währungsreform. Das würde Zeit sparen, die Entscheidung aber vertagen ${ }^{130}$. Die USA fanden einen vorübergehenden Ausweg aus

127 CP, S. 350 (10. 5. 1947). NA, RG 59/CED, box 4, folder: Financial Provisions (Memo of Conversation, 17.6. 1947).

128 Im Juli 1947 erwarteten die Briten, daß eine separate Reform für die Westmächte Probleme in Berlin nach sich ziehen werde; deren Position dort wäre „immeasurably weakened“, weil sie „would have to rely on cash put at their disposal by the Russians“. PRO, FO 1046/752 (Debenham, 17.7. 1947). AMAE, Y 295, Bl. 296 f. (Coates, 9. 8. 1947). Die USA hielten das für ein lösbares Problem. PRO, FO 1046/585 (30. 10. 1947). Konkrete Drei-Mächte-Verhandlungen, unter Einbeziehung deutscher Stellen, begannen im März 1948. AMAE, Eu(1944-60)Allemagne/91, Bl. 34 (GMFB, 8. 3. 1948). Um den 19./20. 4. 1948 wurde ein Modell für Berlin gesucht: entweder mit den Sowjets eine Berliner Vier-Mächte-Währung zu vereinbaren (,this would safeguard prestige and sovereignty considerations and enable us to exercise some control over the circulation and availability of the new mark") oder eine parallele Zirkulation von West- und Ostmark anzustreben. Ein Umlauf nur von Ostmark in ganz Berlin wurde abgelehnt; dann solle eine „perforated DM“ in den Westsektoren ausgegeben werden. Da eine westsektorale Währung aber nicht lebensfähig sein werde, waren die USA bereit, die Einbeziehung Berlins in das sowjetzonale Währungsgebiet zu akzeptieren, wenn ihnen symbolische Rechte im Rahmen der Kommandantur verblieben. BA, Z 45 F/OMGUS, FINAD/2/103-1 (OIR-Report No. 4668, 13. 4. 1948). Diese Linie vertraten die Westmächte noch in den Verhandlungen sowohl im Juni 1948 in Berlin als auch im August 1948 in Moskau.

129 NA, RG 59/Bohlen, box 2, folder: Correspondence - Murphy's Office (Heath an Murphy, 15. 5. 1947).

130 CP, S. 382. 
ihrem Dilemma, indem sie das Geld in Amerika druckten und heimlich nach Deutschland brachten ${ }^{131}$.

Das War Department sprach sich gegen ein wie auch immer geartetes Eingehen auf sowjetische Angebote aus. „Diese Abneigung gründet sich auf das Mißtrauen gegenüber den sowjetischen Motiven [...] und auf die Überzeugung, daß die Notwendigkeit einer Währungsreform nicht so dringlich ist, um die Annahme des sowjetischen Vorschlags zu rechtfertigen." Diesem Votum schloß sich die Treasury an, befürwortete aber im Sinne Clays, die Vorbereitungen für den bi- bzw. trizonalen Notendruck voranzutreiben, jedoch gleichzeitig anzubieten, das Geld bei einer Einigung in ganz Deutschland einzuführen. Ungeachtet der Warnung des stellvertretenden Außenministers Lovett, eine anhaltende Verweigerung könnte im Vorfeld der Londoner Außenministerkonferenz den unerwünschten Eindruck erwecken, die USA seien an der Einheit Deutschlands nicht mehr interessiert, hielten War Department und Treasury ihre Einwände aufrecht. Clay wurde angewiesen, einen neuen Versuch zu unternehmen, Berlin als alleinigen Druckort durchzusetzen, oder aber, im Falle des Scheiterns, Briten und Franzosen zum separaten Druck unter Aufsicht der drei Westmächte zu bewegen. Sollte auch das nicht gelingen, müsse neu beraten werden ${ }^{132}$. Der Vorstoß Clays im Kontrollrat am 30. Juli und die Beratungen im Koordinationskomitee am 6. August brachten, trotz geringfügiger Modifikation der Positionen, keine neuen Aspekte oder gar Aussichten auf eine Lösung ${ }^{133}$. Lediglich über ihre Presse warnte die Sowjetunion, der die Diskussion in der westlichen Öffentlichkeit nicht verborgen geblieben war, die Westmächte vor einem Alleingang: Sie habe „peinlichst jede Maßnahme vermieden [...], die einer gesamtdeutschen Währungsreform hätte hinderlich sein können“. Eine separate Währungsreform in den Westzonen werde nicht nur die wirtschaftliche, sondern auch die staatliche Einheit Deutschlands endgültig und auf Dauer zerstören ${ }^{134}$.

Die inneramerikanische Diskussion könnte den Schluß nahelegen, daß OMGUS und Washington an einer Einigung kein Interesse mehr hatten. Doch war das, nach dem Eindruck Strangs, nicht der Fall ${ }^{135}$. Trotz allen Mißtrauens waren Teile der amerikanischen Administration und des OMGUS noch immer gewillt, die Sowjets durch Entgegenkommen soweit einzubinden, daß sie keinen Alleingang unternehmen konnten. Die letztlich ausschlaggebenden Überlegungen hatte Tenenbaum bereits im Februar 1947 formuliert: Zwar sei infolge der Maßnahmen in der SBZ der unmittelbare

131 Dodge hatte im Februar 1946 gegenüber der britischen Treasury inoffiziell den anglo-amerikanischen Notendruck ins Gespräch gebracht; allerdings sollte die Ausgabe unter Vier-Mächte-Kontrolle stehen. PRO, FO 371/55411/C1477. Den britischen Vorschlag, das Geld in England zu drukken, teilweise in Frankreich, lehnten die USA ab, weil sie die Sterling-Kosten scheuten, kamen aber Anfang 1947 darauf zurück, da in den Westzonen die technischen Voraussetzungen fehlten. FO 371/65005/CE1303 (Chambers, 1. 4. 1947). NA, RG 59/Bohlen, box 4, folder: Financial Provisions (17.6. 1947). Ähnliche Vorbereitungen traf nach amerikanischen Angaben auch die Sowjetunion. Demnach wurden die Druckplatten zum separaten Notendruck im März 1948 hergestellt; zwar fehlte Papier, aber die Druckmaschinen waren vorbereitet. BA, Z 45 F/OMGUS, FINAD/2/ 103-1 (11.3. 1948). Die Coupons, mit denen das neue Geld in der SBZ zunächst markiert wurde, waren nach amerikanischen Informationen bereits im März 1948 gedruckt. AMAE, Eu(1944-60) Allemagne/92, Bl. 41 f. (14. 3. 1948).

132 NA, RG 59/Bohlen, box 4, folder: Financial Provisions. FRUS, 1947/II, S. 876 ff. AMAE, Eu(19441960)Allemagne/91, B1. $167 \mathrm{ff}$.

133 CP, S. 398 (8. 8. 1947).

134 Tägliche Rundschau, 23. 7. 1947, S. 3.

135 PRO, FO 1046/585 (30. 10. 1947). 
Druck für eine Währungsreform nicht so groß wie in den Westzonen, aber das (von den Briten bestätigte) Interesse der Sowjets an einer Inflationsvermeidung schien darauf hinzudeuten, daß auch sie langfristig nicht ohne eine Währungsreform auszukommen meinten. Die SMAD habe zur Kenntnis nehmen müssen, „daß ihre Zone nicht gegen einen allgemeinen Zusammenbruch des Vertrauens in eine gemeinsame Währung abgeschottet werden kann. Daher werden alle Pläne, die sie für eine substantielle Wiederbelebung der deutschen Produktion für Reparations- und andere Zwecke haben mögen, weiterhin von dem allgemeinen Mangel an Vertrauen in die Währung beeinträchtigt werden.“" ${ }^{136} \mathrm{Da}$ eine Inflation in den Westzonen einen Warenabfluß aus der SBZ provozieren könnte, hofften die USA, „daß, solange wie diese Bedrohung anhält, die Russen bereit sein werden, bessere Bedingungen für die Vereinigung Deutschlands anzubieten “137. Abermals glaubten die USA, die Sowjetunion über deren Reparationsinteressen in die Wirtschaftseinheit hineinzwingen zu können ${ }^{138}$.

Das schien den Briten zweifelhaft, deren Vertreter in Berlin, Sir Eric Coates, am 9. August 1947 bei seinem französischen Kollegen Leroy-Beaulieu Möglichkeiten für einen Kompromißvorschlag sondierte. Nach österreichischem Vorbild wollte Coates den Sowjets eine höhere Grundausstattung an neuem Geld zugestehen, um damit die Frage der Besatzungskosten ebenso auszuklammern wie die Reparationsproblematik. Coates überlegte, die sowjetische Zustimmung zu „kaufen“, indem „wir stillschweigend der russischen Forderung nach laufenden Reparationen nachgeben (indem die in ihre Besatzungskosten eingeschlossen werden)“. Er wollte den Sowjets 7,4 Mrd. RM für ,innere“ Besatzungskosten zugestehen, den USA 1,8, Großbritannien 1,6 und Frankreich 1 Mrd. RM, für die „äußeren“ Besatzungskosten (Nachschub und Verbindungslinien nach Deutschland) den USA 640, der Sowjetunion 480, Großbritannien 220 und Frankreich 160 Mio. RM. „Die Pauschalsumme wird selbstverständlich entsprechend den deutschen Ressourcen festgesetzt werden, aber sie wird notwendigerweise einen erheblichen Abschlag von den derzeitigen Aufwendungen der Russen nach sich ziehen." Mit einer solchen Garantie hofften Coates und Leroy-Beaulieu die vermuteten Vorbehalte der Sowjets gegen den alleinigen Druck in Berlin ausräumen zu können - in der Erwartung, „daß angesichts der ernsten Folgen, die die vollständige Spaltung Deutschlands zwischen West und Ost bedeuten würde, die Russen zögern werden und ein Kompromiß gefunden werden kann“. Doch sollte das Projekt scheitern - das hatten Coates und sein amerikanischer Kollege in den vergangenen Tagen mehr als deutlich gemacht - war eine separate bizonale Währungsreform unvermeidlich. Dann aber, so warnte Leroy-Beaulieu seine Regierung, wäre die Stellung der französischen Zone unhaltbar, der Anschluß an die Bizone nicht mehr zu vermei-

136 TL, Tenenbaum Papers, box 4, folder: currency reform (2), (Financial Reform: The Present Status of Discussion, Februar 1947). In der Tat hatte die SBZ Anfang 1947 erkennen müssen, daß das Ausbleiben einer Reform für die eigene Zone langfristig von Nachteil war. „Obgleich rein technisch die Währungsreform zonenweise durchführbar wäre“, sei dieser Weg nicht gangbar, da er die wirtschaftliche und politische Einheit Deutschlands in Frage gestellt hätte. Daher ,ist ein Weg zu einer für alle Zonen tragbaren Lösung zu wählen“. Eine Bedingung war, daß die Kontenblockade des Jahres 1945 nicht rückgängig gemacht wurde; zugleich ging es aber aus politischen Gründen darum, eine Enteignung der "kleinen Leute“ wie 1923 zu verhindern. SAPMO, ZPA, Nl 90/332, Bl. 1 (Kommentar zur vorgesehenen Erklärung zur Währungsreform, 10. 1. 1947).

137 PRO, FO 371/65005/CE1323 (Chambers, 28. 3. 1947).

138 PRO, FO 800, 466/Ger/47/47 (Marshall-Bevin, 4. und 17. 12. 1947). AN, 457 (Bidault) AP 15/Après la CMAE de Londres, 17.-31. 12. 1947. 
den. Als CCG und GFCC den amerikanischen Kollegen im Oktober 1947 ihren Vorschlag unterbreiteten, den Sowjets „eine abnorm hohe Reichsmark-Zuteilung im Hinblick auf Besatzungskosten [zuzugestehen], aus der sie ihre laufenden Reparationsbedürfnisse befriedigen könnten“, waren diese wenig begeistert, stimmten aber zu, weil sie davon ausgingen, daß sich das Problem mangels genereller Einigung nicht stellen werde ${ }^{139}$.

Es mußten also Entscheidungen getroffen werden, politische Entscheidungen, ohne die eine Einigung in den technischen Fragen nicht möglich war. In 14 „Sondersitzungen" hatte das Finanzdirektorat von September 1946 bis November 1947 in keinem wesentlichen Punkt Einigung erzielen können - mit Ausnahme der Umstellungsmodalitäten der deutschen Bargeld- und Bankguthaben ${ }^{140}$. Im Laufe der mehrmonatigen Verhandlungen waren einige Probleme ausgeklammert oder vertagt, andere in Komitees oder benachbarte Direktorate abgeschoben worden. Das hatte bislang die Westmächte des Zwangs enthoben, sich in allen Details untereinander einigen zu müssen. Doch standen gelegentliche Irritationen und Komplikationen trotz konzeptionell-technischer Differenzen oder widerstreitender besatzungspraktischer Interessen einem deutschlandpolitischen Schulterschluß der Westmächte auf höherer Ebene zu keiner Zeit ernsthaft im Wege, wie die Sowjetunion hoffen mochte, auch wenn die Frontlinien noch im Frühjahr 1947 keineswegs immer eindeutig zwischen Ost und West verliefen:

- Prinzipiell bestand zwischen allen Mächten Einigkeit, 70\% der monetären Guthaben $\mathrm{zu}$ streichen, $20 \% \mathrm{zu}$ blockieren und $10 \%$ freizugeben. Die USA und die Sowjetunion neigten jedoch dazu, die Blockierung der $20 \%$ für unbestimmte Zeit aufrechtzuerhalten und damit faktisch $90 \%$ zu streichen; Frankreich schlug eine allgemeine Konversionsrate von 1:5 vor, also eine Reduktion um $80 \%$.

- Anstelle der zu blockierenden 20\% sahen die USA einen Lastenausgleichsfonds vor, den die drei anderen Mächte zunächst ablehnten, weil er neue Kaufkraft schuf. Die Sowjetunion forderte eine Vertagung dieser Frage bis zum Abschluß der Reparationen. Frankreich sah derart komplizierte Ausgleichsregelungen durch seine Konversionsrate von 1:5 als überflüssig an.

- Nach amerikanischen Vorstellungen, die prinzipiell die Unterstützung der Franzosen und Briten fanden, sollte der Lastenausgleichsfonds zur Kompensation von Nazi-Opfern, Kriegsschäden und Reparationsverlusten eingesetzt werden und erst nach seiner vollständigen Auffüllung zur Auszahlung kommen. Die USA lehnten die sowjetische Forderung $a b$, diese Gelder in ein zentrales Budget einzuzahlen, einmal im Interesse der Dezentralisierung, zum anderen weil sie befürchteten, die Gelder könnten insgeheim zur Begleichung von Besatzungskosten eingesetzt werden.

- Briten und Franzosen plädierten für eine ähnliche Behandlung der Reichsschuld, um die Ansprüche ihrer nationalen Investoren aus der Zwischenkriegszeit ebenso zu konservieren wie die tradierte deutsche Sozialstruktur. Dagegen votierten Amerikaner

139 AMAE, Y 295, Bl. 296 ff., 299 f. PRO, FO 1046/752 (Coates, 14. 4. 1947; Notes of Meeting, 30. 9. 1947); FO 1046/585 (30. 10. 1947).

140 Protokolle der 13. Sitzung am 5. 8. und der 14. Sitzung am 25.11. 1947 in BA, Z 45 F/OMGUS, FINAD/2/102-4. PRO, FO 371/65004 (Chambers, 24. 3. 1947). Zum Stand vom Sommer $1947 \mathrm{vgl}$. FO 1046/752 (Chambers, 10.6. 1947). Ein detaillierter Bericht über Verlauf und strittige Diskussionspunkte in den Kontrollratsverhandlungen in den Jahren 1946/47 in: FO 1046/642 (DT/KPW, 20.9. 1948). 
und Sowjets für eine vollständige Streichung; erstere aus finanztechnischen, letztere aus transformationspolitischen Gründen.

- Die Finanzierung der Industrie nach der Währungsreform sollte gemäß Auffassung der USA durch staatlich garantierte Darlehen gewährleistet werden, während die Briten das durch die normalen (und damit entsprechend zu konservierenden) Bankkanäle tun wollten.

- Die USA verstanden, unterstützt von Frankreich und der Sowjetunion, die Reform der Preisstruktur als nachträgliche Anpassungsmaßnahme, während die Briten diese als vorherige Strukturbereinigung forderten. Der mögliche Kompromiß, nämlich Subventionen für bestimmte Güter wie Kohle oder Stahl, wurde von der Sowjetunion verhindert.

- Völlig ungelöst blieben die Dezentralisierung der öffentlichen Finanzen, das Verhältnis von Staats- und Länderhaushalten und die Aufteilung des Steueraufkommens.

- Bei der Reform des Bankensystems, sowohl im Hinblick auf die Entflechtung der privaten Geschäftsbanken als auch auf ein System von Länder-Zentralbanken und einer Alliierten Banken-Kommission, stand die Sowjetunion allein gegen die drei Westmächte. Der Hauptgrund für ihren Widerstand war, daß sie sich in ihrer Zone weder einem alliierten noch gar einem deutschen Gremium unterwerfen wollte.

- Die Umtauschrate der Mark sollte nach Vorstellungen der Briten im Interesse einer raschen Anpassung des inländischen Preisniveaus an das Weltmarktniveau und der Exportankurbelung frühzeitig festgesetzt werden, während die USA sich für eine Übergangs- und Schutzfrist nach vollzogener Währungsreform aussprachen und sich lange intern nicht einigen konnten, ob sie mit einem fixen Umtauschsatz von 1:3 oder 1:10 oder mit einer Serie von gestaffelten Wechselkursen arbeiten sollten ${ }^{141}$.

- Schwierig gestaltete sich auch der Umtausch der alliierten Reichsmark-Guthaben. Die Sowjetunion wollte nicht nur die Guthaben ihrer Soldaten, sondern vor allem auch die Bestände der Militärregierung selbst auf der Basis von 1:1 umstellen. Diese Frage verschaffte den Westmächten ebenfalls Probleme, da sie - abgesehen von den eigenen Reichsmark-, Militärmark- und „Zigarettenmark“-Beständen - keinen Überblick hatten, welche Mittel der SBZ tatsächlich im „Besitz“ der SMAD waren, etwa der Kapitalstock der Sowjet AGs. Insofern wollten die Anglo-Amerikaner dem sowjetischen Verlangen nur zustimmen, wenn die umzutauschende Menge vorher mitgeteilt wurde ${ }^{142}$.

Die Debatten des Finanzdirektorats über diese technischen Probleme während des Sommers 1947 erschienen den Briten als „unwirklich“, solange der durch die amerikanische Prinzipienpolitik in der Druckfrage verursachte Stillstand nicht überwunden war! Doch bestand auch bei ihnen intern keine vollständige Einigkeit, ob sie den Bruch in dieser Frage um jeden Preis herbeiführen sollten. Angesichts der Blockade im Kontrollrat verstärkte sich bei den beiden Finanzexperten der CCG, Coates und Chambers, die Überzeugung, die Sowjets lehnten die westlichen Vorschläge allein deshalb ab, weil die notwendige Revision von Preisstruktur und Preisniveau einerseits, die

141 PRO, FO 371/65005/CE1303 (16. 4. 1947). Da im Kontrollrat eine Einigung über die Konversionsrate nicht möglich war, verstärkte sich in London die Überzeugung, daß „eine Einigung über diesen Punkt wenig wahrscheinlich sei, bis die Vier-Mächte-Verhandlungen zugunsten von zweiseitigen Verhandlungen abgebrochen werden“. FO 1046/534 (8.1. 1947).

142 PRO, FO 371/65005/CE1323 (Chambers, 28. 3. 1947). 
Festlegung des Außenwertes der Mark andererseits ihren (Reparations-)Interessen widerspreche; auf beiden Feldern müsse der Westen jedoch vollständige Freiheit gewinnen. Allein dieser Interessenkonflikt werde die "Scheidung“ bringen ${ }^{143}$. Wolle man das verhindern, sei die Beschränkung auf einen reinen Währungsschnitt erforderlich, über den mit der Sowjetunion noch am ehesten Einigung zu erzielen sei. Wohl weniger im Interesse einer Vier-Mächte-Einigung als der Rückkehr zu ihrer eigenen Konzeption der „kontrollierten Inflation“ erneuerten sie die Kritik am CDG-Plan und empfahlen, die zweite und dritte Stufe, also den Lastenausgleich, aufzugeben bzw. der zukünftigen deutschen Regierung zu überlassen. Die Alternative, die bi- oder trizonale Währungsreform, ließe sich nicht wie die „kontrollierte Inflation“ auf finanztechnische Maßnahmen begrenzen, sondern „werde unmittelbar eine politische Teilung Deutschlands nach sich ziehen“. Doch die USA lehnten jedes Abweichen vom CDGPlan ab, waren höchstens zu einer „Anpassung“ bereit, indem sie den britischen Wünschen nach Bereinigung der Preisstruktur im Vorfeld der Reform und frühzeitiger Festlegung eines einheitlichen Wechselkurses zustimmten ${ }^{144}$. Die Grundsatzentscheidung wurde auf die politische Ebene zurückverlagert und bis zur Londoner Außenministerkonferenz im Dezember vertagt.

Unsicher über die Chancen bzw. die Wünschbarkeit einer Einigung im Kontrollrat, trieben während dieser Zeit Briten und Amerikaner ihre Vorbereitungen für eine bizonale Währungsreform voran, durch Angleichung des Bankensystems etwa. Indem sie derart strukturelle Weichenstellungen in die Wege leiteten und sich zugleich bemühten, Frankreich zum Anschluß an die Bizone zu bewegen und auf eine gemeinsame Währungsreform festzulegen, waren ernsthafte Kompromißchancen im Kontrollrat kaum noch gegeben, zumal nachdem der Marshall-Plan neue politische Prioritäten gesetzt hatte. Die Londoner Konferenz der Außenminister im Dezember 1947 bot eine günstige Gelegenheit für die endgültige Klärung. Insofern war es den Westmächten ausgesprochen unangenehm, als im Vorfeld der Konferenz in der Presse bekannt wurde, daß das neue Geld bereits in den USA gedruckt worden war. Clay dementierte - im Wortsinn korrekt - am 9. Dezember, daß die Entscheidung gegen eine Vier-Mächte-Währungsreform bereits gefallen sei; doch wurde der Zwang stärker, gegenüber der deutschen Öffentlichkeit die politische Verantwortung für das Scheitern einer gemeinsamen Währungsreform zu begründen ${ }^{145}$.

Nachdem die Ergebnisse der Londoner Außenministerkonferenz eine deutschlandpolitische Einigung faktisch unmöglich gemacht hatten, ließ sich jedoch eine Entscheidung nicht länger vertagen, ob, wann und in welchem Umfang die Währungsreform durchgeführt werden und welche Rolle dabei der Kontrollrat spielen sollte. Das galt auch für die Sowjetunion, die seitdem zwar doppelgleisig für SBZ und Gesamtdeutschland plante, aber offenkundig auf eine sowjetzonale Sonderlösung zusteuerte. Ende 1947 beauftragte die SMAD die Deutsche Zentralfinanzverwaltung (DZFV) mit der Ausarbeitung eines Organisationsentwurfs für eine „Zonen-Emissionsbank“, den diese am 7. Januar 1948 dem SMAD-Vertreter Sitnin vorlegte. Dem waren - angesichts des Termindrucks! - „Schönheitsfehler“ nicht wichtig, zumal die Satzung nur

143 PRO, FO 1046/102 (26.11. 1947).

144 PRO, FO 1046/752 (Coates, 14. 7. 1947; Chambers, 10.6. 1947). Die Franzosen erhielten vertraulich Kenntnis von den Verhandlungen. AO, Berlin/3282/5/2130C (GFCC, 5. 11. 1947).

145 BA, Z 45 F/OMGUS, FINAD/2/119/7 (8. 12. 1947; Bennett an Coates, 15. 12. 1947). 
für eine „Übergangszeit“ gelten werde. In der überarbeiteten Fassung, die die DZFV drei Tage später vorlegte, wurde „von einer Verankerung des Notenprivilegs zunächst abgesehen, damit auch der äußere Anschein separatistischer Tendenzen in der Ostzone vermieden wird“. Intern sprach man jedoch von einer „Notenbank“ für die bevorstehende "Geldreform“, und zwar - wie sich in den Beratungen des Kontrollrats erwies - zunächst für eine gesamtdeutsche, notfalls aber für eine rein zonale Währungsreform ${ }^{146}$. Am 27. Februar erläuterte Maletin (SMAD) den Deutschen: „Zurzeit [sic!] im Kontrollrat Erörterungen über einen freien Überweisungsverkehr innerhalb Deutschlands im Gange ${ }^{147}$; aus Gründen, die nicht von der sowjetischen Seite abhingen, lasse ein solcher sich noch nicht ermöglichen. Es empfehle sich jedoch, eine Einigung über dieses Thema nicht erst abzuwarten, sondern wenigstens im zonalen Maßstab schon jetzt eine straffere Regelung des Geldumlaufs und des Überweisungsverkehrs herbeizuführen. Das bedeute nicht, daß das Gesamtziel, eine gesamtdeutsche Regelung zu finden, aufgegeben sei.“ Maletin forderte die Zusammenfassung der Länder-Emissions- und Giro-Banken zu einer Zonenbank, trotz des Ziels einer „einheitlichen deutschen Zentralbank". Daß es um mehr ging als nur um eine Reorganisation und Straffung des SBZ-Bankensystems, wurde aus Maletins weiteren Äußerungen deutlich, als er den Namen „Deutsche Emissionsbank“ für die neue Zonenbank vorschlug, der "wegen der Doppeldeutigkeit des Wortteils ,Emission' gerade im jetzigen Zeitpunkt, d.h. vor Effektuierung des Notenprivilegs, besonders geeignet erscheint“148. Die DZFV unterstützte Ende Februar diese Politik, „um auch hier die Voraussetzungen zu schaffen für die Durchführung der Geldreform, ohne damit jedoch die Koordinierung [!] mit den Westzonen zu präjudizieren. [...], Das Ziel ist die Einheit ““149 Am 5. März wurde auf einer Besprechung mit der SMAD von der „Zentralnotenbank“ gesprochen, die, wie der Präsident der DZFV am 17. März seinen Länderkollegen mitteilte, ,an die Stelle der Reichsbank als Notenbank" treten sollte. Einschränkend fügte er hinzu, daß die SMAD die Details offengelassen habe, weil diese Fragen ,unmittelbar im Zusammenhang mit den Beratungen des Kontrollrats stehen. Komme es im Kontrollrat zu einer Einigung, dann werde die Notenbank einen engumgrenzten Charakter haben, gelinge die Einigung nicht, dann sei es durchaus möglich, dass der Aufgabenkreis der Bank etwas weiter gezogen werde“. Am 14. April wurde von der „bevorstehenden Geldreform“ gesprochen ${ }^{150}$. Die DWK wies am 12. Mai die volkseigenen Betriebe an, eine Eröffnungsbilanz zum 1. Juli vorzulegen,

146 BAC, N-1/2519, Bl. 51 f., 60, 90. Die Sowjetunion hatte am 4. 10. 1946 im Finanzdirektorat gefordert, die Notenemission bei den Länderbanken zu verankern.

147 Zur Erleichterung des Clearings im Interzonenhandel hatte die DZFV im Oktober 1947 nach Vorgesprächen mit der SMAD im Mai 1947 eine Empfehlung erarbeitet. Nach dem Vorbild der Angelsachsen sollte die SBZ eine eigene zentrale Clearingstelle einrichten, an der die Länder-Emissions- und Giro-Banken beteiligt seien. Danach hätten, so ein Vorschlag der DZFV vom 22. 12. 1947, zwei Clearingstellen bestanden, eine für die drei Westzonen und eine für die SBZ. Das war für Sitnin von der SMAD am 17. 1. 1948 ,völlig unannehmbar“, weil es „tatsächlich zu einer Vereinigung der drei westlichen Zonen“ als einer "wirtschaftlichen Einheit" geführt hätte. BAC, N-1/ 731 , Bl. 26 ff., 31, 162, 167, 171.

148 BAC, N-1/835, Bl. 3, 16, 18, 51, 125; N-1/804, Bl. 266. Sitnin, Finansy, S. 47.

149 BAC, N-1/835, Bl. 26 (Boes, 27. 2. 1948).

150 ThHStA, MFin/62. „Die bevorstehende Geldreform habe in letzter Zeit ein etwas anderes Gesicht erhalten. Sie werde u. a. wieder mit einem Lastenausgleich in Verbindung gebracht." 
der insofern wohl der Stichtag sein sollte ${ }^{151}$. Gemäß Befehl Nr. 94 vom 21. Mai nahm die Deutsche Emissions- und Girobank, wie sie in Anlehnung an die Länderbanken genannt wurde, am 1. Juni ihre Arbeit auf. Entwürfe für eine „Verordnung über die Geldreform“ und die „Technischen Durchführungsbestimmungen“ wurden bis zum 16. Juni überarbeitet. Man wartete aus taktischen Gründen die Währungsreform im Westen ab, hatte allerdings die eigenen Vorbereitungen noch nicht abgeschlossen. Eile schien nicht angebracht: „Es ist nicht erforderlich, daß die Geldreform zeitlich unmittelbar auf die West-Geldreform folgt, wenn auch der Abstand wegen des zu erwartenden Unruhezustandes möglichst kurz bemessen werden sollte. Es ist nicht anzunehmen“, obwohl später gerade das als Argument zur Begründung der verschärften Blockade-Maßnahmen herangezogen wurde, „dass westliche Altmark in größerem Umfang nach Osten fließen werden“, einmal aus psychologischen Gründen, zum anderen aufgrund von Grenzkontrollen oder technischen Hindernissen beim Umtausch $^{152}$.

Auf westlicher Seite hatten der britische und der amerikanische Finanzberater bereits vor dem Ende der Londoner Konferenz beschlossen, ihre Planungen abzuschließen und die Entscheidung im Kontrollrat zu forcieren ${ }^{153}$, während nach dem Eindruck der Franzosen Clay (zunächst wohl auch Marshall) im November und Dezember einerseits noch immer die Zuversicht hegten, zu einer Vier-Mächte-Regelung kommen zu können, andererseits aber entschlossen waren, bei einem sowjetischen Zögern bizonal vorzugenen ${ }^{154}$. OMGUS legte der CCG am 23. Dezember 1947 einen Entwurf vor, der im wesentlichen nur die Währungskonversion vorsah, um kontroverse Diskussionen mit den Sowjets zu vermeiden, und der das alleinige Ziel hatte, diese vor die Entscheidung zu stellen: Annehmen oder Ablehnen ${ }^{155}$. Die CCG wies ein solch plumpes Vorgehen zurück. Die amerikanischen Vorschläge seien „taktisch unklug, da die Russen leicht nachweisen könnten, daß sie unvollständig seien“, vor allem angesichts des Ausmaßes an Übereinstimmung, das in einem Papier des Finanzdirektorats festgehalten worden war, welches die Briten, ergänzt durch weitere angloamerikanische Vorstellungen, einer gemeinsamen Vorlage zugrundelegen wollten. Während Clay und Robertson grünes Licht erhielten, am 10. Januar 1948 im Kon-

151 Nach einem Gespräch mit Semjonow notierte Pieck am 5. 6. 1948: „Wäbrungsreform/Sonnabend 7./13./27. Juni.“ Badstübner/Loth, Pieck, S. 231 (Hervorhebung im Original).

152 BAC, N-6/823, Bl. 96-101 (o.D.; Hervorhebung im Original); vgl. ebenda, Bl. 71 ff. (16. 6. 1948), 85 ff. (12. 6. 1948), 104 ff. (4. 6. 1948). BAP, C-15/137, Bl. 2 (31. 5. 1948), 5 ff. (22.6. 1948). Um das Einströmen der entwerteten Reichsmark aus den Westzonen zu verhindern, wurde die Abwicklung des Umtauschs ausschließlich über Bankkonten vorgesehen. In den USA erwartete Colm im Februar 1948, daß die Sowjetunion, um den Zustrom entwerteter Reichsmark aus den Westzonen zu verhindern, nicht nur mit einer Währungsreform in ihrer Zone folgen, sondern, erst recht bei einer Einbeziehung der Westsektoren Berlins seitens der Westmächte, zu „tight border controls“ greifen müsse. NA, RG 335, box 43, folder: 123.7 Germany. Bei den Briten hatte Chambers im Oktober 1947 Pläne ausgearbeitet, um im Falle einer separaten Währungsreform im Westen mit 3000 Deutschen unter britischem Kommando die Zonengrenze zur SBZ abzuriegeln. PRO, FO 1046/585 (21. 10. 1947).

153 Die Finanzabteilung der CCG sah keinen so dringenden Handlungsbedarf wie ihr amerikanisches Pendant. AMAE, Eu(1944-60)Allemagne/91, Bl. $200 \mathrm{ff}$.

154 AN, 457 (Bidault) AP 15/Après CMAE Londres, Dec. 1947 (GFCC an Paris, 1. 11. 1947; BevinMarshall, 17. 12. 1947; Seydoux an MAE, 21.12. 1947; Koenig an MAE, 24. 12. 1947).

155 Der Vorschlag sah vor: Währungsschnitt für Bargeld und Bankguthaben im Verhältnis von 10:1; Streichung der Staatsschuld; Notendruck in Berlin unter Vier-Mächte-Aufsicht; Alliierte Währungskommission unter Aufsicht des Finanzdirektorats. NA, RG 59/CED, box 4, folder: Currency Reform. AMAE, Eu(1944-60)Allemagne/91, Bl. $204 \mathrm{f}$. 
trollrat ihren entscheidenden Vorstoß zu unternehmen, waren sich die Finanzabteilungen noch nicht einig, wie die Vorlage im Detail aussehen sollte. Erst am 13. Januar legte OMGUS einen erweiterten Vorschlag vor, der der CCG als „vernünftige, gute Annäherung an die Russen" erschien, aber nach Auffassung des Foreign Office zu offenkundig „eine Zurückweisung herausfordern würde“: „Die Russen könnten zurecht mit gutem Grund behaupten, daß wir absichtlich die Spaltung herbeigeführt hätten, indem wir ein im Grunde undurchführbares Programm vorlegten, das nach weiteren Vier-Mächte-Verhandlungen hätte durchführbar gemacht werden können, aber in seiner vorliegenden Form offenkundig nicht akzeptabel war.“ Das war das eigentliche Motiv des Zögerns und der internen Debatte. Für Außenminister Bevin war alles ohnehin nur noch eine Frage von „Taktik und Timing“, die Verantwortung für die Spaltung den Russen zuzuschieben. Auch Robertson glaubte sich im Hinblick auf die Reaktion der Deutschen gezwungen, „diesen letzten Versuch zu einer Vier-Mächte-Vereinbarung zu unternehmen; aber er sollte auf den engstmöglichen Bereich begrenzt werden, der mit der Überwindung dieser praktischen Probleme kompatibel ist. In den übrigen Bereichen müssen wir, da bin ich sicher, uns von den Russen trennen, und CLAY denkt auch so, obwohl er sich noch nicht im klaren darüber ist, wie und wann der Bruch gemacht werden sollte." Doch am 16. Januar ermächtigte das Foreign Office Robertson schließlich, einen Antrag im Kontrollrat einzubringen, der ultimativ eine „Übereinkunft im Detail wie im Prinzip über das kurzfristige Minimalprogramm für eine Finanzreform (einschließlich Reform von Preisen, Löhnen und Festsetzung einer Umtauschrate) innerhalb einer festen (und kurzen) Zeitspanne“ fordern sollte. „Diese Resolution sollte einen Vorbehalt enthalten (oder mündlich entsprechend ergänzt werden), daß, wenn eine Übereinkunft bis zum festgelegten Datum nicht erzielt sei, die volle Handlungsfreiheit in dem gesamten Bereich an den Zonenkommandeur zurückfallen würde." Trotz neuer, nachträglicher britischer Bedenken war das die Linie, die Clay im Kontrollrat einschlug, da auch er zu der Auffassung gelangt war, „daß, wenn diese Verhandlungen keine sofortigen, befriedigenden Ergebnisse erzielen, wir unseren eigenen Weg in der Bizone gehen müssen"156.

Parallel bemühten sich die Briten seit Anfang Januar 1948, die Franzosen mitzuziehen, indem sie ihnen das Ultimatum Clays im Kontrollrat als Versuch zu einer Stärkung der Vier-Mächte-Verwaltung darzustellen versuchten. Sollte das am sowjetischen Widerstand scheitern, müsse die Währungsreform separat durchgeführt werden, wolle man den deutschen Beitrag zur (west)europäischen Rekonstruktion nicht in Frage stellen. Um eine geschlossene westliche Front im Kontrollrat zu gewährleisten und ihre eigene Verhandlungsposition gegenüber den USA zu stärken, sicherten sie den Franzosen zu, daß in der Bizone keine Währungsreform ohne deren Konsultation erfolgen werde ${ }^{157}$. In ähnlicher Form suchten Clay und Murphy ihre französischen Kollegen zu bearbeiten. Doch sagten sie diesen lediglich zu, vor einer bizonalen Währungsreform der Sowjetunion ein neues, letztes Angebot zu unterbreiten. Weitere Konsultationen mit den Franzosen waren auf ihrer Seite nicht vorgesehen; lediglich für den Fall, daß die Franzosen sich der Bizone bzw. der Bank deutscher Länder an-

156 PRO, FO 1046/643 (Currency Reform in Western Germany. Dec. 1947-June 1948, 7. 9. 1949, S. 1, Annexes 7 [FO, 16. 1. 1948] und 10 [CCG, 19.1. 1948]).

157 PRO, FO 1046/102. 
schließen wollten, wurden ihnen einige Vergünstigungen zugesagt ${ }^{158}$. Paris hatte nach dem Scheitern der Londoner Konferenz Dreier-Gesprächen über die Bildung einer Trizone zugestimmt, wies aber Koenig zugleich an, bei seinen Kollegen darauf hinzuwirken, „soweit wie möglich das Vier-Mächte-Statut zu erhalten. Die Pläne zur Währungsreform bieten dazu zweifellos eine günstige Gelegenheit.“159 Trotz seiner Bedenken hinsichtlich eines Anschlusses an die Bizone versicherte Koenig seinem Kollegen Robertson, „daß er offiziell nicht hinter seine Zustimmung zurückgehen werde, den [Noten-]Druck in LEIPZIG zuzulassen, aber persönlich halte er das jetzt für zu gefährlich, und er sei froh, daß CLAY eher die Verhandlungen abbrechen als in diesem Punkt nachgeben werde“"160.

Während auf amerikanischer Seite das State Department aus Rücksicht auf Kongreß und Marshall-Plan die sofortige bi- oder trizonale Reform forderte, setzte sich Clay mit dem Argument durch, angesichts der zu erwartenden Spaltung Deutschlands im Falle eines einseitigen Vorgehens sei ein letzter Anlauf im Kontrollrat unumgänglich; allerdings vornehmlich aus taktischen Gründen: Die Haltung der Deutschen, der Politiker wie der Bevölkerung, mache eine eindeutige Schuldzuweisung an die Sowjets notwendig. Um eine Verzögerung durch endlose Verhandlungen im Kontrollrat zu vermeiden, wollte er den Sowjets ein Ultimatum stellen: Wenn nach 90 Tagen eine Einigung nicht erzielt sei, habe er - gemäß der auf die amerikanische Interpretation zurückgehenden Praxis des Kontrollrats - in seiner Zone freie Hand und sei berechtigt, bi- oder trilaterale Arrangements mit anderen Zonen einzugehen. Durch diesen Vorbehalt war, formal zumindest, die Tür für eine spätere Kontrollratslösung nicht völlig zugeschlagen. Erneut beschwor Washington die Gefahr, daß die Sowjets zwar dem Notendruck in Berlin zustimmten, die für die technische Abwicklung erforderlichen acht Monate aber zu neuen Verzögerungsmanövern benutzten, und drängte darauf, „daß die Währungsreform auf bizonaler (oder trizonaler) Ebene aggressiv und rasch vorangetrieben werden sollte, wenn keine Vier-Mächte-Vereinbarung möglich ist $^{\text {"161 }}$. Ein Einlenken der Sowjets wollte man nicht ausschließen, da diese Ende 1947, nach langem Widerstand und wider Erwarten, der zweiten österreichischen Währungsreform zugestimmt hatten, nachdem ihnen günstige Konditionen für ihre Schilling-Guthaben zugestanden worden waren ${ }^{162}$. Aus all diesen Gründen drängte das State Department auf die Festlegung des 1. April als absolut letzten Termin für eine verbindliche Einigung, der im übrigen auch für Frankreich gelten sollte. Am 19. Januar erhielt Clay, trotz anhaltender Bedenken der Treasury, aus Washington grünes Licht für sein Ultimatum im Kontrollrat, das er am 21. Januar als amerikanisches (und nicht als gemeinsames britisch-amerikanisches) Papier einbrachte, einmal um den

158 AMAE, Eu(1944-60)Allemagne/91, Bl. 200 ff. passim.

159 AN, 457 (Bidault) AP 15/Allemagne (Bidault an Koenig, 4. 1. 1948; MAE an London und Washington, 9. 1. 1948).

160 PRO, FO 1046/643 (Currency Reform, Annex 8 [18. 1. 1948]).

161 NA, RG 59/CED, box 4, folder: Currency Questions (Murphy an Saltzmann, 5.1. 1948); RG 59/ ASSOA, box 2, folder: Currency Reform (9.1., 26. 1., 4. 2. 1948). Das State Department fürchtete, daß Clay im Interesse einer Kontrollratslösung den Sowjets zu weit entgegenkommen könnte, und suchte dessen Alleingang mit dem Hinweis zu verhindern, eine einseitige Währungsreform, die „zumindest eine vorübergehende Teilung Deutschlands“ bedeuten werde, stelle einen Hoheitsakt dar, den Clay als Militärgouverneur zwar vollziehen, aber nicht ohne Konsultation mit Washington unternehmen dürfe.

162 BA, Z 45 F/OMGUS, FINAD/2/102-4 (26. 1. 1948). 
Eindruck eines konzertierten Vorgehens zu vermeiden, zum anderen, weil den Briten neue Bedenken kamen ${ }^{163}$.

Sokolowski durchschaute Clays Versuch, die Sowjetunion „an die Wand zu drükken“. Er konterte dessen „Ultimatum“ geschickt, indem er für seine Forderungen die gleiche Aufmerksamkeit wie für die amerikanischen Vorschläge einforderte und indem er ein entscheidendes Zugeständnis machte, das die Zurückweisung seines Angebots unmöglich machte: den Banknotendruck ausschließlich in Berlin ${ }^{164}$. Das Finanzdirektorat verhandelte in „Sondersitzungen“ vom 2. bis 7. Februar 1948 sowohl den Antrag Clays als auch die Gegenvorschläge Sokolowskis und bereitete Stellungnahmen zu den politischen wie technischen Aspekten vor ${ }^{165}$. In zentralen Punkten gaben die Sowjets weiter nach, verlangten jedoch „Zusätze und Ergänzungen“: die Abfederung der sozialen Folgewirkungen durch Freibeträge und differenzierte Umtauschraten; die gesonderte Behandlung der Konten von Nazis und Kriegsverbrechern; den Umtausch der alliierten Markbestände „zu günstigen Bedingungen“ und ohne vorherige Festlegung der Konditionen ${ }^{166}$; die völlige Ausklammerung der britischen und amerikanischen „Gutscheine“ sowie der französischen Besatzungs-Francs. Damit waren neue Hürden aufgebaut, zumal Sokolowski im Sinne der amerikanischen Befürchtungen forderte, zunächst prinzipielle Einigkeit herbeizuführen und die Details später zu regeln. Das konnte nach den Erfahrungen der vergangenen Jahre keine der Westmächte mehr akzeptieren. Komplizierend kam hinzu, daß die Sowjets angesichts der politischen und sozialen Tragweite der Währungsreform die Deutschen zu beteiligen verlangten; diese sollten durch eine Zentralverwaltung für Finanzen und die Zentrale Emissionsbank „verantwortlich für Vorbereitung und Ausführung“ der Maßnahmen unter alliierter Kontrolle gemacht werden. Das hätte neue Zeitverzögerung nach sich gezogen, wenn man nicht auf die in der Gründung befindliche Emissionsbank der SBZ zurückgriff, war vielleicht auch, ähnlich wie die Forderung nach Streichung der inneren Reichsschuld, auf die Ablehnung durch die Franzosen (und Engländer) berechnet. Eine offene Ablehnung gesamtdeutscher Institutionen, deutscher zumal, hätte eine ebensolche propagandistische Signalwirkung gehabt wie die westliche $\mathrm{Zu}$ stimmung zu einem Generalkompromiß und eine separate Währungsreform in den Westzonen politisch unmöglich gemacht. Im Finanzdirektorat verlangten daher jetzt

163 NA, RG 59, 740.00119 Control(Germany)/1-1548; RG 59/ASSOA, box 2, folder: Currency Reform (Hilliard an Laux, 9. 1. 1948; Hilliard an Saltzman, 21. 1. 1948); RG 59, 862.51/1-2248.

164 AMAE, Eu(1944-60)Allemagne/92, Bl. 2. FRUS, 1948/II, S. 870 f. CP, S. 553 f. (5. 2. 1948), 561 (12. 2. 1948). Neben einer Verurteilung jeder separaten Währungsreform forderte die Sowjetunion die Errichtung einer deutschen Zentralverwaltung für Finanzen und einer Deutschen Zentralbank sowie Regelung der Behandlung von Privatschulden, Defizitausgleich bei Banken und eine besondere Besitzsteuer. Die Einigung über diese Fragen war Vorbedingung für die Zustimmung zum Notendruck in Berlin. Das Finanzdirektorat ordnete am 19. 2. 1948 die technische Vorbereitung der Druckarbeiten an. BA, Z 45 F/OMGUS, FINAD/2/103-1 (22. 3. 1948).

165 BA, Z 45 F/OMGUS, FINAD/2/102-1 (DFIN/SP/Memo(48)1).

166 Bei der SBZ-Währungsreform erhielt die SMAD eine Erstausstattung von 150 Mio. Coupon-Mark, bei einem Gesamtvolumen von 6,424 Mrd. Coupon-Mark. Beim ersten Bargeldumtausch wurden 22,3 Mrd. RM aus dem Verkehr gezogen, auch Alliierte Militärmark. BAP, C-15/137, Bl. 60 (14. 10. 1948). Nach Sitnin, Finansy, S. 40, betrug das umlaufende Geld 4,145 Mrd. RM, die Summe des eingezogenen Altgeldes $28 \mathrm{Mrd}$. RM; zu den Umtauschraten ebenda, S. $36 \mathrm{ff}$. Die 286,6 Mio. RM der Sowjet AGs und 1905,3 Mio. RM der Staatsbank der UdSSR wurden 1:1 umgetauscht; diese Gelder stellten „einen Teil der auswärtigen Schulden Deutschlands für Besatzungskosten dar“. C-15/731, Bl. 96 (Sitnin, 21. 12. 1948). Vgl. oben S. 285 Anm. 101. 
die USA, bisher stets die Hauptprotagonisten einer solchen Einrichtung, die Errichtung einer Zentralverwaltung für Finanzen dürfe keine Vorbedingung der Währungsreform sein. Als die Sowjets überraschend auch dem zustimmten, war Clays Vorstoß gescheitert: „Wir mußten diesen Vorschlag akzeptieren oder wären sonst vor dem deutschen Volk in eine Position hineingezwungen worden, den nächsten Schritt zur Teilung ohne wirklichen Grund zu machen."167

Jetzt ließen auch die Briten - wie die Franzosen - Clay noch einmal im Stich. Mit einer gewissen Erleichterung nahm man in London das sowjetische Einlenken zur Kenntnis und ließ Robertson am 8. Februar wissen, „daß wir nicht wollen, daß Sie zu diesem Zeitpunkt gezielt auf einen Bruch hinarbeiten“168, obwohl sich die Regierung dort bewußt war, daß sie faktisch über keine Entscheidungsfreiheit mehr verfügte, da sie um jeden Preis vermeiden wollte, infolge mangelnder Abstimmung im Kontrollrat auf der sowjetischen Seite gegen die USA stehen zu müssen: „Sollten die Amerikaner jedoch darauf bestehen, eine russische Forderung nach weiteren Verhandlungen zum Anlaß für einen offenen Bruch zu nehmen, müssen wir aus politischen Gründen ihre Marschroute akzeptieren, auch wenn nach unserer Meinung die Forderung berechtigt war, und wir würden in einen Bruch einwilligen, für den die Russen die Verantwortung auf die Westmächte abzuwälzen versuchen würden." ${ }^{169}$ OMGUS erneuerte mit Erfolg auf Expertenebene den Druck auf die Briten. Ostrander (OMGUS), Wilkinson (CCG) und Experten von BICO empfahlen ihren (Militär-)Regierungen verschiedentlich im Laufe des Februar und März 1948, nach entsprechender taktischer Vorbereitung endlich den Bruch mit der Sowjetunion zu vollziehen: Eine Einigung auf diesem Feld sei nicht möglich ${ }^{170}$. Daß die Sowjetunion alle in ihrer Zone einseitig durchgeführten Maßnahmen rückgängig machen würde, etwa die Bankenreform und die Blokkade aller Konten, war nicht zu erwarten, zumal nicht, nachdem die Bizonen-Mächte mit der Gründung der Alliierten Bankenkommission am 16. Februar 1948 erneut einen großen Schritt in Richtung auf eine separate Lösung für ihre Zonen getan hatten. Die Sowjets konnten eine solche einseitige Präjudizierung gesamtdeutscher Regelungen schon aus Prestigegründen nicht akzeptieren.

Es gab für die Westmächte in dieser Konstellation keine Alternative zum Bruch. Offen blieb nur, wer die Verantwortung für einen solchen Schritt übernahm. Zudem bestand noch immer keine Einigung zwischen den angelsächsischen Mächten über verschiedene technische Aspekte der Währungsumstellung ${ }^{171}$. Auch zwischen Washington und OMGUS wurde weiter um Einzelfragen gestritten. Und die Haltung Frankreichs blieb zurückhaltend, ja schwankend. In dieser Situation fiel Clay die Initiative und damit die Verantwortung zu. Seine Lage war wenig glücklich, weil er Anfang März konkret und im Grunde abschließend mit den Briten über eine bi-

167 CP, S. 561 (12. 2. 1948). Clay schloß am 3. 2. 1948 gegenüber den Deutschen eine Einigung über die Währungsreform im Kontrollrat am 10. des Monats nicht aus. Daher wurde die Preisrevision am 14. 2. noch einmal vertagt. Clay und Murphy waren sich „absolut sicher“, daß sich die französische Zone der Währungsreform anschließen werde; das sei nur eine Frage der Zeit. AVBRD, Bd. 4, S. 295 f. Vgl. CP, S. 553 (5. 2. 1948).

168 PRO, FO 1046/643 (Currency Reform, Annex 17 [FO, 8. 2. 1948]; Hervorhebung im Original).

169 PRO, FO 1046/643 (Currency Reform, Annex 11 [FO, 23. 1. 1948]).

170 Vgl. oben S. 278.

171 PRO, FO 1046/643 (Currency Reform, Annex 23 [22. 3. 1948]). Die endgültige Einigung wurde in dem am 20. 4.1948 beginnenden Konklave der deutschen Experten erzielt. 
zonale Reform verhandelte, während in den parallelen gemeinsamen Gesprächen mit den Franzosen bzw. den Vier-Mächte-Verhandlungen im Kontrollrat andere, kaum vereinbare Positionen verfolgt wurden ${ }^{172}$. Der politische Einklang zwischen den westlichen Delegationen bestand im Finanzdirektorat Anfang Februar nicht mehr uneingeschränkt, weil Briten und Franzosen sich weigerten, die amerikanische Forderung nach Annullierung der inneren und äußeren Reichsschuld mitzutragen. Daß zugleich die Sowjets den Franzosen ihren Wunsch offenbarten, „ein Terrain der Entspannung zu suchen", und sich über die amerikanische Intransigenz beschwerten, bestärkte Koenig in seiner Entschlossenheit, einen Bruch im Kontrollrat zu vermeiden, und sei es nur, um die französische Verhandlungsposition gegenüber der Bizone zu verbessern $^{173}$. Da die Franzosen im Februar den Vorsitz in allen Gremien innehatten, sahen sie sich besonders verpflichtet, einen Kompromiß herbeizuführen. Ihr Vertreter im Finanzdirektorat, Leroy-Beaulieu, hielt die Chancen für eine Einigung auf der technischen Ebene für gut, da im Direktorat über verschiedene Einzelforderungen Sokolowskis im Prinzip Übereinstimmung erzielt worden war. Im wesentlichen blieben die deutsche Zentralverwaltung und die Bank deutscher Länder umstritten, die gerade auch für Frankreich einen Stolperstein darstellten. Wenn in diesen Punkten eine Grundsatzentscheidung erzielt werden sollte, die auch den französischen Bedenken Rechnung trug, dann blieben sechs Monate, während das neue Geld gedruckt wurde, in denen der Außenministerrat Einigung über die Einsetzung einer deutschen Regierung oder die Errichtung einer Zentralverwaltung erzielen könne ${ }^{174}$.

Die drohende Einigung war zum Hauptproblem für Washington geworden. Denn die Sowjets erwiesen sich als unerwartet flexibel. Im Finanzdirektorat gaben sie weiter nach, indem sie nur noch einen positiven Grundsatzbeschluß über ihre Vorschläge als Voraussetzung für den Beginn des Banknotendrucks forderten, allerdings eine spätere Einigung im Detail zur Voraussetzung für die Ausgabe der Noten machten ${ }^{175}$. Das State Department mußte sich Anfang März 1948 entscheiden, ob die Verhandlungen in der Bizone oder im Kontrollrat Vorrang haben sollten. Am 10. März plädierte Frank Wiesner für den Abbruch der Verhandlungen im Kontrollrat, „da die VierMächte-Währungsreform die Sowjets in die Lage versetzen könnte, die wirtschaftliche Erholung Westdeutschlands durch eine Obstruktions- oder Verzögerungstaktik bei einem solchen Währungsreform-Programm weiter zu beeinträchtigen. Zudem würde eine Vier-Mächte-Währung, im Gegensatz zu einer bizonalen oder trizonalen Währung, uns eines sehr wichtigen monetären Instrumentes berauben, um die effektive wirtschaftliche Verwaltung der Westzonen zu erreichen, und könnte die Verwirklichung einiger Vereinbarungen behindern, die wir gerade auf einer Drei-Mächte-Basis ausarbeiten.“ Zwar werde eine Absage an die Vier-Mächte-Währungsreform „einen sehr endgültigen Schritt zur Anerkennung der Ost-West-Spaltung Deutschlands“ bedeuten, aber zugleich „ein wichtiger Schritt zur dringend notwendigen wirtschaftlichen Stabilität in Westdeutschland“ sein. Wiesner empfahl, Clay anzuweisen, „daß es nicht länger die Politik dieser Regierung ist, eine Vier-Mächte-Vereinbarung über die

172 NA, RG 200/Clay, box 5, folder: 1948 (Draper an Clay, 12. 3. 1948).

173 AMAE, Eu(1944-60)Allemagne/92, Bl. 6 f. (Seydoux, 9. 2. 1948).

174 AO, Berlin/3272/2/2450, A12 (11. 2. 1948). AMAE, Eu(1944-60)Allemagne/92, Bl. 29.

175 PRO, FO 1046/643 (Currency Reform, Annex 15 [8. 2. 1948]). Zum Stand der technischen Gespräche am 20.3. vgl. AO, Berlin/3272/2/2450, A12 (22.3. 1948). 
Währungs- und Finanzreform in Deutschland zu erreichen, und daß es dementsprechend sein Auftrag sein sollte, sich von den Vier-Mächte-Verhandlungen spätestens am Ende der 60-Tage-Frist zurückzuziehen, die jetzt im Kontrollrat für die Diskussion der Vier-Mächte-Währungsreform beschlossen worden ist“, also am 12. April. Diese Empfehlung, die von weiteren Abteilungen des State Department mitgetragen wurde, fand am 11. März auch die Billigung des stellvertretenden Außenministers Lovett. Nach Konsultation mit dem Department of the Army, das Clay noch am 9. Februar angewiesen hatte: „Ziel unserer Politik ist eine Vier-Mächte-Vereinbarung, vorausgesetzt, diese ist sofort erreichbar", wurde dieser über den Kurswechsel informiert. Er akzeptierte die Anweisung, da er inzwischen selbst endgültig eine Vereinbarung nicht mehr für möglich hielt ${ }^{176}$. Die Entscheidung war gefallen. Den richtigen Weg zu finden, das war das eigentliche Problem der nächsten Tage und Wochen.

OMGUS suchte sofort für den neuen Kurs Verbündete zu gewinnen. Bei den Briten stieß man nur auf geringen Widerstand, zumindest bei der Treasury und ihren Vertretern in der $\mathrm{CCG}^{177}$. Am 14. März fühlte Bennett bei seinem französischen Kollegen im Finanzdirektorat vor: Die Sowjets könnten ihren Vorsitz im März dazu benutzen, „um die Fragen zu verwickeln, Scheinvereinbarungen einzugehen und zu versuchen, die Meinungsunterschiede zu verringern. Unter diesen Umständen riskiere man, sich am 12. April im Kontrollrat in einer undurchsichtigen Situation zu befinden, die einen Bruch schwierig machen würde. Nun sei aber unter den gegenwärtigen politischen Umständen eine Einigung nicht wünschenswert. [...] Es wäre daher zweckmäßig, wenn sich die westlichen Alliierten nicht auseinandermanövrieren ließen und schon jetzt die Bruchpunkte festlegten. Monsieur Bennett hat mir daher vorgeschlagen, daß wir zusammen mit unseren britischen Kollegen die Bruchpunkte festlegen, die am leichtesten vor den Deutschen zu rechtfertigen seien"178.

Alle weiteren Verhandlungen im Kontrollrat waren nur noch taktische Rückzugsgefechte, die darauf abzielten, einen plausiblen Grund gegenüber der deutschen Öffentlichkeit für das Scheitern der Vier-Mächte-Reform zu finden. Die Westmächte waren sich bewußt, daß ein Bruch in der Währungsreformfrage das faktische Ende des Kontrollrats bedeuten würde und daß Clay am 12 . April, wenn er turnusgemäß den Vorsitz hatte, diesen selbst suspendieren mußte. Es war ein ebenso unverhoffter wie unschätzbarer Glücksfall, daß Sokolowski ihn dieser Notwendigkeit enthob, indem er seinerseits am 20. März den Kontrollrat verließ, nachdem die Sowjets angeblich wenige 'Tage zuvor endgültig die Hoffnung aufgegeben hatten, doch noch zu einer Einigung in der Währungsreformfrage zu gelangen ${ }^{179}$. Der Kontrollrat vollzog den Beschluß zur „vorübergehenden“ Teilung Deutschlands, obwohl bis zuletzt zumindest die Vertreter aller vier Kontrollratsdelegationen eine Einigung auf technischer Ebene prinzipiell für möglich gehalten hatten. Es hatte sich die Auffassung des britischen Fi-

176 FRUS, 1948/II, S. 879 f.

177 Die vertraten, abweichend vom Foreign Office, gegenüber den Franzosen die Auffassung, die Preisund Lohnpolitik, die Rationierungs- und Zuteilungssysteme seien so unterschiedlich in den Zonen, daß eine positive Wirkung der Währungsreform in Frage gestellt sei. Für wichtiger hielten sie, daß die Sowjets über das „régime du crédit“ Einfluß auf die Wirtschaft der Westzonen ausüben könnten, indem sie z. B. der Ruhrindustrie jegliche Kredite verweigerten. AMAE, Eu(1944-60)Allemagne/92, Bl. 37 f. (Sergent, 4. 3. 1948).

178 AMAE, Eu(1944-60)Allemagne/92, Bl. 41 f. (14.3. 1948).

179 Nach Geheimdienstberichten hatte Tjulpanow am 16.3. das vor deutschen Beamten in Potsdam erklärt. BA, Z 45 F/OMGUS, FINAD/2/103-1 (10. 4. 1948). 
nanzexperten Chambers vom Juli 1946 durchgesetzt, daß Vereinbarungen mit den Sowjets technisch möglich, aber politisch nicht wünschenswert (weil nicht umsetzbar) seien ${ }^{180}$. Die Deutschen, ohnehin nur als Berater in technischen Fragen zugelassen, waren trotz der Tragweite dieser politischen Entscheidung von ihren jeweiligen Besatzungsmächten nicht gefragt worden.

180 Die Überzeugung, daß Übereinkommen mit der Sowjetunion möglich, aber nicht umsetzbar seien, bestimmte auch in anderen Fällen die britische Verhinderung solcher Úbereinkünfte. Vgl. oben S. 242 und 280. PRO, CAB 21/1874 (Bevin am 8. 4. 1947 in Moskau). 